\author{
UNIVERSIDADE DE SÃO PAULO \\ ESCOLA DE ENGENHARIA DE SÃO CARLOS
}

GUILHERME PEREIRA BORGES

\begin{abstract}
Análise de Observabilidade e Identificação de Medidas Críticas para Sistemas de Medição Formados por Medidas Convencionais e Fasoriais Sincronizadas
\end{abstract}

São Carlos 2011 



\title{
Análise de Observabilidade e Identificação de Medidas Críticas para Sistemas de Medição Formados por Medidas Convencionais e Fasoriais Sincronizadas
}

\author{
Dissertação apresentada ao \\ Departamento de Engenharia Elétrica da \\ Universidade de São Paulo \\ para obtenção do título de \\ Mestre em Ciências, \\ programa de Engenharia Elétrica.
}

Área de concentração: Sistemas Elétricos de Potência

Orientador: Prof. Dr. João Bosco Augusto London Jr

\section{São Carlos}

2011

Trata-se da versão corrigida da dissertação. A versão original se encontra disponível na EESC/USP que aloja o Programa de Pós-Graduação de Engenharia Elétrica. 
AUTORIZO A REPRODUÇÃO E DIVULGAÇÃO TOTAL OU PARCIAL DESTE TRABALHO, POR QUALQUER MEIO CONVENCIONAL OU ELETRÔNICO, PARA FINS DE ESTUDO E PESQUISA, DESDE QUE CITADA A FONTE.

Ficha catalográfica preparada pela Seção de Tratamento da Informação do Serviço de Biblioteca - EESC/USP

Borges, Guilherme Pereira

Análise da observabilidade e identificação de medidas críticas para sistemas de medição formados por medidas convencionais e fasoriais sincronizadas. / Guilherme Pereira Borges; orientador João Bosco Augusto London Junior. São Carlos, 2011.

Dissertação (Mestrado-Programa de Pós-Graduação em Engenharia Elétrica e Área de Concentração em Sistemas Elétricos de Potência) -- Escola de Engenharia de São Carlos da Universidade de São Paulo, 2011.

1. Sistemas elétricos de potência. 2. Estimação de estado. 3. Análise de observabilidade. 4. Identificação de medidas críticas. 5. Medição fasorial sincronizada. I. Título. 
FOLHA DE JULGAMENTO

Candidato(a): Engenheiro GUILHERME PEREIRA BORGES.

Dissertação defendida e julgada em 04/05/2011 perante a Comissão Julgadora:

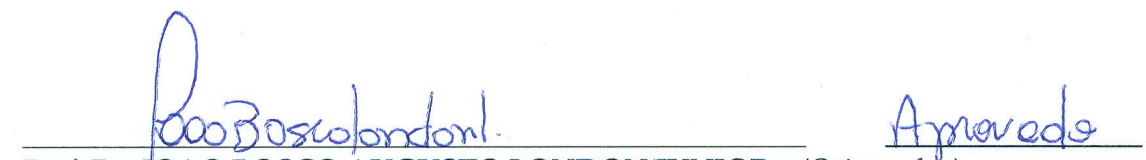

Prof. Dr. JOAO BOSCO AUGUSTO LONDON JUNIOR - (Orientador)

(Escola de Engenharia de São Carlos/USP)

Liús In anonde Costa Allute

Prof. Associado LUí́s FERNANDO COSTA ALBERTO

Aprovado

(Escola de Engenharia de São Carlos/USP)

Prof. Dr. MADSON CORTES DE ALMEIDA

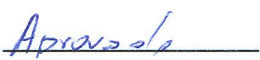

(Universidade Estadual de Campinas/UNICAMP)

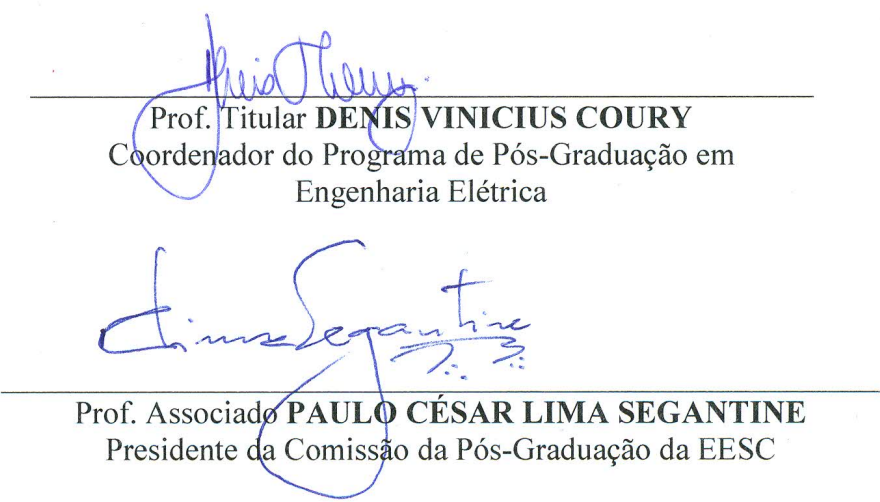



Aos meus pais Marcos, Rita e ao meu irmão Rafael. À minha companheira de todas as horas Olivia. 



\section{Agradecimentos}

À Deus por iluminar meu caminho e me dar forças para tocar o barco.

Ao meu orientador, Professor Doutor João Bosco Augusto London Júnior, por me receber como aluno, pelo conhecimento compartilhado, pela paciência fora do normal, por sempre surgir com palavras de incentivo quando se esperava cobranças, pelas contribuições e por acreditar que seria possível.

Ao professor Luiz Fernando, e a Madeleine Rocio pelas valiosas contribuições na ocasião do exame de qualificação, bem como ao professor Madson Cortes pelas contribuições durante o trabalho e na ocasião do exame de defesa.

Aos meus amigos virtuais Rui Menezes e Renan Augusto por estarem sempre a disposição para eventuais dúvidas.

À Capes e aos meus pais pelo apoio financeiro.

À Escola de Engenharia de São Carlos da Universidade de São Paulo, ao Programa de Pós-Graduação em Engenharia Elétrica e aos excelentes professores com os quais tive o prazer de conviver e muito aprender, bem como à equipe de funcionários.

À Jussara Ramos e Marisa Helena por estarem sempre prontas a resolver os "pepinos".

À Margareth, pelas correções e pelas sugestões.

Aos parceiros de laboratório, Camila Fantin, Carolina Ribeiro, Daniel Siqueira, Elmer Pablo, Edwin Choque, Edson Aparecido, José Carlos Salgado, Marcelo Castoldi, Moussa Mansour, Raphael Benedito, Rodrigo Salim, Saulo Pieretti, Tatiane Cristina e ao amigo de longa data, Rogério Lúcio Lima.

Ao amigo do clube do bolinha Fernando Fabrizzi. 
Ao Cristiano Torezzan, por me ajudar com a programação nos momentos iniciais de desespero.

Ao Danilo Sipoli Sanches, por dividir as agonias e ajudar a resolver meus problemas de programação.

Aos meus avôs Francisco e Lourival, e às minhas avós Dinorah e Isabel, por suas orações.

À toda minha família.

Aos amigos Roberto Perillo e Regiane Barros, por incentivarem a minha vinda para São Carlos.

À Angelina Orlandi, por dar suporte no início da jornada.

Aos meus pais Rita e Marcos por me darem suporte, carinho e incentivo.

À Olívia, por acreditar e incentivar, em momentos que até eu duvidava.

À todos aqueles que de uma forma ou de outra contribuíram para que este trabalho fosse realizado. 
"O custo de alguma coisa é aquilo que você desiste para obtê-la" 



\section{Resumo}

Borges, Guilherme Pereira (2011). Análise de Observabilidade e Identificação de Medidas Críticas para Sistemas de Medição Formados por Medidas Convencionais e Fasoriais Sincronizadas. Dissertação de Mestrado - Escola de Engenharia de São Carlos, Universidade de São Paulo, São Carlos, 2011.

Neste trabalho de dissertação propõe-se uma metodologia para análise de observabilidade (restauração e identificação de ilhas) e identificação de medidas críticas para sistemas de medição formados por medidas convencionais (medidas de amplitude de tensão e de potência obtidas via sistema SCADA) e medidas fasoriais sincronizadas. A metodologia possibilita análise e restauração da observabilidade a partir da fatoração triangular da matriz jacobiana, associada a um sistema de medição possuindo medidas convencionais e fasoriais sincronizadas. Para identificar as ilhas observáveis, no caso de o sistema não ser observável como um todo, a metodologia faz uso do conceito de caminhos de fatoração, associado à matriz jacobiana fatorada. As medidas críticas são identificadas a partir da análise da estrutura da matriz $H_{\triangle}^{t}$, que é obtida a partir da fatoração triangular da matriz jacobiana. A metodologia proposta é simples, de execução rápida, de fácil implantação e não exige a solução de equações algébricas. Dessa forma a mesma atende aos requisitos para operação em tempo-real. Com o intuito de mostrar como a metodologia proposta funciona, são apresentados exemplos da sua aplicação em um sistema teste de 4 barras. Vale destacar que resultados de diversas simulações computacionais, utilizando os sistemas teste do IEEE (14, 30 e 57 barras), têm demonstrado a eficiência da metodologia.

Palavras-Chave: Sistemas elétricos de potência, Estimação de estado, Análise de observabilidade, Identificação de medidas críticas, Medidas fasoriais sincronizadas. 



\section{Abstract}

Borges, Guilherme Pereira (2011).Observability Analysis and Identification of Critical Measurements for Metering Systems Formed by Conventional and Synchronized Phasor Measurements. Master's Thesis -School of Engineering of São Carlos, University of São Paulo, São Carlos, 2011.

This dissertation proposes a methodology for observability analysis (restoration and identification of observable islands) and identification of critical measurements for metering systems composed of both synchronized phasor and conventional measurements (power and voltage magnitude measurements). The methodology enables observability analysis and restoration via the triangular factorization of the jacobian matrix associated with metering systems formed by those two types of measurements. The identification of observable islands is carried out through the analysis of the path graphs associated with the factorization of the jacobian matrix. Critical measurements are identified via analysis of the structure of the $H_{\triangle}^{t}$ matrix, which is obtained by the triangular factorization of the jacobian matrix. The methodology is simple, fast and easy to implement and does not require solutions of any algebraic equation. Consequently, it is useful for real-time operation. Small numerical examples, using a 4-bus test system, showing the application of the proposed methodology are presented. The IEEE 14, 30 and 57 bus systems with different measurement scenarios were used to evaluate the performance of the proposed methodology.

Key-Words: Electric power systems, State estimation, Observability analysis, Synchronized phasor measurements. 



\section{Lista de Figuras}

2.1 Modelo da rede em nível de seção de barramento e dispositivos seccionadores (UG representa unidade geradora; LT representa linha de transmissão; TR representa transformador; e CS representa condensador síncrono). . . . 6

2.2 Modelo barra-linha obtido pelo configurador de redes para o sistema apresentado na Figura 2.1. . . . . . . . . . . . . . . . . . . . . . 6

2.3 Visão geral dos ângulos de fase relativos a uma referência comum . . . . . 18

2.4 Visão geral de um sistema de medição fasorial sincronizada de fasores . . . 19

2.5 Estrutura básica de uma PMU . . . . . . . . . . . . . . . . . . . 20

2.6 Representação Fasorial de uma forma de onda senoidal . . . . . . . . . . . 21

3.1 Matrizes associadas a um sistema observável . . . . . . . . . . . . . . . . 31

3.2 Sistema teste de 20 barras . . . . . . . . . . . . . . . . . . . . . . 32

3.3 Fatores triangulares superiores e Caminhos de fatoração - Sistema 20 barras 33

3.4 Matriz dos fatores triangulares $U \ldots \ldots$. . . . . . . . . . . . 34

3.5 Matriz dos fatores triangulares $U$ - pivô zero . . . . . . . . . . . . . 35

3.6 Matrizes associadas a um sistema não observável . . . . . . . . . . . . 35

3.7 Sistema de 14 barras do IEEE . . . . . . . . . . . . . . . . . . . . . . . 38

3.8 Matriz $H_{\theta}$ fatorada (Passo 2) - Sistema de 14 barras do IEEE . . . . . . . 38

3.9 Caminhos de fatoração (Passo 3) - Sistema de 14 barras do IEEE . . . . . 39

3.10 Matriz $H_{\theta}$ fatorada (Passo 2') - Sistema de 14 barras do IEEE . . . . . . . 40

3.11 Caminhos de fatoração (Passo 3') - Sistema de 14 barras do IEEE . . . . . 40

3.12 Matriz $H_{\theta}$ fatorada (Passo 2") - Sistema de 14 barras do IEEE . . . . . . . 41

3.13 Caminhos de fatoração (Passo 3") - Sistema de 14 barras do IEEE . . . . . 41

4.1 Modelo $\pi$ generalizado para equacionamento de fluxo de potência . . . . . 45

4.2 Definição do ângulo da corrente . . . . . . . . . . . . . . . . . 47

4.3 Representação topológica de um sistema observável por meio do GPS. . . . 50

4.4 Sistema teste de 3 barras em anel. . . . . . . . . . . . . . . . . . . . 52

5.1 Matrizes associadas a um sistema não observável com MFS de ângulo de fase de tensão . . . . . . . . . . . . . . . . . . . . . . . . . . . . 61

5.2 Matriz $H_{\triangle}$ para um sistema observável . . . . . . . . . . . . . . . . 62 
5.3 Sistema teste de 4 barras radial - Exemplo $1 \ldots$. . . . . . . . . . . 63

5.4 Matriz jacobiana transposta fatorada - Sistema teste 4 barras - Exemplo 164

5.5 Caminhos de Fatoração - Sistema teste 4 barras radial - Exemplo 1 . . . . 64

5.6 Matriz $H^{t}$ inicial - Sistema teste 4 barras radial - Exemplo 2 . . . . . . . 66

5.7 Matriz $H^{t}$ fatorada - Sistema teste 4 barras radial - Exemplo 2 . . . . . . . 66

5.8 Caminhos de Fatoração - Sistema teste 4 barras radial - Exemplo 2 . . . . 66

5.9 Matriz $H^{t}$ fatorada - Sistema teste 4 barras radial - Exemplo 3 . . . . . . . 67

5.10 Matriz $H^{t}$ fatorada - Sistema teste 4 barras radial- Exemplo 4 . . . . . . 68

5.11 Observabilidade sob o ponto de vista topológico . . . . . . . . . . . . 69

5.12 Sistema teste de 4 barras radial - Exemplo $5 \ldots$. . . . . . . . . . 71

5.13 Matriz $H^{t}$ fatorada - Sistema teste 4 barras radial - Exemplo 5 . . . . . . . 74

5.14 Caminhos de Fatoração - Sistema teste 4 barras radial - Exemplo 5 . . . . 74

5.15 Matriz $H_{\triangle}^{t}$ fatorada - Sistema teste 4 barras radial - Exemplo 5 . . . . . . 74

5.16 Matriz $H_{f}^{t}$ fatorada - Sistema teste 4 barras radial - Exemplo 6 . . . . . . 75

5.17 Caminhos de Fatoração - Sistema teste 4 barras radial - Exemplo 6 . . . . 75

5.18 Matriz $H_{\triangle}^{t}$ fatorada - Sistema teste 4 barras radial - Exemplo 6 . . . . . 76

5.19 Matriz $H^{t}$ fatorada - Sistema teste 4 barras radial - Exemplo 7 . . . . . . 77

5.20 Matriz $H_{\triangle}^{t}$ fatorada - Sistema teste 4 barras radial - Exemplo 7 . . . . . . 77

5.21 Matriz $H^{t}$ fatorada - Sistema teste 4 barras radial - Exemplo 8 . . . . . . 78

5.22 Matriz $H_{\triangle}^{t}$ fatorada - Sistema teste 4 barras radial - Exemplo 8 . . . . . 78

5.23 Sistema teste de 14 barras do IEEE . . . . . . . . . . . . . . . . . . 80

5.24 Sistema teste de 30 barras do IEEE . . . . . . . . . . . . . . . . . . . 81

5.25 Sistema teste de 57 barras do IEEE . . . . . . . . . . . . . . . . . . . . . . 83 


\section{Lista de Tabelas}

4.1 Fundo de escala para medidores . . . . . . . . . . . . . . . . . . . 51

4.2 Medidas disponíveis para o sistema teste de 3 barras - Exemplo 1 . . . . . 52

4.3 Parâmetros de linha para o sistema teste de 3 barras - Exemplo 1 . . . . . 53

4.4 Relatório de saída do sistema teste de 3 barras - Exemplo 1 . . . . . . . . 53

4.5 Relatório de saída do fluxo de carga - sistema 3 barras em anel . . . . . . . 53

4.6 Medidas disponíveis para o sistema teste de 3 barras - Exemplo 2 . . . . . 53

4.7 Relatório de saída do sistema teste de 3 barras - Exemplo 2 . . . . . . . . . 54

5.1 Medidas disponíveis para o sistema teste de 4 barras . . . . . . . . . . 72

5.2 Parâmetros de linha do sistema teste 4 barras . . . . . . . . . . . . . . . 72

5.3 Sistema de Medição (IEEE - 14 barras) . . . . . . . . . . . . . . . . . . . . 79

5.4 Sistema de Medição (IEEE - 30 barras) . . . . . . . . . . . . . . . . . . . 81

5.5 Sistema de Medição (IEEE - 57 barras) . . . . . . . . . . . . . . . 84 



\section{Lista de Algoritmos}

1 Algoritmo para Estimação de Estado - (WLS) . . . . . . . . . . . . . . . . 12

2 Algoritmo para Análise de Observabilidade e Identificação de Ilhas Observáveis 37

3 Algoritmo para Estimação de Estado com Medidas Fasoriais . . . . . . . . . 49

4 Algoritmo para Busca por Pseudo-Medidas . . . . . . . . . . . . . . 60 



\section{Lista de Abreviaturas e Siglas}

$C C M s \quad$ Conjuntos Críticos de Medidas.

EGs Erros Grosseiros.

EESEP Estimação de Estado em Sistemas Elétricos de Potência.

GPS Sistema de Posicionamento Global, do inglês Global Positioning System.

MCs Medidas Críticas.

MFSs Medidas Fasoriais Sincronizadas

ONS Operador Nacional do Sistema

PMU Unidade de Medição Fasorial, do inglês Phasor Measurement Units.

$S C A D A$ Sistema de Controle Supervisório e de Aquisição de Dados, do inglês Supervisory Control and Data Aquisition.

SEPs Sistemas Elétricos de Potência.

$S G E \quad$ Sistema de Gerenciamento de Energia.

SIN Sistema Interligado Nacional

SMFS Sistema de Medição Fasorial Sincronizada. 



\section{Sumário}

Resumo $\quad$ xi

Abstract $\quad$ xiii

$\begin{array}{ll}\text { Lista de Figuras } & \text { Xv }\end{array}$

Lista de Tabelas $\quad$ xvii

Lista de Algoritmos $\quad$ xix

Lista de Abreviaturas e Siglas $\quad$ xxi

1 Introdução 1

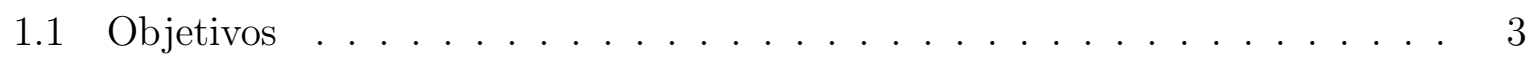

1.2 Organização do Trabalho . . . . . . . . . . . . . . . . . . . . . . 3

2 Revisão Bibliográfica 5

Introdução . . . . . . . . . . . . . . . . . . . . . . . . . . 5

2.1 Estimação de Estado Convencional . . . . . . . . . . . . . . . . . . 5

2.1.1 Aplicações de Estimação de Estado . . . . . . . . . . . . . . . . . 7

2.1.2 Método de Estimação de Estado . . . . . . . . . . . . . . . . . . 9

2.1.3 Estimador por mínimos quadrados ponderados . . . . . . . . . . . . 10

2.1 .4 Algoritmo . . . . . . . . . . . . . . . . . . . 11

2.1.5 Estimador de Estado Linearizado . . . . . . . . . . . . . . . . 11

2.1.5.1 Formulação do Estimador de Estado Linearizado .... . 12

2.2 Processamento de Erros Grosseiros . . . . . . . . . . . . . . . . . . . . 13

2.2.1 Detecção e Identificação de Erros Grosseiros . . . . . . . . . . . . . 14

2.3 Observabilidade de Sistemas Elétricos de Potência . . . . . . . . . . . . . . 15

2.4 Medidas Críticas e Conjuntos Críticos de Medidas . . . . . . . . . . . . . 16

2.5 Medição Fasorial Sincronizada . . . . . . . . . . . . . . . . . . . . 17

2.5.1 Sistema de Medição Fasorial Sincronizada . . . . . . . . . . . . . . 18

2.5.2 Unidades de Medição Fasorial . . . . . . . . . . . . . . . . . . . . 19

2.5.3 Processo de Medição Fasorial . . . . . . . . . . . . . . . . . . . 20 
2.5.4 Conceituação Histórica . . . . . . . . . . . . . . . . . . . . . . . 21

2.5.5 Medição Fasorial Sincronizada no Processo de Estimação de Estado 22

2.6 Conclusões . . . . . . . . . . . . . . . . . . . . . . . 26

3 Análise de Observabilidade e Identificação de Ilhas Observáveis por meio de Caminhos de Fatoração associados à matriz Jacobiana 27

Introdução . . . . . . . . . . . . . . . . . . . . . . . . . 27

3.1 Matriz Jacobiana . . . . . . . . . . . . . . . . . . . . . . . . . 28

3.2 Análise de Observabilidade por meio da fatoração da Matriz Jacobiana . 30

3.3 Análise de Observabilidade por meio de Caminhos de fatoração . . . . . . 31

3.3.1 Propriedades de caminhos de fatoração . . . . . . . . . . . . . . . 32

3.4 Análise de observabilidade . . . . . . . . . . . . . . . . . . . . 34

3.5 Identificando Ilhas Observáveis por meio de Caminhos de Fatoração . . . . 35

3.5.1 Ilhas Observáveis e Medidas Irrelevantes . . . . . . . . . . . 36

3.5 .2 Algoritmo . . . . . . . . . . . . . . . . . . . . . 36

3.5.3 Exemplo: Identificando Ilhas Observáveis . . . . . . . . . . . . . . . 37

4 Estimador de Estado Utilizando Medidas Convencionais e Medidas Fasoriais Sincronizadas $\quad 43$

Introdução . . . . . . . . . . . . . . . . . . . . . . . . . . . . . . . 43

4.1 Formulação do Problema . . . . . . . . . . . . . . . . . . . . 43

4.1.1 Medidas de magnitude de corrente . . . . . . . . . . . . . . 45

4.1 .2 Derivadas parciais . . . . . . . . . . . . . . . . . 46

4.1.2.1 Medidas de ângulo de corrente . . . . . . . . . . . . 47

4.2 Algoritmo . . . . . . . . . . . . . . . . . . . . . . . . . . . . . 48

4.3 Observabilidade e Processamento de Erros Grosseiros . . . . . . . . . . . . 49

4.4 Exemplos . . . . . . . . . . . . . . . . . . . . . . 51

4.5 Conclusões . . . . . . . . . . . . . . . . . . . . . 54

5 Metodologia Proposta para Análise de Observabilidade e Identificação de Medidas Críticas para Sistemas de Medição Formados por Medidas Convencionais e Fasoriais $\quad 55$

Introdução . . . . . . . . . . . . . . . . . . . . . . . . . 55

5.1 Metodologia Proposta . . . . . . . . . . . . . . 56

5.1 Matriz Jacobiana com MFS . . . . . . . . . . . . . . . 56

5.2 Análise de Observabilidade com Medidas Convencionais e Fasoriais . . . . 58

5.3 Identificação de Medidas Críticas . . . . . . . . . . . . . . . . . . . . 61

5.4 Matriz $H_{\triangle}$ Formada por Medidas Convencionais e Fasoriais . . . . . . . . 62

5.5 Exemplos: Análise de Observabilidade . . . . . . . . . . . . . . . 63

5.6 Aplicando a metodologia proposta na matriz Jacobiana Completa . . . . . 69 
5.7 Simulações Computacionais com os Sistemas de 14, 30 e 57 barras do IEEE 79 5.7 .1 Sistema de 14 barras do IEEE . . . . . . . . . . . . . . . . . . 79

5.7 .2 Sistema de 30 barras do IEEE . . . . . . . . . . . . . . . . . . . 80

5.7 .3 Sistema de 57 barras do IEEE . . . . . . . . . . . . . . . . 82

5.8 Conclusões . . . . . . . . . . . . . . . . . . . . . . . . . . . . 83

6 Conclusão $\quad 85$

6.1 Publicação . . . . . . . . . . . . . . . . . . . . . . . 87

6.2 Perspectivas Futuras . . . . . . . . . . . . . . . . . 87

Referências Bibliográficas $\quad 89$ 



\section{Capítulo 1}

\section{Introdução}

A estimação de estado tornou-se fundamental para a operação em tempo real dos sistemas elétricos de potência (SEP), em razão de ser capaz de fornecer dados para uso em outras funções avançadas de segurança e otimização, integrantes do Sistema de Gerenciamento de Energia (SGE) (WU, 1990).

O processo de estimação de estado em sistemas elétricos de potência (EESEP) foi inicialmente proposto por Schweppe e colaboradores no começo da década de 70 (SCHWEPPE, 1989a,b; SCHWEPPE; WILDES, 1989), passando a ser alvo de inúmeras pesquisas.

O processo de estimação de estado consiste na obtenção, em tempo real, das variáveis de estado (tensões complexas nodais) de um SEP, através de um modelo da rede elétrica, dos seus parâmetros e de um conjunto redundante de medidas analógicas com ruído, obtidas através do Sistema de Aquisição e Supervisão de Dados (SCADA, do inglês Supervisory Control and Data Aquisition). Usualmente as medidas analógicas utilizadas no processo de EESEP são: fluxo de potência ativa e reativa nas linhas; injeção de potência ativa e reativa; e, algumas magnitudes de tensão nos barramentos.

Independente do estimador de estado adotado, o sucesso do processo de EESEP depende da qualidade e redundância das medidas disponíveis. A redundância depende da quantidade, tipo e localização dos medidores sendo importante não apenas para garantir a observabilidade do sistema, mas também para possibilitar o tratamento de medidas portadoras de erros grosseiros (EGs) ${ }^{1}$. A qualidade das medidas, por outro lado, depende da precisão de todos os equipamentos envolvidos no processo de medição e a disponibilização das mesmas no centro de operação.

Dentre as possíveis causas de EGs, pode-se destacar: erros de conversão analógicodigital, erros nos canais de comunicação das telemedidas, e também a falta de sincronismo dos dados obtidos pelo sistema SCADA, o que ocorre devido a ausência de uma fonte de sincronização das medições realizadas nos SEP.

Na tentativa de melhorar a confiabilidade do processo de EESEP, diversas pesquisas

\footnotetext{
${ }^{1}$ Em geral dizemos que uma medida é portadora de EG, quando a mesma desvia do seu valor verdadeiro de, no mínimo, três vezes a sua variância (MILLI; VAN CUTSEM; RIBBENS-PAVELLA, 1984).
} 
vêm investigando a possibilidade de inclusão das medidas fasoriais sincronizadas (MFSs).

Justifica-se o interesse crescente pela inclusão de MFSs no processo de EESEP, não apenas pelo fato de as mesmas apresentarem, em geral, um nível maior de precisão que as medidas adquiridas pelo sistema SCADA, mas também pelo fato de variáveis cuja medição, antes inviável, passaram a ser monitoradas através das MFS, obtidas pelas Unidades de Medição Fasorial (PMU, do inglês Phasor Measurement Units) como é o caso dos ângulos de fase das tensões nodais e dos fasores de corrente nos ramos da rede elétrica.

Nas últimas décadas a tecnologia de medição fasorial sincronizada tem mostrado grande potencialidade para aplicações de monitoramento e controle. Várias pesquisas têm abordado a possibilidade da obtenção de um sistema de medição sincronizada de fasores (THORP; PHADKE; KARIMI, 1985; PHADKE, 1986, 2002) e, atualmente, a implantação de equipamentos responsáveis por essas aferições, as PMUs, é uma realidade, que se nos apresenta como uma forte tendência de utilização.

Esse instrumento de medição, desenvolvido em meados da década de 80, realiza a amostragem sincronizada das tensões e correntes analógicas trifásicas. A base de tempo utilizada, para a sincronização, é o sinal de relógio do Sistema de Geoposicionamento por Satélite (GPS).

Pesquisas recentes demonstram que a inclusão de MFS, no processo de EESEP, proporciona uma melhoria significante no desempenho e na robustez do estimador (PHADKE, 2002; ZHU; ABUR, 2007a). Além disso, desde que todas as tensões complexas nodais do sistema sejam monitoradas por PMUs, o problema de estimação pode ser resolvido utilizando somente medidas fasoriais (PHADKE, 2002; CEASE; FELDHAUSS, 1999). Neste caso o problema torna-se linear, já que as medidas relacionam diretamente as variáveis de estado, ao contrário das medidas convencionais de potência, as quais relacionam medidas e variáveis através de funções não-lineares.

Entretanto, devido aos elevados custos envolvidos para instalação de PMUs, principalmente decorrentes das necessidades de telecomunicação, os atuais sistemas de medição, destinados ao processo de EESEP, não serão completamente substituídos por PMUs em um curto intervalo de tempo. Eis a razão de já terem sido propostos diversos estimadores híbridos, que fazem uso de medidas convencionais (medidas de potência e de magnitude de tensão obtidas pelo sistema SCADA) e fasoriais sincronizadas.

Uma das dificuldades encontradas para implantação de estimadores de estado híbridos é a determinação da referência de ângulo de fase para as tensões. Observa-se que no processo de EESEP convencional, isto é, sem MFSs, uma das barras do sistema é escolhida como referência angular. Assim, atribui-se zero para o ângulo de tensão dessa barra e os ângulos estimados para as demais barras do sistema, a tomam como referência. Porém, quando estão presentes medidas convencionais e MFSs, essa prática não é adequada porque as medidas de ângulo de fase de tensão, fornecidas pelas PMUs, são obtidas a partir de outro referencial, que é determinado pelo instante de tempo fornecido pela recepção do 
sinal emitido pelo sistema GPS. Desta forma, não se pode utilizar diretamente as medidas de ângulo das PMUs.

Ante o exposto, torna-se necessário o estudo e desenvolvimento de metodologias para analisar as diversas etapas do processo de EESEP, considerando medidas convencionais e medidas fasoriais sincronizadas.

\subsection{Objetivos}

O objetivo deste trabalho é o desenvolvimento e implementação de uma metodologia para análise de observabilidade e identificação de medidas críticas, para sistemas de medição formados por medidas convencionais e MFSs.

A metodologia proposta baseia-se nos trabalhos apresentados por LONDON; ALBERTO; BRETAS (2007) e BENEDITO et al. (2008) e requer a fatoração triangular da matriz jacobiana associada a um sistema de medição possuindo medidas convencionais e MFSs. A matriz jacobiana considerada neste trabalho baseia-se na formulação do estimador de estado híbrido proposto em ZHU; ABUR (2007b).

Para identificar as ilhas observáveis, no caso de o sistema não ser observável como um todo, a metodologia faz uso do conceito de caminhos de fatoração, associado à matriz jacobiana fatorada. As medidas críticas são identificadas a partir da análise da estrutura da matriz $H_{\triangle}^{t}$, que é obtida a partir da fatoração triangular da matriz jacobiana.

\subsection{Organização do Trabalho}

No Capítulo 2, apresentamos uma revisão bibliográfica a respeito dos processos de estimação de estado, com e sem medidas fasoriais, tais como: análise de observabilidade, redundância de medidas e detecção de erros grosseiros.

No Capítulo 3, salientamos o método de análise de observabilidade e identificação de ilhas observáveis através de caminhos de fatoração associado a matriz jacobiana. $\mathrm{O}$ algoritmo para estimação de estado com medidas convenionais e fasoriais proposto por ZHU; ABUR (2007b) é explicado no Capítulo 4 com detalhes de sua implementação computacional e testes realizados. Lembrando que a metodologia proposta faz uso da matriz jacobiana desse estimador.

A metodologia proposta, para a análise de observabilidade e identificação de MCs para conjuntos de medidas formados por medidas convencionais e fasoriais sincronizadas, é apresentada no Capítulo 5.

Por fim, no Capítulo 6, discutimos algumas conclusões obtidas neste trabalho. 



\section{Capítulo 2}

\section{Revisão Bibliográfica}

\section{Introdução}

A tecnologia de medição fasorial sincronizada, em sistemas elétricos de potência (SEP), apesar de ser um recente campo de estudo, vem sendo muito abordada em diversas pesquisas, pois vários projetos englobando o uso de unidades de medição fasorial, e a exploração de suas potencialidades se converteram em realidade. Alguns países como China e Estados Unidos têm apresentado números consideráveis de PMUs instaladas, para fins específicos, principalmente no que diz respeito a registros de perturbações, monitoração de segurança, controle de emergência e implementações de caráter experimental.

Neste capítulo, são apresentadas pesquisas sobre o processo de estimação de estado linear e não linear em sistemas elétricos de potência (EESEP), com e sem medidas fasoriais sincronizadas, bem como pesquisas tratando da utilização de medidas fasoriais sincronizadas em estimação de estado e os conceitos de análise de observabilidade e redundância de medidas.

\subsection{Estimação de Estado Convencional}

O processo de estimação é fundamental para operação em tempo-real dos SEP, isto porque as variáveis de estado estimadas, ao invés das medidas, constituem a base de dados para execução de funções relacionadas com a segurança da operação dos SEP.

A finalidade do processo de estimação de estado é fornecer, em tempo-real, as variáveis de estado do sistema (tensões complexas nas barras do mesmo) a partir do processamento das seguintes informações: medidas analógicas obtidas em tempo real, provenientes do sistema SCADA, parâmetros dos elementos do SEP, disponíveis no banco de dados das companhias de energia elétrica; e topologia atual do SEP, obtida previamente pelo configurador de rede.

Usualmente, as medidas analógicas utilizadas no processo de EESEP são medidas de 
fluxo de potência ativa e reativa nas linhas, injeção de potência ativa e reativa e algumas magnitudes de tensão nos barramentos.

O primeiro passo, para a realização do processo de EESEP, é a obtenção da topologia do sistema no modelo barra-linha, por meio do configurador de redes, que se realiza a partir de medidas lógicas obtidas de forma contínua, consistindo em estados de chaves e disjuntores. Vale lembrar que as informações processadas pelo configurador de redes são modeladas ao nível de seção de barramento (representação física dos elementos do sistema) e dos ramos (ligações entre seções de barramento, através de linhas de transmissão e transformadores), conforme ilustrado na Figura (2.1).

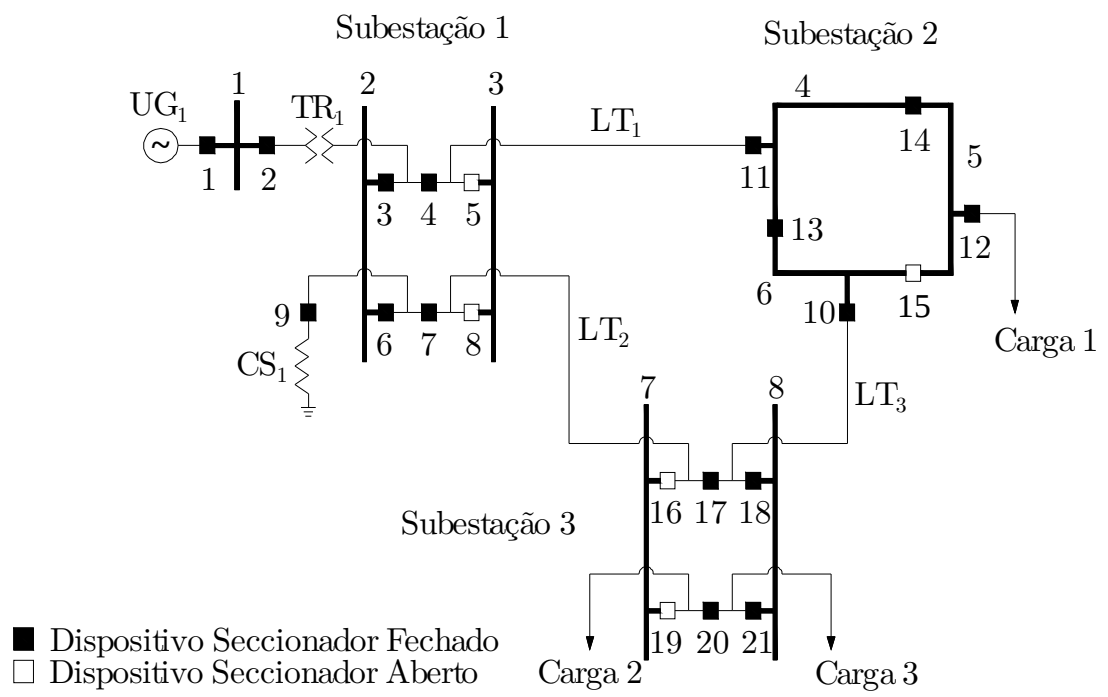

Figura 2.1: Modelo da rede em nível de seção de barramento e dispositivos seccionadores (UG representa unidade geradora; LT representa linha de transmissão; TR representa transformador; e CS representa condensador síncrono).

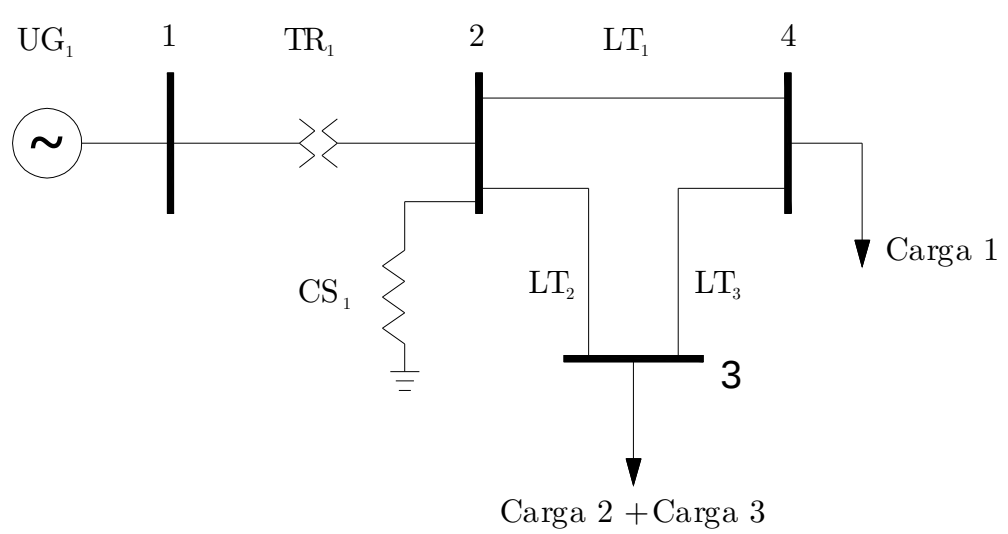

Figura 2.2: Modelo barra-linha obtido pelo configurador de redes para o sistema apresentado na Figura 2.1.

Uma vez obtida a topologia do sistema barra-linha (Figura (2.2)), o próximo passo será verificar se é possível, por meio do conjunto disponível de medidas analógicas, determinar todos as variáveis de estado do sistema. Em caso afirmativo, o sistema dir-se-á observável. 
Caso contrário, a falta de medidas pode ser suprida por pseudo-medidas ${ }^{1}$, pelas quais o sistema se tornará observável como um todo. Sendo o sistema observável, a partir da sua topologia e dos seus parâmetros ${ }^{2}$, armazenados no banco de dados dos centros de operação, bem como do conjunto de medidas analógicas disponível, realizar-se-á a estimação de estado propriamente dita.

Independente do estimador de estado utilizado, o seu sucesso vai depender da qualidade e redundância das informações que lhe forem fornecidas, uma vez que, erros nessas informações podem levar o processo de estimação a valores estimados muito distantes dos valores "verdadeiros", ou, até mesmo, à não convergência.

Nesse contexto, vale destacar que as medidas aferidas são afetadas por perturbações aleatórias, e nem sempre todas as grandezas são acessíveis.

Pode-se destacar algumas causas para a existência de erros:

- Má calibração de aparelhos;

- Erros no equipamento de medida e de teletransmissão;

- Falta de leituras;

- Falta de sincronismo das medidas obtidas pelo sistema SCADA;

- Modelos matemáticos imprecisos;

- Medidas efetuadas durante fenômenos transitórios.

Um dos principais benefícios dos estimadores de estado está relacionado com o processamento de EGs, ou seja, a habilidade de detectar e identificar medidas analógicas, com grau de imprecisão muito maior que o suportado pelo modelo de medição.

Vale ressaltar que o processo de estimação de estado pode ser estático ou dinâmico. O estático abordado neste trabalho, podendo ser considerado uma generalização do problema clássico de fluxo de carga (HANDSCHIN et al., 1975). Já no estimador dinâmico consideram-se as relações entre as grandezas, em instantes de tempo diferentes.

Em DO COUTTO FILHO; SOUZA (2009) apresenta-se-nos uma revisão bibliográfica sobre estimadores de estado que utilizam informações obtidas previamente, conhecidos de uma forma geral como estimadores dinâmicos de estado ou estimadores FASE (do inglês, Forecasting-Aided State Estimators).

\subsubsection{Aplicações de Estimação de Estado}

A aplicação e utilização de algoritmos de estimação justificam-se por dois aspectos importantes: o primeiro é garantir um controle mais eficiente do sistema, considerando

\footnotetext{
${ }^{1}$ Pseudo-medidas são dados de previsão de carga, previsão de geração, dados históricos, etc, que fazem parte do banco de dados dos centros de operação.

${ }^{2}$ Impedância de linhas de transmissão, posição de taps de transformadores, etc.
} 
para isso a utilização em tempo real de uma base de dados confiável e consistente, utilizada para análises on-line de segurança, diagnósticos de defeitos e anomalias. Isto permite um melhor conhecimento das capacidades do sistema, facilidade e rapidez na tomada de decisões em situações críticas, diminuindo o risco de tomar decisões erradas e facilitando a deteç̧ão de avarias nos equipamentos de medição.

O segundo aspecto importante é facilitar a implementação de ações de controle, tornando mínima a exigência de investimentos adicionais em equipamentos, seja de medição ou de teletransmissão.

A utilização do estimador de estado on-line fornece alguns benefícios às ações de controle, como, por exemplo:

- Controle Carga-frequência: É importante que o operador disponha de estimativas ótimas de todas as potências injetadas nos barramentos e que circulam na rede, em especial as grandezas não medidas em tempo real, mas estimadas e atualizadas periodicamente pelo operador.

- Despacho ótimo de potência ativa e reativa: Baseia-se no valor das cargas individuais dos barramentos. O estimador de estado poderá fornecer as estimativas destas cargas, cujas medidas não são transmitidas ao centro de controle.

- Análise de contingências: Esta análise consiste na verificação periódica das reservas de produção de energia, cargas nas linhas, tensões nos barramentos, características de estabilidade transitória do circuito e na previsão dos efeitos de contingências simuladas.

- Planejamento das saídas de serviço: Permite analisar os efeitos da saída de serviço de certos componentes da rede, na segurança do sistema, bem como, a simulação de operações de alteração da configuração da rede. As variáveis de estado estimadas servem de base para estes estudos.

O resultado da estimação de estado permite que o operador do centro de controle tenha acesso às seguintes informações:

- Estimativas de potências nas linhas, potências geradas, cargas, tensões (módulo e fase), etc, assim como as respectivas precisões;

- Anomalias no sistema, bem como a sua localização geográfica, alertando o operador para problemas na rede ou o mau funcionamento do sistema de informação;

- Saídas de serviço de componentes não comunicadas ao centro de controle e a sua localização geográfica, permitindo ao operador um melhor diagnóstico dos defeitos; 
- Índices de segurança, como reserva de capacidade de produção e de transporte, margem de estabilidade transitória, indicando ao operador que o sistema se encontra em um estado vulnerável;

- Ações corretivas necessárias à eliminação de condições indesejáveis, do ponto de vista de níveis de tensão ou de potência nas linhas, assim como apoio ao operador durante as operações de restabelecimento de serviço, após a ocorrência de incidentes graves.

A estimação de estado off-line também proporciona vantagens, por possibilitar a definição do local e a precisão da aparelhagem de medição a instalar. Isto se deve ao fato de obter-se como resultado da estimação, não só os valores estimados para o vetor de variáveis de estado do sistema e para as grandezas elétricas medidas, mas também as respectivas matrizes de covariância, o que torna possível a comparação entre diferentes configurações dos sistemas de medição.

\subsubsection{Método de Estimação de Estado}

Em um estimador de estado estático, as entradas são identificadas por medidas (z), configuração da rede e pelo valor dos parâmetros. Por outro lado, as saídas serão as variáveis de estado do sistema (tensões complexas nas barras do SEP). Admitindo-se que a configuração da rede e o valor dos parâmetros dos seus componentes sejam conhecidos, apresentam-se as entradas do estimador de estado como sendo:

$\mathbf{z}$ - vetor de medidas disponíveis no centro de controle e como tal, afetadas por ruídos w. Estas medidas podem ser de potência ativas e reativas injetadas nos barramentos $\left(P_{k}, Q_{k}\right)$, fluxos de potências ativas e reativas nas linhas $\left(P_{k m}, Q_{k m}\right)$ e ainda magnitude de tensão nas barras $\left(V_{k}, V_{m}\right)$.

w — vetor de ruído das medidas;

Para as saídas do estimador há as seguintes variáveis:

$\hat{\mathbf{x}}$ — vetor de variáveis de estado estimadas do sistema. São as estimativas dos módulos e fase das tensões em todos os barramentos;

$\hat{\mathbf{z}}$ — valores estimados para as medidas disponíveis;

$\mathbf{z}-\hat{\mathbf{z}}=r$ - vetor de resíduos. Diferença entre os valores medidos e os valores estimados para as medidas;

$R_{\hat{\mathrm{x}}}$ - matriz covariância dos estados estimados. Fornece uma medida da precisão da estimação, uma vez que cada elemento da sua diagonal principal apresenta a variância, do correspondente componente de $\hat{\mathbf{x}}$. 
O estimador de estado permite o cálculo das variáveis de estado desconhecidas, por meio de um conjunto de medidas não exatas. Logo, o resultado obtido para as variáveis de estado desconhecidas também não será exato.

Dessa forma, o problema de estimação de estado consiste em encontrar uma maneira de atingir-se a melhor estimativa das variáveis de estado desconhecidas. Para isto, dos muitos métodos existentes, o mais utilizado é o método dos Mínimos Quadrados Ponderados ou simplesmente estimador WLS (do inglês, Weighted Least Squares) (ABUR; EXPOSITO, 2004).

\subsubsection{Estimador por mínimos quadrados ponderados}

Conhecida a topologia da rede, pode-se escrever as equações não-lineares para estimação de estado do SEP, estabelecendo uma relação entre as variáveis medidas e o vetor de variáveis de estado.

$$
\mathbf{z}=h\left(\mathbf{x}_{v}\right)+\mathbf{w}
$$

Em que:

$\mathbf{z}$ - vetor de medidas com dimensão $(m \times 1)$, sendo $m$ o número total de medidas efetuadas;

$h($.$) — vetor de funções não lineares do sistema, também de dimensão (m \times 1)$. Estas funções são determinadas a partir da matriz das admitâncias e por aplicações das leis de Kirchoff;

$\mathbf{x}_{v}$ — vetor das variáveis de estado verdadeiras, com dimensão $(2 n-1)$, sendo " $n$ " o número de barramentos do sistema;

$\mathbf{w}$ - vetor de ruídos das medidas $(m \times 1)$. São considerados como variáveis aleatórias independentes, com distribuição Gaussiana de média zero (SCHWEPPE; HANDSCHIN, 1974) e matriz de covariância $W$ com dimensão $(m \times m)$, dada por:

$$
W=\left[\begin{array}{cccc}
\sigma_{1}^{2} & & & \\
& \sigma_{1}^{2} & & \\
& & \ddots & \\
& & & \sigma_{m}^{2}
\end{array}\right]
$$

sendo $\sigma_{1}^{2}$ a variância do erro (ou ruído) da medida $\mathbf{z}_{i}$.

Os valores de $\sigma_{1}^{2}$ dependem da precisão dos aparelhos de medida e do sistema de teletransmissão. O desvio padrão caracteriza a precisão de cada medida e é fundamental na obtenção de uma estimativa de boa qualidade. 
O vetor de estado estimado $\hat{\mathbf{x}}$ é obtido minimizando a função de mínimos quadrados ponderados $J(\mathbf{x})$ dados por:

$$
J(\mathbf{x})=\frac{1}{2}[\mathbf{z}-h(\mathbf{x})]^{t} \cdot W^{-1} \cdot[\mathbf{z}-h(\mathbf{x})]
$$

Pretende-se determinar o vetor de estado x que torna mínima a função objetivo $J(\mathbf{x})$, isto é:

$$
\frac{\partial J(\mathbf{x})}{\partial \mathbf{x}}=0
$$

A solução desta equação é:

$$
H^{t} \cdot(\hat{\mathbf{x}}) \cdot W^{-1} \cdot[\mathbf{z}-h(\hat{\mathbf{x}})]=0
$$

Sendo $H(\hat{\mathbf{x}})$ a matriz jacobiana dada por:

$$
\left.H(\hat{\mathbf{x}}) \triangleq \frac{\partial h(\mathbf{x})}{\partial \mathbf{x}}\right|_{\mathbf{x}=\hat{\mathbf{x}}}
$$

No processo de determinação de $\hat{\mathbf{x}}$ pelo método iterativo de Newton-Raphson, calculamse as correções para cada iteração através de:

$$
G\left(\mathbf{x}^{k}\right) \cdot \triangle \mathbf{x}^{k}=H^{t}\left(\hat{\mathbf{x}}^{k}\right) \cdot W^{-1} \cdot\left(\mathbf{z}-h\left(\hat{\mathbf{x}}^{k}\right)\right)
$$

denominada Equação Normal, e obtêm-se:

$$
\mathbf{x}^{k+1}=\mathbf{x}^{k}+\triangle \mathbf{x}^{k}
$$

sendo $k=0,1,2 \ldots$ até que o critério de parada seja atingido.

A matriz ganho $(G)$ é expressa por:

$$
G\left(\mathbf{x}^{k}\right)=H^{t}\left(\mathbf{x}^{k}\right) \cdot W^{-1} \cdot H\left(\mathbf{x}^{k}\right)
$$

O processo iterativo termina quando $\left|\mathbf{x}^{k+1}-\mathbf{x}^{k}\right|$ for menor que um valor pré-estabelecido.

\subsubsection{Algoritmo}

O Algoritmo (1) apresenta a sequência finita de instruções bem definidas de estimação de estado WLS.

\subsubsection{Estimador de Estado Linearizado}

Ao estimador de estado linearizado atribuímos importância considerável, em termos de estudos dos métodos e técnicas ligadas ao processo de EESEP, principalmente em relação aos métodos de análise de observabilidade e processamento de EGs. 


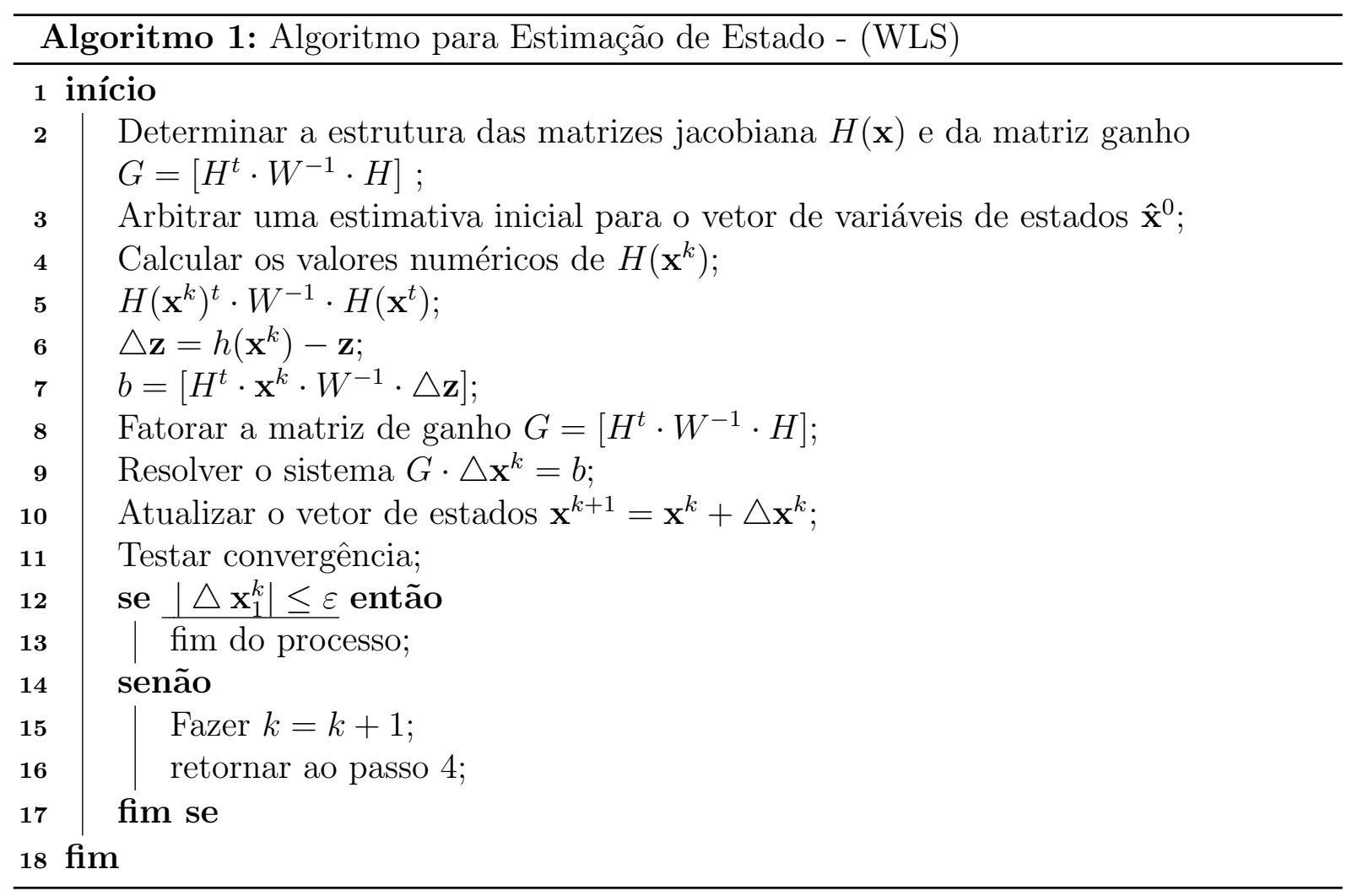

As simplificações que esse estimador permite transforma o problema de estimação em um processo não iterativo (problema torna-se linear), facilitando o entendimento dos vários métodos destinados à EESEP.

A formulação do estimador de estado linearizado tem como fundamento as equações de fluxo de carga linear, que despreza as perdas e considera todas as magnitudes de tensão iguais a $1[p u]$.

Segundo MONTICELLI (1999), os fluxos de potência ativa nas linhas $\left(P_{k m}\right)$ e as injeções de potência ativa nas barras $\left(P_{k}\right)$, para o estimador de estado linearizado, calculam-se respectivamente pelas seguintes equações:

$$
\begin{gathered}
P_{k m}=\frac{\theta_{k}-\theta_{m}}{x_{k m}} \\
P_{k}=\sum_{m \in \Omega_{k}}\left(\frac{\theta_{k}-\theta_{m}}{x_{k m}}\right)
\end{gathered}
$$

Os ângulos de tensão nas barras $k$ e $m$ são respectivamente $\theta_{k}$ e $\theta_{m}$. A reatância da linha de transmissão que liga as barras $k$ e $m$ e o conjunto das barras vizinhas à barra $k$ são respectivamente $x_{k m}$ e $\Omega_{k}$.

\subsubsection{Formulação do Estimador de Estado Linearizado}

O modelo de medição para o estimador linear é: 


$$
\mathbf{z}=H(\mathbf{x})+\mathbf{w}
$$

$\mathbf{z}$ — vetor de medidas de potência ativa, com dimensão $(n p \times 1)$;

$\mathbf{x}$ - vetor de variáveis de estado verdadeiras $(n v \times 1)$, correspondente, na formulação linear, aos ângulos de tensão nas barras do sistema;

$H$ - matriz jacobiana $(n p \times n v)$, tal que $H=\frac{\partial h}{\partial x}$

$\mathbf{w}$ - vetor de ruído das medidas de potência ativa $(n p \times 1)$;

$n p$ — número de medidas de potência ativa;

$n v$ — número de ângulos de tensão a serem estimados.

No caso não linear, a Equação 2.7 representa o sistema linear a ser resolvido a cada iteração, para determinar o vetor de incremento $\triangle \mathbf{x}$, significando que a cada iteração, associada à solução do estimador não linear, um estimador linear é resolvido.

$\mathrm{Na}$ busca para determinar uma estimativa $\hat{\mathbf{x}}$ que torne mínima a seguinte função:

$$
J(\mathbf{x})=\frac{1}{2}[\mathbf{z}-H(\mathbf{x})]^{t} \cdot W^{-1} \cdot[\mathbf{z}-H(\mathbf{x})]
$$

É obtida por:

$$
H^{t} \cdot W^{-1}[\mathbf{z}-H(\hat{\mathbf{x}})]=0
$$

considerando,

$$
\hat{\mathbf{x}}=G^{-1} \cdot H^{t} \cdot W^{-1} \cdot \mathbf{z}
$$

e

$$
G^{-1}=\left(H^{t} \cdot W^{-1} \cdot H\right)^{-1}
$$

Consequentemente teremos:

$$
\hat{\mathbf{z}}=H \cdot \hat{\mathbf{x}}
$$

\subsection{Processamento de Erros Grosseiros}

Conforme observado anteriormente, quando as medidas analógicas apresentam imprecisão muito maior do que o esperado, dizemos que possuem EGs. Os EGs podem levar o processo de estimação a um estado não "verdadeiro", ou, até mesmo, à não convergência. Desta forma, o estimador de estado deve ser robusto o suficiente para detectar e identificar a ocorrência de medidas com EGs. 


\subsubsection{Detecção e Identificação de Erros Grosseiros}

Os métodos desenvolvidos para processamento (detecção e identificação) de EGs mais usados são baseados na análise estatística dos resíduos das medidas, ou em uma função dos mesmos, isso porque os resíduos fornecem informações úteis sobre eventuais violações das suposições feitas em relação ao modelo de medição (MONTICELLI, 1999; ABUR; EXPOSITO, 2004).

A detecção de EGs pode realizar-se através da análise do índice $J(\hat{\mathbf{x}})$. Admitindo a hipótese de que o vetor dos erros das medidas possua distribuição normal, caso não haja nenhuma medida com EG, HANDSCHIN et al. (1975) demonstraram que o índice $J(\hat{\mathbf{x}})$ apresenta uma distribuição Qui-quadrada $\left(\chi^{2}\right)$, com $(m-n)$ graus de liberdade.

Escolhendo uma probabilidade " $1-\alpha$ ", de falso alarme, sendo " $\alpha$ " o nível de significância do teste, determina-se o parâmetro "C", que é utilizado para detectar a existência de EGs, da seguinte forma: se $J(\hat{\mathbf{x}})>C$, rejeita-se a hipótese de que não haja EG; e se $J(\hat{\mathbf{x}})<C$, aceita-se a mesma.

Outro caminho para detecção de EGs é por meio da análise dos resíduos normalizados. Admitindo a mesma hipótese de que o vetor de erros nas medidas possua distribuição normal, caso não haja medida com EG, o vetor dos resíduos $r$ é calculado para $\hat{\mathbf{x}}$, normalizado e submetido a um teste de validação:

$$
r_{i}^{N}=\frac{\left|r_{i}\right|}{\sigma_{i i}} \leq \alpha(\text { limiar })
$$

onde $\sigma_{i i}=\sqrt{\Omega_{i i}}$ é o desvio padrão do i-ésimo componente do vetor dos resíduos; e

$$
\Omega=W^{-1}-H(\hat{\mathbf{x}}) \cdot\left[H^{t}(\hat{\mathbf{x}}) \cdot W^{-1} \cdot H(\hat{\mathbf{x}})\right]^{-1} \cdot H^{t}(\hat{\mathbf{x}})
$$

é a matriz covariância dos resíduos; $\alpha$ é o limite de identificação e depende de níveis de probabilidade aceitáveis de falso-alarme e de não identificação (usualmente $\alpha=3$ ), (ABUR; EXPOSITO, 2004).

Define-se $r_{(i) \max }^{N}$ o maior resíduo normalizado. Se $r_{(i) \max }^{N}>\alpha$, a medida "i" correspondente apresenta EG.

Destaca-se que os métodos para processamento de EGs apresentam um bom desempenho para diversas situações, mas possuem algumas limitações, como, por exemplo, o fato de não detectarem EGs em medidas críticas (resíduo zero) e não identificarem EGs em conjuntos críticos de medidas (resíduos normalizados iguais). 


\subsection{Observabilidade de Sistemas Elétricos de Potên- cia}

Conforme mencionado anteriormente, a análise de observabilidade em SEP constitui um tópico fundamental no contexto de estimação de estado, permitindo verificar se é possível determinar as variáveis de estado, nas barras do sistema supervisionado, por meio do conjunto de medidas disponível.

Para efetuar-se a análise de observabilidade em SEP, vários métodos foram desenvolvidos, tomando como base os conceitos de observabilidade apresentados em (KRUMPHOLZ; CLEMENTS; DAVIS, 1980), listados a seguir, que foram definidos em função da formulação do estimador de estado WLS apresentada na seção (2.1.3):

a — Observabilidade algébrica: um sistema de potência dir-se-á "algébricamente" observável, se a matriz jacobiana $H$, correspondente à associação desse sistema a um conjunto de medidas, tiver posto igual ao número de variáveis de estado a serem estimadas;

b — Observabilidade Numérica: um sistema de potência é "numericamente" observável, com respeito a um conjunto de medidas, se for possível fazer uma estimativa para o vetor de variáveis de estado, através das equações do estimador de estado ${ }^{3}$;

c — Observabilidade Topológica: um sistema de potência é "topológicamente" observável, com relação a um conjunto de medidas, unicamente se existir, associada a tal sistema, uma árvore geradora de posto completo (árvore geradora é uma árvore abrangendo todas as barras da rede; uma árvore é de posto completo, se for possível atribuir a cada um de seus ramos, pelo menos uma medida distinta).

Por definição, um SEP é observável se o conjunto de medidas aferidas for suficiente para a determinação de todas as suas variáveis de estado, isto é, das tensões complexas de todas as suas barras. Caso contrário, o mesmo é dito não observável, acarretando duas possibilidades: a identificação de ilhas observáveis, isto é, porções do SEP onde é possível a determinação de todas as vaiáveis de estado; ou a restauração da observabilidade via pseudo-medidas.

Os métodos desenvolvidos para análise de observabilidade são aplicados na fase do projeto de sistemas de medição, indicando onde devem ser instalados os medidores, para garantir um sistema observável, bem como no processamento on-line, permitindo verificar a observabilidade do SEP referente a cada amostra de medidas que se torna disponível para o processo de estimação de estado.

\footnotetext{
${ }^{3}$ Equações apresentadas na seção (2.1.3)
} 


\subsection{Medidas Críticas e Conjuntos Críticos de Medi- das}

A redundância das medidas aferidas é de especial importância para o sucesso do processo de EESEP, independentemente do estimador utilizado. Redundância é importante não apenas para garantir a observabilidade do SEP, mas também para possibilitar a deteç̧ão e identificação de EGs. Eis a razão do desenvolvimento de diversas pesquisas relacionadas ao tema.

Em termos de redundância de medidas, os conceitos de medida crítica (MC) e conjunto crítico de medidas (CCM), introduzidos nos trabalhos apresentados por (CLEMENTS; KRUMPHOLZ; DAVIS, 1981; MILLI; VAN CUTSEM; RIBBENS-PAVELLA, 1984) respectivamente, são de suma importância:

Definição 1: Medida Crítica (MC) é a medida que, se retirada do conjunto de medidas de um sistema observável, torna o mesmo não observável.

Definição 2: Conjunto Crítico de Medidas (CCM) é o conjunto de medidas formado por medidas não críticas, em que a eliminação de uma medida qualquer, a ele pertencente, torna as demais medidas do conjunto críticas.

Os métodos para identificação de MCs e CCMs podem ser divididos, assim como os desenvolvidos para análise de observabiliade, em Topológicos (CLEMENTS; KRUMPHOLZ; DAVIS, 1981; BRETAS et al., 2005; COSTA; PIAZZAM; MANDEL, 1990) e Numéricos (DO COUTTO FILHO et al., 2001; KORRES; CONTAXIS, 1991; LONDON; ALBERTO; BRETAS, 2007).

Com base nos conceitos topológicos, uma medida é considerada crítica se a mesma for necessária para construção de uma árvore geradora de posto completo, ou seja, a sua supressão do conjunto de medidas impede a construção daquela árvore.

Os algoritmos topológicos utilizam o conceito de observabilidade topológica. Apesar de não exigirem cálculos numéricos, os mesmos apresentam natureza combinatória, requerendo rotinas específicas, que geram grandes esforços computacionais.

Em BRETAS et al. (2005), foi proposto um novo método topológico para identificação de MCs. Neste método, explora-se a natureza das medidas (fluxo e injeção), de forma a reduzir as possibilidades de busca, evitando assim a chamada "explosão combinatória". Entretanto, o método não possibilita a identificação de CCMs.

Em LONDON; ALBERTO; BRETAS (2007) foi proposto um método para tratamento das características qualitativas de conjunto de medidas, para efeito de EESEP. O algoritmo permite a identificação de MCs e de CCMs, de uma forma direta e simples.

Os pontos positivos do método proposto por LONDON; ALBERTO; BRETAS (2007), em relação aos já desenvolvidos para identificação de MCs e de CCMs, são os seguintes: (i) possibilita a identificação de CCMs de uma forma bastante direta, sem exigir busca com base na teoria de grafos; $(\boldsymbol{i i})$ em relação aos métodos numéricos já desenvolvidos, a 
quantidade de cálculo necessária é bem menor, pois, não exige a obtenção da matriz de sensibilidade, nem mesmo de uma estimação de estado inicial. O método requer apenas a fatoração da matriz jacobiana e, em seguida, a análise dos elementos não nulos que aparecem na matriz fatorada, que recebe o nome de matriz $H_{\triangle}$ (LONDON; ALBERTO; BRETAS, 2007).

\subsection{Medição Fasorial Sincronizada}

Os trabalhos de pesquisa como (THORP; PHADKE; KARIMI, 1985; PHADKE, 1986) abordam a possibilidade da obtenção de um sistema de medição fasorial sincronizada (SMFS), sendo que atualmente, a implantação de equipamentos responsáveis pela aferição de medidas fasoriais, as PMUs, já é uma realidade, que se nos apresenta como uma forte tendência de utilização.

A tecnologia de medição fasorial sincronizada é considerada importante no futuro dos sistemas de gerenciamento de energia (SGE), devido a sua capacidade única de amostrar a forma de onda da tensão e corrente em sincronismo por meio do sinal de relógio do sistema de Geoposicionamento por satélite (GPS), bem como calcular a correspondente componente fasorial de $60 \mathrm{~Hz}$ (números complexos que representam a amplitude e o ângulo de fase de uma onda senoidal de $60 \mathrm{~Hz}$ ), de locais muito dispersos (Figura (2.3)). Este processo de amostragem sincronizada das diferentes formas de onda fornece uma referência comum, para os cálculos fasoriais em todos os locais geograficamente distantes.

A tecnologia de MFS fornece um fasor sincronizado no tempo, normalmente 20, $30 \mathrm{ou}$ 60 amostras por segundo. Assim, estas amostras podem ser aplicadas com o intuito de monitorar amplas áreas, tornando possível o acompanhamento em tempo real da dinâmica e estabilidade; avaliações de sistema dinâmico de energia operando perto da margem para reduzir os custos, bem como melhorias nos processos de EESEP, proteção e controle.

Os sistemas SCADAs, utilizados usualmente para obter informações dos SEPs, baseiamse em constantes análises de fluxo de potência, e não permitem observar as características dinâmicas dos mesmos.

A tecnologia de MFS fornece medições em quantidade e qualidade, tal que torna possível a análise do comportamento dinâmico do sistema, superando assim as limitações de "visibilidade", que possuem os sistemas baseados em tecnologia SCADA.

A precisão da amostragem sincronizada dos dados fasoriais torna-os úteis para além do barramento local, onde a medida é tomada, ou seja, a tecnologia oferece uma visibilidade em áreas distantes geograficamente e isto, por sua vez, facilita a capacidade de detecção e distribuição de ações de controle coordenado.

As medições fasoriais sincronizadas fornecem diretamente os ângulos de fase da tensão nas barras com elevada taxa de amostragem. Tradicionalmente, esses ângulos de fase têm sido obtidos a partir de estimadores de estado, de forma lenta e susceptível a erros. 


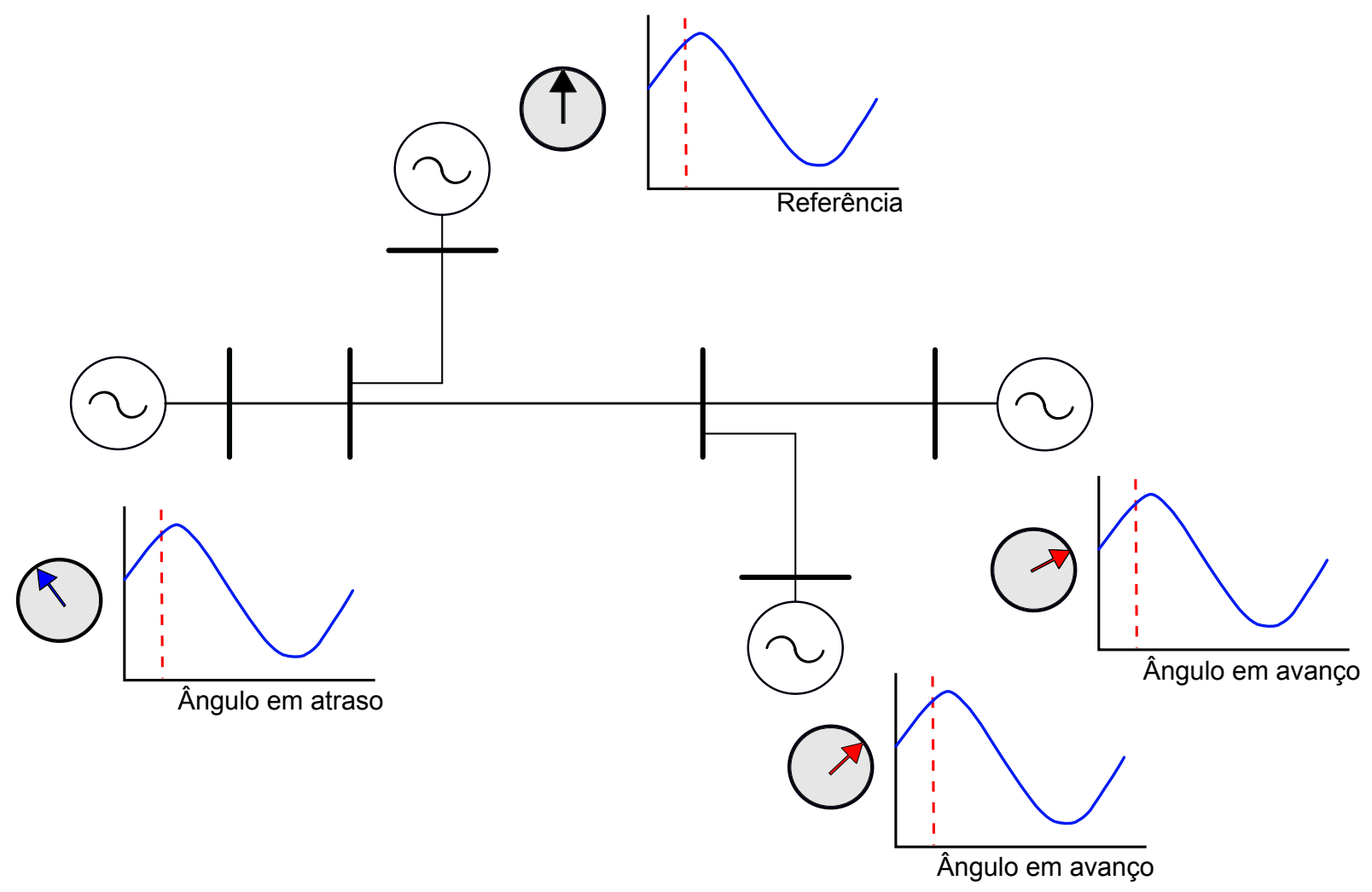

Figura 2.3: Visão geral dos ângulos de fase relativos a uma referência comum

As altas taxas de dados e baixa latência, associadas aos sistemas de aquisição de fasores, proporcionam a agilidade desejada para responder a condições anormais.

\subsubsection{Sistema de Medição Fasorial Sincronizada}

Basicamente, a estrutura de um SMFS é constituída pelos seguintes elementos: PMU, elemento base de todo o sistema; estações de recepção do sinal de GPS; concentrador de dados (PDC, do inglês Phasor Data Concentrator) e canais de comunicação (Figura $(2.4))$.

A PMU é um instrumento desenvolvido em meados da década de 1980 nos Estados Unidos, na Virginia Politechnic Institute and State University, que realiza a amostragem sincronizada das tensões e correntes analógicas trifásicas, processa os dados amostrados, efetuando a medição das grandezas fasoriais, formata e envia ao concentrador de dados.

O concentrador de dados tem como principal finalidade receber e organizar as medidas fasoriais enviadas pelas PMUs, disponibilizando-as para uso em diversas aplicações (por exemplo a estimação de estado).

Os canais de comunicação considerados para uso em SMFS incluem opções de estruturas que operam tanto por meios físicos específicos (linhas telefônicas, cabos de fibra ótica ou mesmo a rede de baixa e média tensão), quanto por tecnologia sem fio, amplamente denominada wireless (canais de micro-ondas ou de sistemas de satélites). 


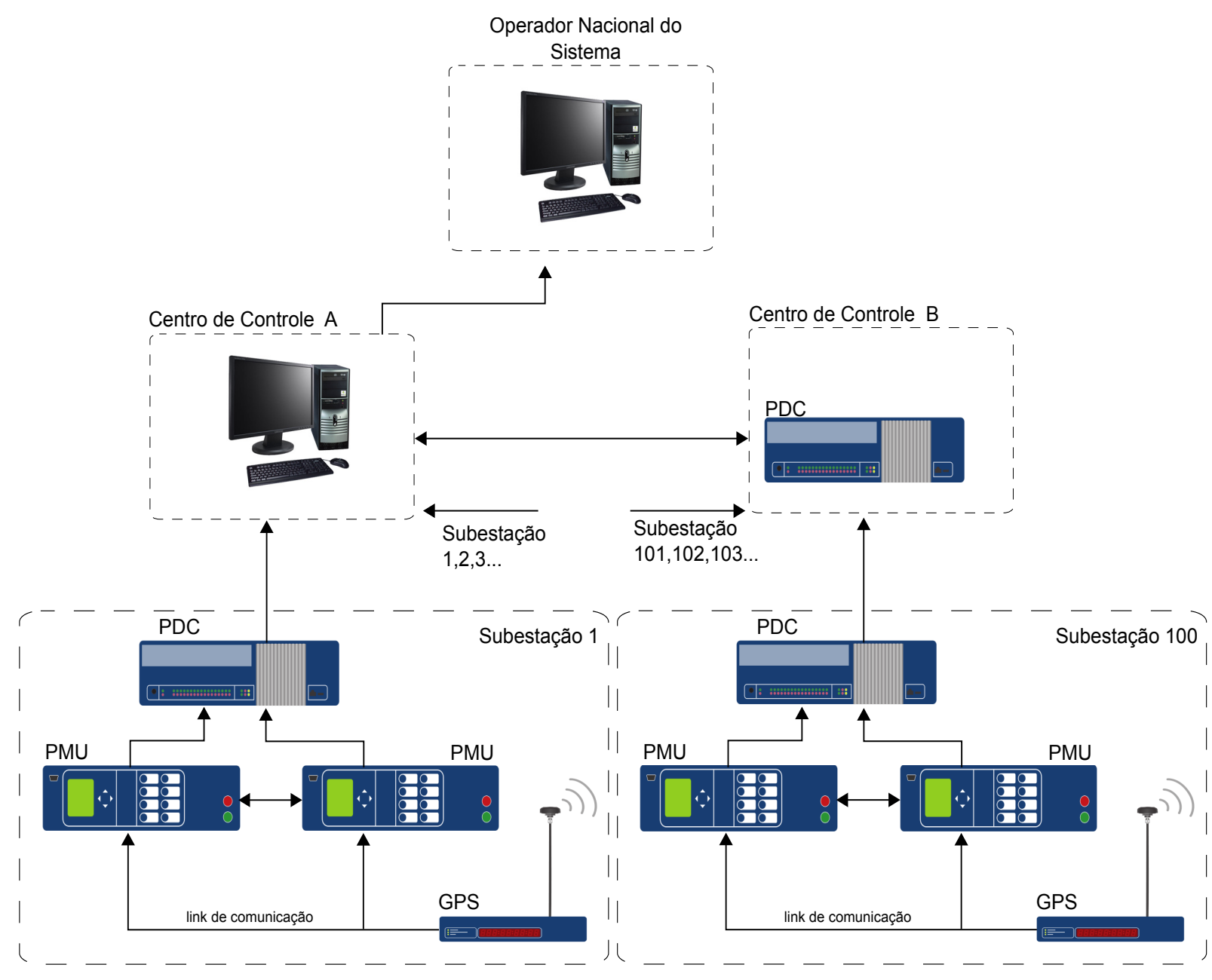

Figura 2.4: Visão geral de um sistema de medição fasorial sincronizada de fasores

\subsubsection{Unidades de Medição Fasorial}

A PMU é o instrumento de medição que realiza a aquisição dos dados de tensão e corrente nas barras do sistema e processa esses dados efetuando a medição das grandezas fasoriais para, em seguida, enviá-las ao concentrador de dados.

A Figura (2.5) ilustra a estrutura simplificada de uma PMU, que consiste basicamente de um sistema de aquisição de dados onde se encontram os filtros anti-aliasing e o módulo de conversão analógica/digital, bem como de um microprocessador, em que se realiza o tratamento matemático das amostras.

Cada PMU deve estar acoplada a um equipamento receptor de sinal de GPS. Proposta por PHADKE (1994), a estrutura básica de uma PMU, apresentada na Figura (2.5) tem se mantido até os dias atuais. 


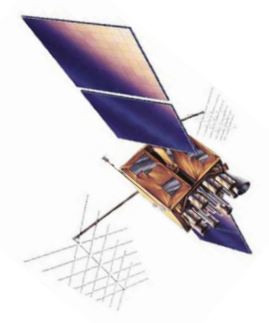

$\longrightarrow$ Sinal de Tensão

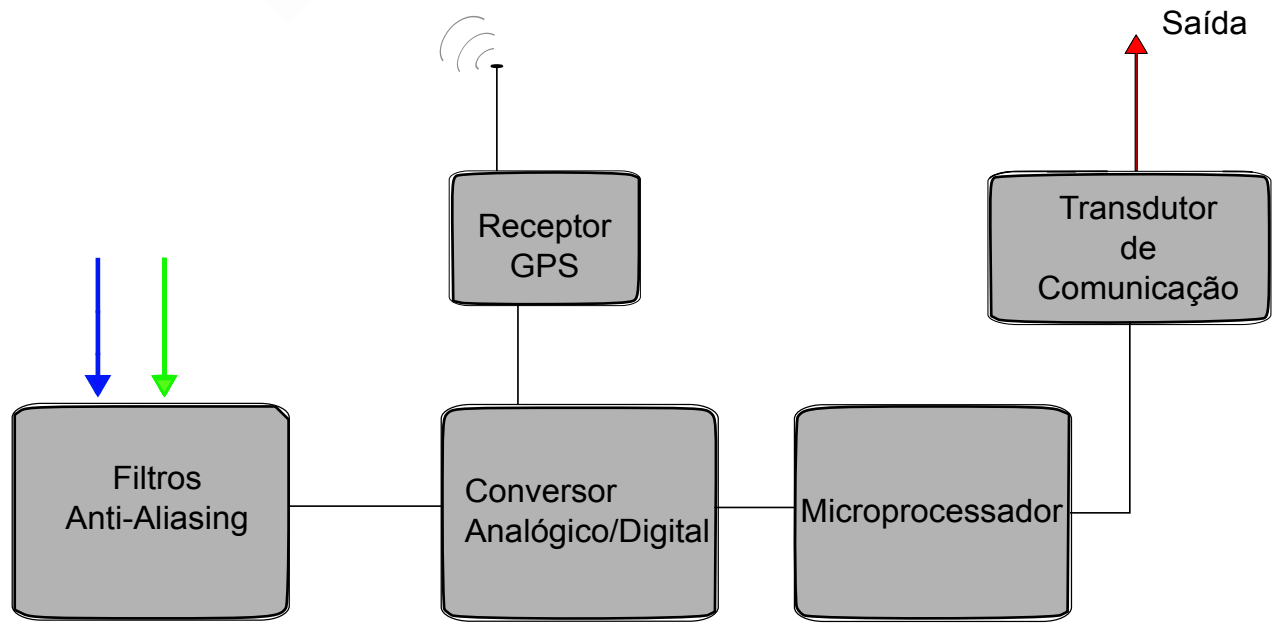

Figura 2.5: Estrutura básica de uma PMU

\subsubsection{Processo de Medição Fasorial}

Em razão de as PMUs utilizarem uma fonte eficaz de sincronização, fornecida pelo sistema GPS, as mesmas viabilizam a realização da medição de grandezas fasoriais, a uma taxa de 60 medidas por segundo, e, com precisão angular adequada aos requisitos da maioria das aplicações de monitoração e controle em tempo real.

Continuamente, o sistema GPS envia sinal de um pulso por segundo às estações receptoras. Considerando que esse trem de pulsos é enviado com precisão maior do que $1[\mu \mathrm{s}] \mathrm{e}$ que pode ser recebido por estações distantes entre si com igual precisão, é possível a sincronização das amostras obtidas por diversas PMUs, instaladas em pontos geograficamente distantes.

As PMUs disponíveis atualmente têm a capacidade de medir fasores de tensão, corrente e potência, além da frequência e variação da frequência no tempo. Os dados medidos são exteriorizados em grandezas de fase ou grandezas de sequência positiva. Em seguida, estes dados são transferidos, por meio de canais de comunicação, ao concentrador de dados, utilizando um formato de dados padronizado atualmente pela norma IEEE-C37.118 (2005).

Destaca-se que atualmente as PMUs são produzidas por diversos fabricantes, podendo, assim, apresentar configurações distintas. Consequentemente, o número de canais para medição dos fasores de tensão e corrente pode variar, em função do tipo de PMU utilizada. 
Dessa forma, algumas PMUs dispõem de vários canais permitindo a medição do fasor de tensão da barra onde a mesma foi instalada, bem como dos fasores de corrente em todos os ramos incidentes àquela barra. Entretanto, existem PMUs que possuem somente um par de canais, viabilizando o processamento de apenas uma medida fasorial de corrente, além da medida fasorial de tensão na barra onde foi instalada (EMAMI; ABUR; GALVAN, 2008).

O proceso de cálculo dos fasores é um ponto chave do desempenho das PMUs. Normalmente se utiliza a transformada de Fourier (PHADKE; THORP, 2008).

Vale lembrar que o fasor é uma representação matemática de uma forma de onda senoidal, tomando como referência, para a determinação do ângulo de fase, o instante do início da amostragem e considerando a frequência constante, conforme apresentado na Figura (2.6). O conceito de fasor com frequência variável, como ocorre na prática, não é claramente definido e pode gerar diferentes interpretações. Para contornar tal situação, normas definem limites de erros permissíveis, em condições limites, em termos de variação da frequência e magnitude do sinal medido.
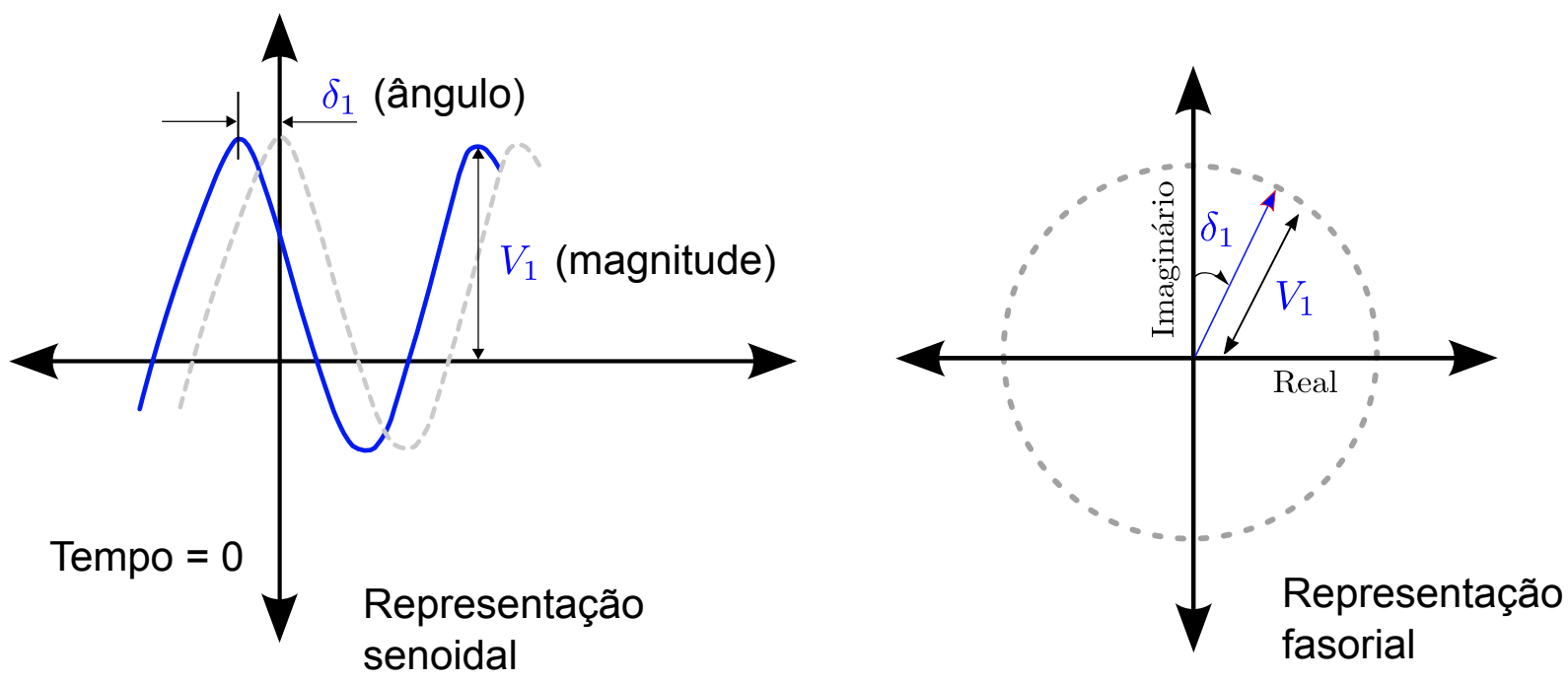

Figura 2.6: Representação Fasorial de uma forma de onda senoidal

\subsubsection{Conceituação Histórica}

Em PHADKE; THORP; ADAMIAK (1983), permite-se identificar o ponto de partida para os modernos SMFS. Neste artigo, os autores identificam a importância dos fasores de tensão e corrente de sequência positiva e alguns dos usos desse tipo de medida.

O GPS passou a ter amplo uso com a liberação para civis. Estava claro que o sistema oferecia o mais efetivo meio de sincronização das medidas do SEP, amostradas em regiões geograficamente distantes. O primeiro protótipo, das modernas PMUs usando GPS, foi construído nos anos 80, na Virginia Tech, e implantado em algumas subestações da 
Bonneville Power Administration, American Eletric Power Service Corporation e da New York Power Autority. A primeira PMU comercial foi desenvolvida pela Macrodyne em 1991, com a colaboração da Virginia Tech.

Incentivados pela complexidade da operação dos SEP, atualmente existem diversos projetos para implantação, ou ampliação de SMFS em vários países.

No Brasil, o interesse pelo uso de SMFS data do início da década de 90, inicialmente para fins de registro de perturbações e estudos off-line. Entretanto, ainda não há registro de aplicação em larga escala.

A primeira iniciativa brasileira foi por meio de um projeto de desenvolvimento tecnológico, o projeto Medfasee, que se iniciou em 2001, com pesquisas de prospecção desenvolvidas de forma conjunta pela Universidade Federal de Santa Catarina (UFSC) e REASON Tecnologia S.A. Em 2003, os trabalhos ganharam forte impulso em decorrência de financiamentos, o que permitiu a implantação de um protótipo de SMFS em baixa tensão, sendo este o primeiro do Brasil.

Atualmente, o projeto conta com um protótipo instalado no sistema de $500[\mathrm{kV}]$, da Eletrosul Centrais Elétricas S.A. e um protótipo de baixa tensão, que monitora o Sistema Interligado Nacional (SIN). Esta última iniciativa deve-se a nove Universidades, com excelência em pesquisa na área de sistemas elétricos de potência, incluindo a Escola de Engenharia de São Carlos, da Universidade de São Paulo. Esta rede tem também o objetivo de incentivar e divulgar a pesquisa nesta área.

\subsubsection{Medição Fasorial Sincronizada no Processo de Estimação de Estado}

Tendo em vista a sincronização dos dados no tempo, a possibilidade de se dispor de medições sincronizadas ao longo de um SEP de grandes dimensões e a elevada frequência com que os dados são apresentados, verifica-se que a medição proporcionada pelas PMUs é de qualidade bem superior àquela obtida pelo sistema SCADA convencional (medidas de potência e de magnitude de tensão).

Nos últimos anos, diversas propostas vêm sendo apresentadas para a inclusão das medidas fasoriais sincronizadas, visando à melhoria do processo de estimação de estado.

Em trabalhos como (ZIVANOVIC; CAIRNS, 1996; PHADKE, 1986; ZHOU et al., 2006; THORP; PHADKE; KARIMI, 1985), demonstra-se que, quando as medidas fasoriais são adicionadas às medidas convencionais, no processo de estimação de estado, a precisão deste é aumentada. Além disto, desde que todas as tensões nas barras do sistema sejam monitoradas por PMUs, o problema de estimação pode ser resolvido utilizando somente medidas fasoriais (PHADKE, 2002; CEASE; FELDHAUSS, 1999). Neste caso o problema torna-se linear, já que as medidas se relacionam diretamente às variáveis de estado, ao contrário das medidas convencionais de potência, as quais relacionam medidas e variáveis 
por funções não lineares.

Em ZIVANOVIC; CAIRNS (1996) apresentou-se um estimador por mínimos quadrados ponderados WLS, que faz uso apenas de medidas fasoriais.

Entretanto, como a maioria dos SEP ainda não são observáveis como um todo, considerando apenas medidas fasoriais sincronizadas, foram desenvolvidos estimadores de estado não lineares, que fazem uso de medidas convencionais e fasoriais, (THORP; PHADKE; KARIMI, 1985; ZIVANOVIC; CAIRNS, 1996), os quais chamaremos de Estimadores Híbridos.

Pelo fato de as variáveis de estado serem mais sensíveis aos erros em medidas fasoriais, do que aos erros em medidas convencionais, alguns trabalhos indicam que o processamento simultâneo de medidas convencionais e fasoriais é a melhor escolha para o processo de estimação (ZIVANOVIC; CAIRNS, 1996).

PHADKE (1986) propôs a utilização em conjunto de dois tipos de estimadores: um linear que faz uso apenas de medidas fasoriais, para as partes do SEP que são observáveis, considerando apenas PMUs, e um estimador convencional, não linear, para as partes do SEP ainda não supervisionadas por PMUs. O problema desse procedimento é o tratamento dado às barras fronteiras, entre regiões cobertas por cada um dos estimadores, bem como a definição do ângulo de referência.

Deve-se destacar que uma das principais dificuldades dos estimadores de estado que fazem uso de medidas convencionais e fasoriais é o tratamento dado às medidas de ângulo.

Em ZHOU et al. (2006), apresentam-se duas alternativas de como incorporar estas medidas aos estimadores de estado convencionais já existentes. A primeira considera que as medidas fasoriais sejam simplesmente acrescentadas ao estimador convencional, mesclando essas medidas com as convencionais. Como as medidas de corrente e tensão fasoriais são obtidas em sua forma retangular, e os vetores de estado apresentam-se em coordenadas polares, é necessária uma conversão. Os ângulos dos fasores são ajustados para ficarem em conformidade com a convenção de que o ângulo da barra de referência é nulo.

A segunda alternativa, seria a de, em um processo posterior, de posse das variáveis de estado estimadas considerando somente medidas convencionais, realizar a estimação somente com medidas fasoriais. Este processo seria então linear, e os vetores de estado e de medidas seriam expressos em coordenadas retangulares. Conclui-se, pelos testes apresentados, que a segunda opção seria a melhor, pois não requer modificações nos estimadores já existentes, podendo ser implementada de forma rápida e simples. Mostra-se também o aumento da qualidade do processo de estimação, em virtude do aumento do número de PMUs instaladas no sistema.

Muitos trabalhos apresentam métodos interessantes para o tratamento de medidas convencionais e fasoriais. Em (BI; QIN; YANG, 2008), mostra-se a vantagem de trabalhar com os dois tipos de medidas, e como tratar a covariância do erro das medidas 
fasoriais. Este problema é de extrema importância, visto que as medidas fasoriais apresentam precisão muito maior do que as medidas convencionais, sendo que os estimadores híbridos, deve tratá-las de forma diferenciada, visando-se a evitar mau condicionamento numérico no processo de estimação.

São apresentadas, a seguir, algumas alternativas para definição da referência de ângulo de fase, para as tensões em estimadores híbridos:

\section{- Utilizando diretamente o valor da medida de ângulo}

Neste caso, para incluir as medidas fasoriais na formulação do processo de estimação de estado não linear, apresentado na seção (2.1.3), necessita-se apenas de uma pequena alteração, que consiste na inclusão de novas linhas na matriz jacobiana, correspondentes às medidas de ângulo de fase de tensão, que possuirão apenas um elemento não nulo, igual a 1, na coluna correspondente ao ângulo da barra com a medida de ângulo.

Para entender o problema deste tipo de representação, basta lembrar que, no processo de estimação de estado não linear, considerando apenas medidas convencionais, uma das barras do sistema é escolhida como referência angular. Assim, atribui-se zero para o ângulo de tensão dessa barra e os ângulos estimados para as demais barras do sistema são relativos a barra de referência. Tendo em vista que não é usual a monitoração direta dos ângulos de fase de tensão via sistema SCADA convencional, essa prática é apropriada, uma vez que é irrelevante, para o processo de estimação de estado, o valor absoluto do ângulo de tensão da barra de referência. Porém, quando estão presentes medidas convencionais e PMUs, aquela prática não é adequada, isto porque as medidas de ângulo de tensão, fornecidas pelas PMUs, são obtidas a partir de outro referencial, que é determinado pelo instante de tempo fornecido pela recepção do sinal emitido pelo sistema GPS. Desta forma, não se pode utilizar diretamente as medidas de ângulo das PMUs.

Uma solução proposta para esse problema é instalar uma PMU na barra de referência do estimador. Assim, o ângulo medido nessa barra seria subtraído de todos os demais ângulos medidos. Deve-se destacar, entretanto, que esse procedimento não é muito confiável, pois, a ocorrência de uma simples falha na PMU, instalada na barra de referência, inviabilizaria todo o processo.

Para contornar esse problema, foi proposto o método da barra física com backup. Na ocorrência de falha na comunicação, ou perda de sincronismo da PMU instalada na barra de referência, transfere-se instantaneamente a referência para outra barra com PMU. Destaca-se como vantagem do método a facilidade de implementação e a confiabilidade, caso sejam utilizadas várias PMUs como backup. Porém, a desvantagem do método é o salto nos valores de ângulo relativo, que ocorre durante a mudança de referência.

O chamado método da barra virtual (EIPP, 2005) utiliza a média dos ângulos de PMUs, selecionadas como ângulo de referência. Caso ocorra a falha de alguma PMU, a 
média é realizada sobre as demais, mantendo a confiabilidade e evitando a mudança de PMU.

Foi proposto também, em EIPP (2005), o método da barra real com cálculo retroativo, que faz uso do ângulo de uma PMU previamente selecionada e registra os ângulos de diversas PMUs vizinhas. Em caso de falha da PMU selecionada, o ângulo da mesma é calculado a partir dos ângulos das PMUs vizinhas. Esse procedimento não evita saltos do ângulo de referência durante falhas, mas diminui a magnitude dos mesmos, uma vez que o ângulo calculado será próximo ao ângulo medido pela PMU previamente selecionada.

\section{- Utilizando a diferença angular entre duas medidas de ângulo em barras ligadas por linhas ou transformadores}

Ao invés de utilizar diretamente a medida de ângulo, utiliza-se a diferença angular entre duas medidas de ângulo obtidas por duas PMUs instaladas em barras ligadas por linhas de transmissão ou transformadores. Para incluir essa medida, na formulação do estimador de estado não linear apresentada na seção (2.1.3), bastaria incluir novas linhas na matriz jacobiana, correspondentes às medidas de diferença angular, com apenas dois elementos não nulos, iguais a 1 e -1 , nas colunas correspondentes aos ângulos das barras, relacionadas pelas medidas de diferença angular.

Em tal caso, o problema das duas referências angulares não existiria, uma vez que a medida da diferença angular não depende da referência adotada.

Em ZIVANOVIC; CAIRNS (1996), diversos testes foram realizados demonstrando a eficiência do processo de estimação de estado não linear, com a inclusão de medidas de diferença angular.

No entanto, deve-se destacar que tal procedimento poderia ser inviabilizado, caso exista algum erro de parâmetro nas linhas ou transformadores, sobre os quais as medidas de diferenças angulares foram obtidas.

\section{- Tratamento Alternativo}

Analisando as alternativas previamente citadas, para o tratamento da referência de ângulo de fase para as tensões em estimadores híbridos, e outras propostas na literatura, destaca-se, a nosso ver, a apresentada por ZHU; ABUR (2007b). As vantagens dessa proposta são as seguintes: não exige muitas mudanças na formulação do processo de estimação de estado convencional por mínimos quadrados ponderados; não requer a escolha de uma barra como referência angular, nem mesmo a criação de uma barra de referência virtual; e, possibilita o processamento de EGs em medidas fasoriais sincronizadas, desde que a redundância seja adequada.

Na formulação apresentada por ZHU; ABUR (2007b), evidenciada no (Capítulo 4), as medidas de PMU são tratadas como se fossem medidas convencionais, e, na existência de pelo menos uma medida de ângulo de tensão, a referência de ângulo vai ser determinada 
pelo sinal emitido pelo sistema GPS. Porém, na ausência de tais medidas, utilizar-se-á a prática convencional, ou seja, uma das barras do sistema é escolhida como referência angular.

\subsection{Conclusões}

Foi apresentado, neste capítulo, o processo de EESEP, que é fundamental para operação em tempo real dos SEPs. Destacou-se que diversas pesquisas vêm sendo desenvolvidas para inclusão de PMUs no processo de EESEP. As principais justificativas para isso são as seguintes: $(\boldsymbol{i})$ as PMUs possibilitam a medição direta das variáveis de estado (tensões complexas nas barras do sistema); (ii) as medidas obtidas por PMUs possuem exatidão maior do que as obtidas pelo sistema SCADA convencional; $(\boldsymbol{i i i})$ as medidas obtidas por PMUs localizadas em pontos diversos no SEP podem ser sincronizadas; e $(\boldsymbol{i v})$ diferentemente das medidas obtidas pelo sistema SCADA convencional, cujos tempos de varredura variam de 2 a 5 segundos, as medidas das PMUs são disponibilizadas em taxas de 5 a 60 fasores por segundo.

Deve-se destacar, entretanto, que devido aos elevados custos envolvidos para instalação de PMUs, principalmente decorrentes das necessidades de telecomunicação num SEP de grande dimensão, os atuais sistemas de medição, destinados ao processo de EESEP, não serão completamente substituídos por PMUs em um curto período de tempo. Nesse sentido vale destacar que, de acordo com pesquisas desenvolvidas para alocação de PMUs, para um SEP ser observável, considerando apenas medidas fasoriais sincronizadas, sem nenhuma redundância, requer-se a instalação de PMUs em, no mínimo, 30\% das barras do SEP (XU; ABUR, 2004; BALDWIN et al., 1993), o que representa um número bastante significativo e de difícil alcance nos próximos anos.

Vislumbra-se, assim, que as PMUs devem ser instaladas por etapas, ao longo dos próximos anos, e que serão utilizadas no processo de estimação de estado em conjunto com as medidas convencionais. Ante o exposto, torna-se necessário o desenvolvimento de metodologias para analisar as diversas etapas do processo de EESEP, considerando medidas convencionais e medidas fasoriais sincronizadas. 


\section{Capítulo 3}

\section{Análise de Observabilidade e Identificação de Ilhas Observáveis por meio de Caminhos de Fatoração associados à matriz Jacobiana}

\section{Introdução}

Diversos métodos já foram desenvolvidos para análise de observabilidade, os quais podem ser agrupados, de uma forma geral, em topológicos e numéricos.

Os métodos topológicos (KRUMPHOLZ; CLEMENTS; DAVIS, 1980; QUINTANA; COSTA; MANDEL, 1982; MORI; TSUZUKI, 1991) fundamentam-se nos conceitos da teoria de grafos e requerem a criação de rotinas específicas, que não exigem cálculos, mas que são de natureza combinatória e complexa. Por sua vez, os métodos numéricos (MONTICELLI; WU, 1985, 1986; BRETAS, 1996; LONDON; ALBERTO; BRETAS, 2007; ALMEIDA; ASADA; GARCIA, 2008; BENEDITO; LONDON; BRETAS, 2009) geralmente são mais simples, já que em sua maioria visam à utilização de rotinas já disponíveis nos programas de estimadores de estado, facilitando assim sua implementação. Entretanto, estão sujeitos a erros numéricos e alguns requerem uma grande quantidade de operações matriciais, ou, até mesmo, a solução de equações algébricas (MONTICELLI; WU, 1985, 1986).

Dentre os métodos numéricos, destaca-se o método proposto por MONTICELLI; WU (1985), que se baseia na fatoração triangular da matriz Ganho. No caso em que o sistema não é observável como um todo, para proceder à identificação das ilhas observáveis ou a restauração de observabilidade (via pseudo-medidas), tal método requer a solução de equações algébricas.

Na tentativa de diminuir a quantidade de cálculos necessários, BRETAS (1996) propôs 
um método para análise de observabilidade, que também se baseia na fatoração triangular da matriz Ganho. Entretanto, fazendo uso do conceito de caminhos de fatoração, tal método não requer a solução de sistemas de equações algébricas.

Em razão de a matriz jacobiana ser melhor condicionada numericamente que a matriz Ganho, em MONTICELLI; WU (1986) desenvolveu-se um método para análise de observabilidade, por meio da fatoração triangular da matriz jacobiana. Por ser uma extensão da metodologia proposta por MONTICELLI; WU (1985), o método proposto por MONTICELLI; WU (1986) também exige a solução de equações algébricas. Deve-se destacar, também, que em FALCÃO; ARIAS (1994) se desenvolveu outro método que possibilita a análise de observabilidade e identificação de medidas críticas, através da fatoração triangular da matriz $H$, o qual, entretanto, não identifica ilhas observáveis.

LONDON; ALBERTO; BRETAS (2007) desenvolveram um método que possibilita, de uma forma simples e rápida, a análise e restauração da observabilidade (através de pseudo-medidas críticas), bem como a atualização das características qualitativas de um conjunto de medidas ${ }^{1}$, quando uma ou mais medidas são perdidas. Tal método baseia-se na análise da estrutura da chamada matriz $H_{\triangle}^{t}$, obtida por meio da fatoração triangular da matriz jacobiana transposta, $H^{t}$.

Dando continuidade às pesquisas realizadas por BRETAS (1996) e LONDON; ALBERTO; BRETAS (2007), em BENEDITO et al. (2008) desenvolveu-se um método para análise de observabilidade e identificação de ilhas observáveis, baseado na fatoração triangular da matriz $H^{t}$ e no conceito de caminhos de fatoração. Deve-se destacar que esse método apresenta características apropriadas à operação em tempo real, tais como rapidez e simplicidade para implementação, além de não exigir a solução de equações algébricas. Eis a razão de o mesmo ter sido escolhido como base para o desenvolvimento da metodologia proposta neste trabalho. Neste capítulo, apresentar-se-á o método proposto por BENEDITO et al. (2008). Para isto, a próxima seção deste capítulo será dedicada à apresentação da matriz jacobiana.

\subsection{Matriz Jacobiana}

A matriz jacobiana $H$, definida pela Equação (2.6), relaciona as medidas com as variáveis de estado do sistema, que são os ângulos de fase $(\theta)$ e as magnitudes de tensão $(V)$ nas barras. Usualmente as medidas disponíveis são as seguintes:

$$
\begin{aligned}
& P_{l} \text { - fluxo de potência ativa no ramo } l ; \\
& Q_{l} \text { - fluxo de potência reativa no ramo } l ; \\
& P_{i} \text { — injeção de potência ativa na barra } i ;
\end{aligned}
$$

\footnotetext{
${ }^{1}$ Análise de observabilidade e identificação de medidas críticas e de conjuntos críticos de medidas.
} 
$Q_{i}$ — injeção de potência reativa na barra $i$;

$V_{i}$ — magnitude de tensão na barra $i$;

Dessa forma, pode-se representar a matriz jacobiana dada pela Equação (2.6) da seguinte forma:

$$
H=P_{i}\left[\begin{array}{cc}
\theta & V \\
P_{l} \\
Q_{i} \\
V
\end{array}\left[\begin{array}{cc}
\frac{\partial P_{l}}{\partial \theta} & \frac{\partial P_{l}}{\partial V} \\
\frac{\partial Q_{l}}{\partial \theta} & \frac{\partial Q_{l}}{\partial V} \\
\frac{\partial P_{i}}{\partial \theta} & \frac{\partial P_{i}}{\partial V} \\
\frac{\partial Q_{i}}{\partial \theta} & \frac{\partial Q_{i}}{\partial V} \\
& 1
\end{array}\right]\right.
$$

Pela definição de observabilidade algébrica, proposta por KRUMPHOLZ; CLEMENTS; DAVIS (1980) e apresentada no Capítulo 2 desta dissertação, um sistema com $n$ barras é observável se:

$$
\operatorname{Posto}(H)=2 n-1
$$

sendo $(2 n-1)$ a dimensão do vetor de variáveis de estado a ser estimado.

Por meio do desacoplamento $P \theta-Q V$, conhecido como desacoplamento do modelo, que é obtido considerando o fato de as sensibilidades $\frac{\partial P}{\partial \theta}$ e $\frac{\partial Q}{\partial V}$ serem mais intensas que as sensibilidades $\frac{\partial P}{\partial V}$ e $\frac{\partial Q}{\partial \theta}$, pode-se realizar a análise de observabilidade algébrica separadamente, para cada um dos modelos. Assim, um sistema dir-se-á $P \theta$ algebricamente observável, se:

$$
\operatorname{Posto}\left(H_{\theta}\right)=n-1
$$

onde

$$
H_{\theta}=P_{P_{i}}\left[\begin{array}{c}
\theta \\
\frac{\partial P_{l}}{\partial \theta} \\
\frac{\partial P_{i}}{\partial \theta}
\end{array}\right]
$$

sendo $(n-1)$ o número de ângulos de fase a serem estimados, observando que o ângulo de uma das barras é considerado como referência angular. Da mesma forma, um sistema é dito $Q V$ algebricamente observável, se:

$$
\operatorname{Posto}\left(H_{V}\right)=n \text {, }
$$


onde:

$$
H_{V}=Q_{l} Q_{i}\left[\begin{array}{c}
V \\
\frac{\partial Q_{l}}{\partial V} \\
\frac{\partial Q_{i}}{\partial V} \\
1
\end{array}\right]
$$

sendo $n$ o número de magnitudes de tensão a serem estimadas.

Considerando que as medidas de potência ativa e reativa são realizadas aos pares e que exista uma (ou mais) medida de magnitude de tensão, o número de variáveis de estado a serem estimadas para o modelo $Q V$ (conhecido também como modelo reativo), é igual (ou menor) que para o modelo $P \theta$ (conhecido também como modelo ativo). Assim, um sistema de potência sendo algebricamente observável para o modelo $P \theta$, também o será para o modelo $Q V$ (KRUMPHOLZ; CLEMENTS; DAVIS, 1980; MONTICELLI; WU, 1985).

Desta forma, a análise de observabilidade pode ser realizada considerando apenas o modelo $P \theta$. Isto equivale a uma aproximação para que seja possível analisar o modelo linear de estimação de estado, apresentado no Capítulo 2.

\subsection{Análise de Observabilidade por meio da fatoração da Matriz Jacobiana}

Torna-se necessário, através das considerações abordadas sobre observabilidade algébrica, proceder à análise das relações de dependência linear entre as linhas da matriz $H_{\theta}$. Dentre as metodologias existentes para verificação do posto de uma matriz retangular $(m \times n)$, em que $m$ é o número de medidas do sistema, a decomposição $L U$, através do método de eliminação de Gauss, é uma das mais rápidas e simples (QUARTERONI; SACCO; SALERI, 2000).

Por meio dessa metodologia, em MONTICELLI; WU (1986) e (LONDON; ALBERTO; BRETAS, 2007) demonstrou-se que, se um sistema elétrico com $m$ medidas e $n$ barras $(m>n-1)$ for $P \theta$ observável, apenas um pivô nulo aparecerá ao final da decomposição $L U$ (fatoração triangular) da matriz $H_{\theta}$ e todos os elementos da última coluna da matriz $L$ serão nulos, quando nenhum ângulo de fase da rede for adotado como referência. A seguir, encontram-se as estruturas das matrizes $L$ (Figura (3.1(a))) e $U$ (Figura (3.1(b))).

Na Figura (3.1), as partes em branco correspondem aos elementos nulos, e as áreas sombreadas a possíveis elementos não-nulos.

Nota 1: Observe que os fatores triangulares do método de eliminação de Gauss são obtidos de modo a eliminar as linhas do triângulo superior; sendo os mesmos aplicados às suas respectivas colunas, seguindo a ordem de cima para baixo. Isto porque, os autores 


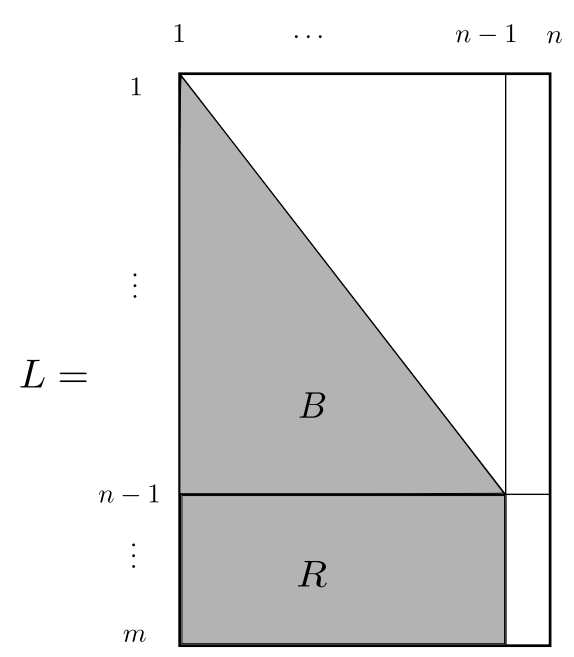

(a) Matriz trapezoidal inferior

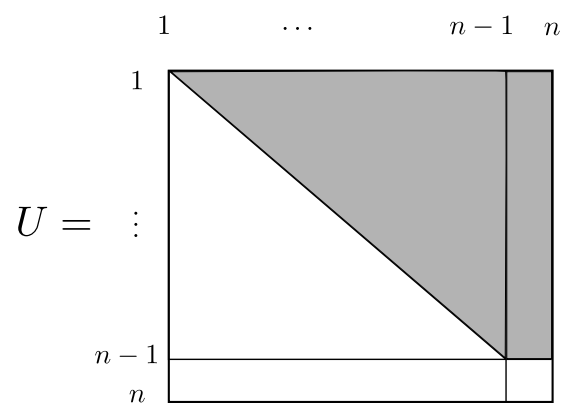

(b) Matriz trapezoidal superior

Figura 3.1: Matrizes associadas a um sistema observável

desejam realizar uma transformação no espaço das variáveis de estado e não no espaço das medidas. Com isso, as colunas resultantes das matrizes $L$ e $U$ corresponderão às variáveis de estado equivalentes, isto é, a combinações lineares das variáveis de estados do sistema.

A submatriz $B$ (Figura (3.1(a))) é composta por linhas linearmente independentes, cuja dimensão é $(n-1) \times(n-1)$. Em virtude disto, as medidas correspondentes a essas linhas são chamadas de Medidas Básicas (LONDON; ALBERTO; BRETAS, 2007), pois tais medidas são suficientes para a observabilidade do sistema. Por outro lado, a submatriz $R$ (Figura (3.1(a))) é composta por linhas linearmente dependentes de $B$, cuja dimensão é $[m-(n-1)] \times(n-1)$. Logo, as medidas correspondentes a essas linhas serão chamadas de Medidas Suplementares, já que as mesmas não influenciam no posto da matriz $H_{\theta}$, mas sim na redundância das medidas.

Também foi provado por MONTICELLI; WU (1986) e LONDON; ALBERTO; BRETAS (2007) que, para um sistema não observável, aparecerá um pivô nulo antes da diagonal $(n, n)$, durante a fatoração triangular da matriz $H_{\theta}$. Diante disto, há duas alternativas: a restauração da observabilidade, através de pseudo-medidas; e a identificação de ilhas observáveis. O texto presente, entretanto, limitar-se-á à identificação de ilhas observáveis e será apresentado na próxima seção uma metodologia baseada no conceito de caminhos de fatoração, associados à fatoração triangular da matriz $H_{\theta}$.

\subsection{Análise de Observabilidade por meio de Cami- nhos de fatoração}

Antes de apresentar o método proposto em BENEDITO et al. (2008), serão apresentadas algumas propriedades de caminhos de fatoração. 


\subsubsection{Propriedades de caminhos de fatoração}

Considere o sistema de equações lineares dado por:

$$
A \cdot x=b
$$

sendo:

- $A$ uma matriz não singular $(n \times n)$;

- $b$ um vetor independente $(n \times 1)$;

- $x$ o vetor de variáveis de estado a calcular $(n \times 1)$.

Com base no trabalho desenvolvido por TINNEY; BRANDWAJN; CHAN (1985), apresentam-se algumas propriedades de caminhos de fatoração.

Propriedade 1: Se a matriz $A$, da Equação (3.7), for singular (posto igual a $n$ ), então, os caminhos de fatoração, associados à matriz dos fatores triangulares $U$ da decomposição $L U$ de $A$, darão origem a uma árvore geradora. Veja o exemplo a seguir:

\section{Exemplo:}

Considere a matriz de incidência barra-ramo (não singular), associada à rede de 20 barras, ilustrada pela Figura (3.2) (TINNEY; BRANDWAJN; CHAN, 1985):

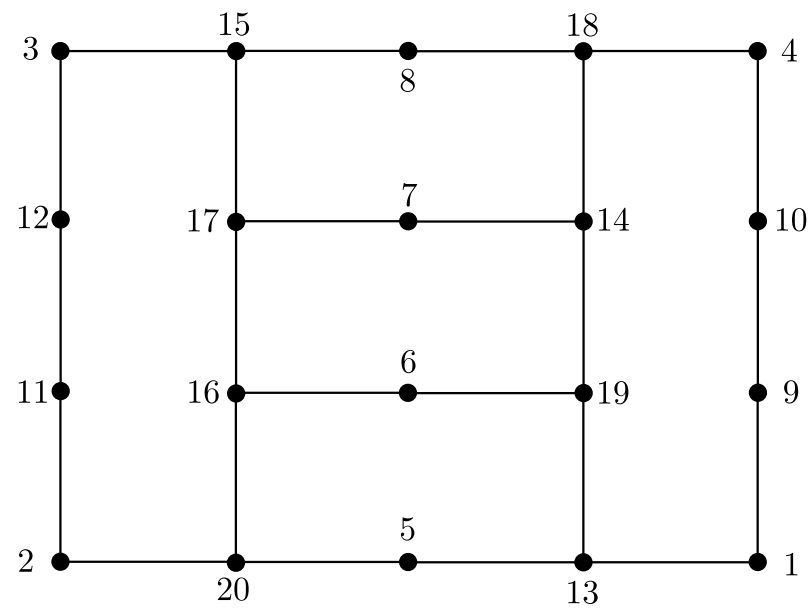

Figura 3.2: Sistema teste de 20 barras

Com a decomposição $L U$ da matriz de incidência barra-ramo, obtemos a matriz dos fatores triangulares $U$ e traçamos o caminho de fatoração a partir de seus elementos, conforme pode ser visualizado pela Figura (3.3).

Os caminhos de fatoração são obtidos através da análise dos elementos não nulos da matriz dos fatores $U$. Percorre-se a linha $(i)$, a partir do elemento $(i, i)$, até o primeiro elemento não nulo $(i, j)$ e passa-se para a próxima linha. O processo é repetido até a penúltima linha da matriz. 


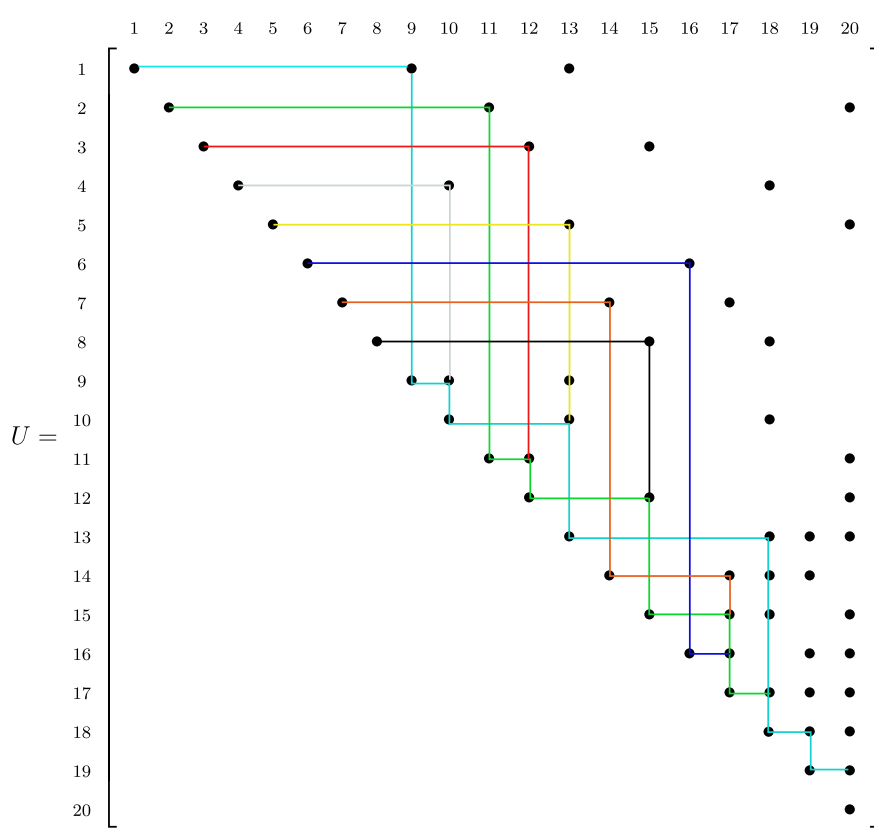

(a) Elementos não nulos

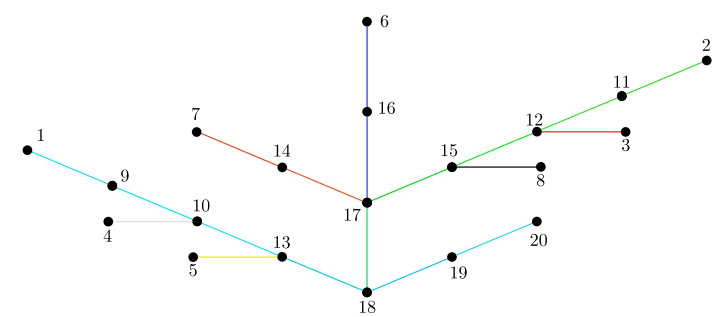

(b) Caminhos de fatoração dando origem a uma árvore geradora

Figura 3.3: Fatores triangulares superiores e Caminhos de fatoração - Sistema 20 barras

Propriedade 2: Se a matriz A, da Equação (3.4), for não singular (posto menor que "n"), então, o sistema de equações pode ser escrito da seguinte forma:

$$
A_{1} \cdot x_{1}=b_{1}, A_{2} \cdot x_{2}=b_{2}, \cdots, A_{n} \cdot x_{n}=b_{n}
$$

Com o vetor de estado $x^{t}=\left[x_{1}, x_{2}, \cdots, x_{n}\right]$; o vetor independente $b^{t}=\left[b_{1}, b_{2}, \cdots, b_{n}\right]$; e a matriz $A$ dada pela Equação (3.9) que mostra a matriz $A$ particionada em $n$ submatrizes não singulares:

$$
A=\left[\begin{array}{llll}
{\left[A_{1}\right]} & & & \\
& {\left[A_{1}\right]} & & \\
& & \ddots & \\
& & & {\left[A_{1}\right]}
\end{array}\right]
$$

Para esse caso, existirão $n$ caminhos de fatoração (ou $n$ árvores) associados à matriz dos fatores triangulares $U$ da decomposição $L U$ de $A$, cada um associado a seu subconjunto de equações e definido de forma única. Cada caminho de fatoração será desconectado um do outro, visto que os subgrupos de variáveis relacionadas aos mesmos são subgrupos desacoplados. 
Embora o conceito de caminho de fatoração, apresentado por TINNEY; BRANDWAJN; CHAN (1985), tenha sido aplicado apenas em matrizes quadradas, verificamos que o mesmo pode ser estendido ao caso de sistemas sobredeterminados, ou seja, àqueles em que o número de equações $(m)$ seja maior que o número de variáveis de estado $(n)$. Assim, tem-se o seguinte teorema: ${ }^{2}$.

Teorema 1: Considere uma matriz $A$ de dimensão $(m \times n)$, associada a um sistema de equações lineares sobredeterminado com $(m>n)$. Se a matriz $A$ tem posto igual a $n$, então os caminhos de fatoração, associados à matriz $U$ da decomposição $L U$ de $A$ $\left(A^{\prime}=P \cdot A=L \cdot U\right.$, sendo $P$ a matriz de permutação de linhas de $A$ ), darão origem a uma árvore geradora.

Dependendo da sequência e da possibilidade de permutações entre as linhas da matriz $A$, a sequência (ordem) do caminho de fatoração, associado à matriz dos fatores triangulares $U$, pode variar. Entretanto, existirá apenas um caminho, se a matriz $A$ apresentar posto igual a $n$ (TINNEY; BRANDWAJN; CHAN, 1985).

\subsection{Análise de observabilidade}

Aplicando as propriedades de caminhos de fatoração, bem como o teorema 1, para matriz jacobiana $H_{\theta}$ do problema de estimação de estado, associada a um SEP com $n$ barras e $m$ medidas, são derivadas as seguintes propriedades BENEDITO et al. (2008):

Propriedade 3: Se o sistema é observável (posto $(H)=n-1)$, a decomposição $L U$ da matriz $H_{\theta}$, resulta em somente uma árvore geradora. Consequentemente, a matriz dos fatores triangulares $U$, associada à decomposição $L U$ de $H_{\theta}$, apresentará a estrutura mostrada na Figura (3.4) (quando não se define nenhum ângulo de fase como referência):

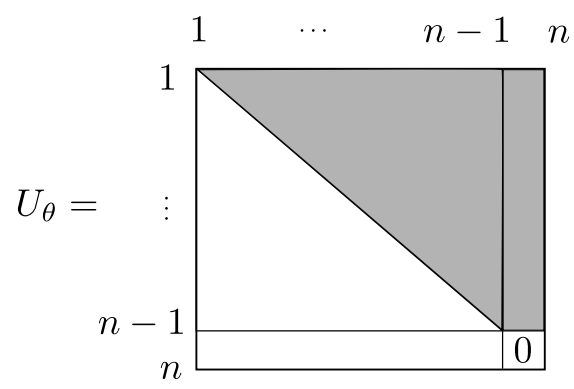

Figura 3.4: Matriz dos fatores triangulares $U$

Propriedade 4: Se durante o processo de decomposição $L U$ de $H_{\theta}$ um pivô zero aparecer na diagonal $(i \times i)$, sendo $(i<n)$, o sistema não é observável, e os outros elementos da linha e coluna " $i$ " são nulos. Isto significa que os nós restantes, correspondentes às colunas de $U$ de $i+1$ até $n$, farão parte de outros caminhos de fatoração (ou outras

\footnotetext{
${ }^{2}$ Em BENEDITO et al. (2008) apresenta-se a prova do Teorema 1.
} 
árvores de caminhos de fatoração) que não possuem conexão com o caminho de fatoração (ou árvore de caminho de fatoração) anterior. Nesse instante da decomposição, a matriz $U$ resultante terá a forma apresentada na Figura (3.5).

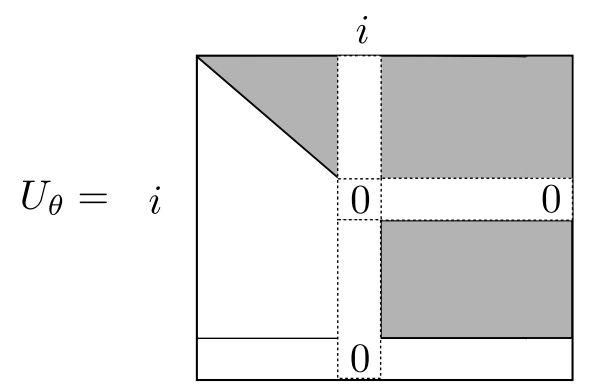

Figura 3.5: Matriz dos fatores triangulares $U$ - pivô zero

Com base nas Propriedades 1 e 2, verifica-se que o número de pivôs nulos encontrados na decomposição $L U$ de $H_{\theta}$ é igual ao número de caminhos de grafos (ou árvores) associados a essa fatoração BENEDITO et al. (2008).

\subsection{Identificando Ilhas Observáveis por meio de Ca- minhos de Fatoração}

Conforme apresentado na seção anterior, no caso em que um sistema não é observável, aparecerá um pivô nulo durante o processo de decomposição $L U$ de $H_{\theta}$, tornando impossível essa decomposição. Por outro lado, se uma pseudo-medida de ângulo, contendo valor unitário na posição daquele pivô nulo, for inserida em $H_{\theta}$, a decomposição $L U$ tornar-se-á possível (MONTICELLI; WU, 1986) (Figura (3.6)).

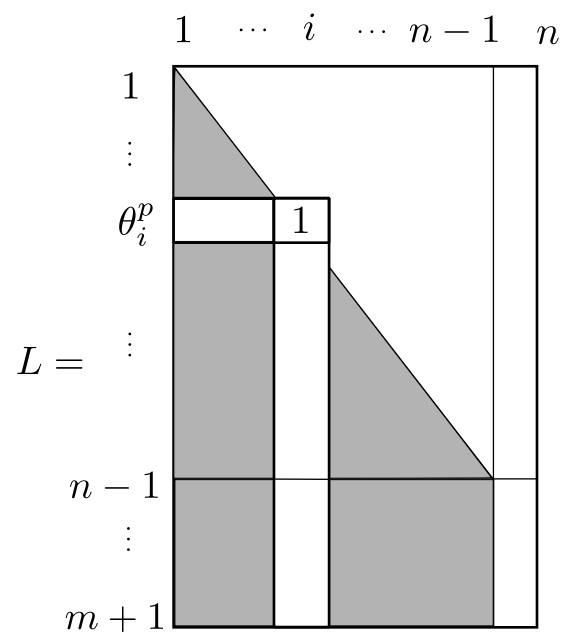

(a) Matriz trapezoidal inferior associada a um sistema não observável

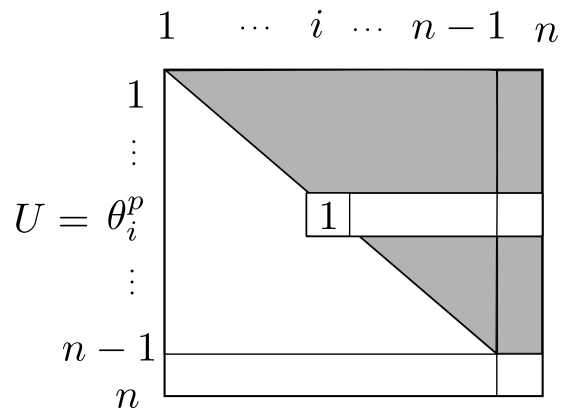

(b) Matriz trapezoidal superior associada a um sistema não observável

Figura 3.6: Matrizes associadas a um sistema não observável 
Pela análise da estrutura da matriz $U$ apresentada na Figura (3.6(b)), verifica-se que a linha correspondente à pseudo-medida de ângulo $\left(\theta_{i}^{p}\right)$ é composta por zero, exceto o elemento da diagonal. Consequentemente, o caminho de fatoração (ou árvore) que contém esta variável não possui conexão com nenhum outro, implicando em mais de um caminho de fatoração. Além disso, o nó correspondente à pseudo-medida de ângulo fará parte do caminho de fatoração determinado até aquele instante, ou então será um nó isolado. Dessa forma, existirão tantos caminhos de fatoração quantos forem os pivôs nulos encontrados.

A partir desses conceitos, constatou-se que os teoremas demonstrados por BRETAS (1996), aplicados à fatoração triangular da matriz Ganho $(G)$, podem ser aplicados à matriz triangular superior $U$, resultante da decomposição $L U$ da matriz jacobiana.

\subsubsection{Ilhas Observáveis e Medidas Irrelevantes}

Para encontrar as ilhas observáveis, por meio dos caminhos de fatoração associados à matriz $H_{\theta}$, duas situações devem ser levadas em consideração (BRETAS, 1996):

i) Não existindo medidas de injeção, relacionando nós de caminhos de fatoração distintos (ou de distintas árvores de caminhos de fatoração), o sistema não é observável como um todo e cada um de seus caminhos (ou árvores) constitui uma ilha observável da rede, ou uma sub-rede observável;

ii) Existindo medidas de injeção, relacionando nós de caminhos de fatoração diferentes (ou distintas árvores de caminhos de fatoração), além de o sistema não ser observável como um todo, nada nos permite afirmar sobre a observabilidade das sub-redes, associadas aos caminhos de fatoração (ou árvores) obtidos. Assim, para obter as ilhas observáveis, importa identificar e descartar as medidas de injeção que conectam esses caminhos de fatoração e depois refatorar a nova matriz $H_{\theta}$. Caso não existam mais medidas com essa característica, os caminhos de fatoração, relacionados com a nova matriz $H_{\theta}$ refatorada, serão as ilhas observáveis da rede.

Essas medidas de injeção, que relacionam variáveis de caminhos de fatoração distintos (ou de distintas árvores de caminhos de fatoração), são irrelevantes ao processo de estimação de estados das ilhas observáveis e os ramos não observáveis serão aqueles que interligam caminhos de grafos distintos.

\subsubsection{Algoritmo}

Apresenta-se o Algoritmo (2) para análise de observabilidade e identificação de ilhas observáveis. Aplicado por simplicidade somente ao modelo $P \theta$, este algoritmo pode também ser estendido ao modelo $Q V$ ou ao modelo completo. 


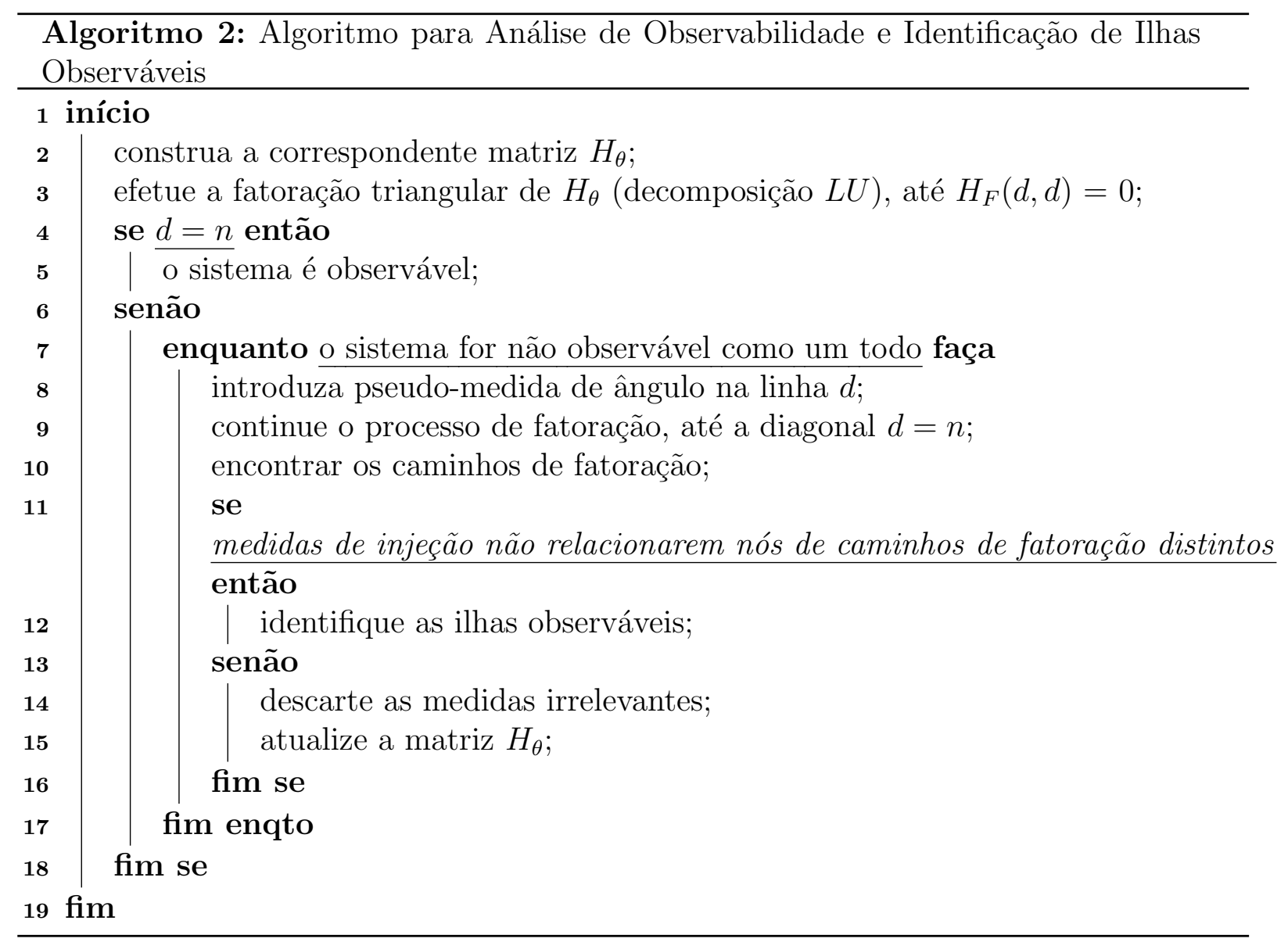

Este algoritmo pode tornar-se iterativo, pois, quando as medidas irrelevantes são identificadas e descartadas, outras medidas irrelevantes podem aparecer.

\subsubsection{Exemplo: Identificando Ilhas Observáveis}

Considere o conjunto de medidas apresentado na Figura (3.7), associado ao sistema de 14 barras do IEEE.

Sabendo-se que o nível de redundância do conjunto de medidas depende somente do tipo e da localização das mesmas, e não do valor dos parâmetros da rede, a matriz $H_{\theta}$ pode ser construída atribuindo-se às reatâncias de linha o valor 1. Entretanto, a utilização do valor real das reatâncias de linha não inviabilizaria a utilização do método.

Passo 1: A partir do plano de medidas apresentado na Figura (3.7), constrói-se a matriz $H_{\theta}$;

Passo 2: Pela decomposição $L U$ da matriz $H_{\theta}$ (com possíveis permutações e/ou inserção de pseudo-medidas de ângulo), obtém-se a matriz fatorada representada na Figura (3.8):

Nota 2: A área em branco refere-se aos fatores triangulares de $U$ e a área sombreada corresponde à matriz trapezoidal inferior $L$. Como foi necessária a inserção de uma 


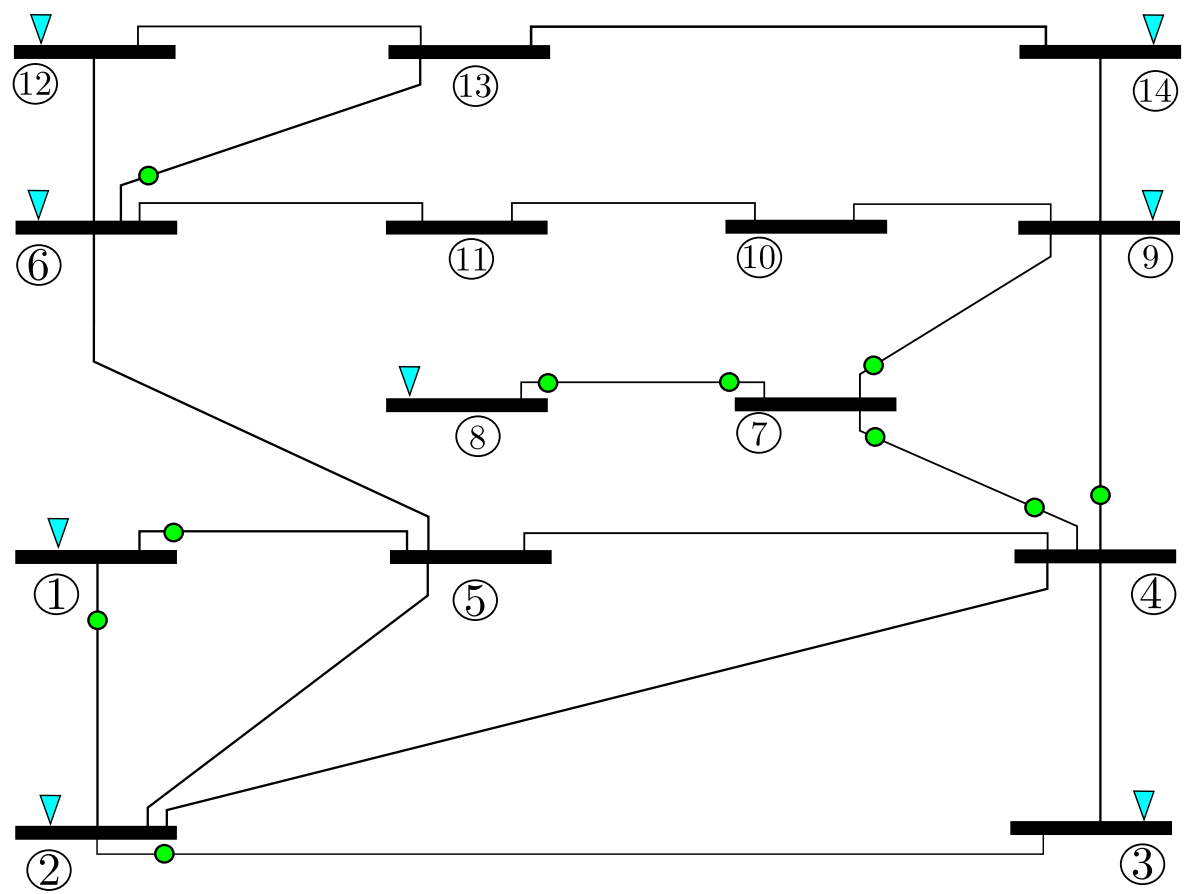

$\nabla$ Medidas de Injeção de Potência

o Medidas de Fluxo de Potência

Figura 3.7: Sistema de 14 barras do IEEE

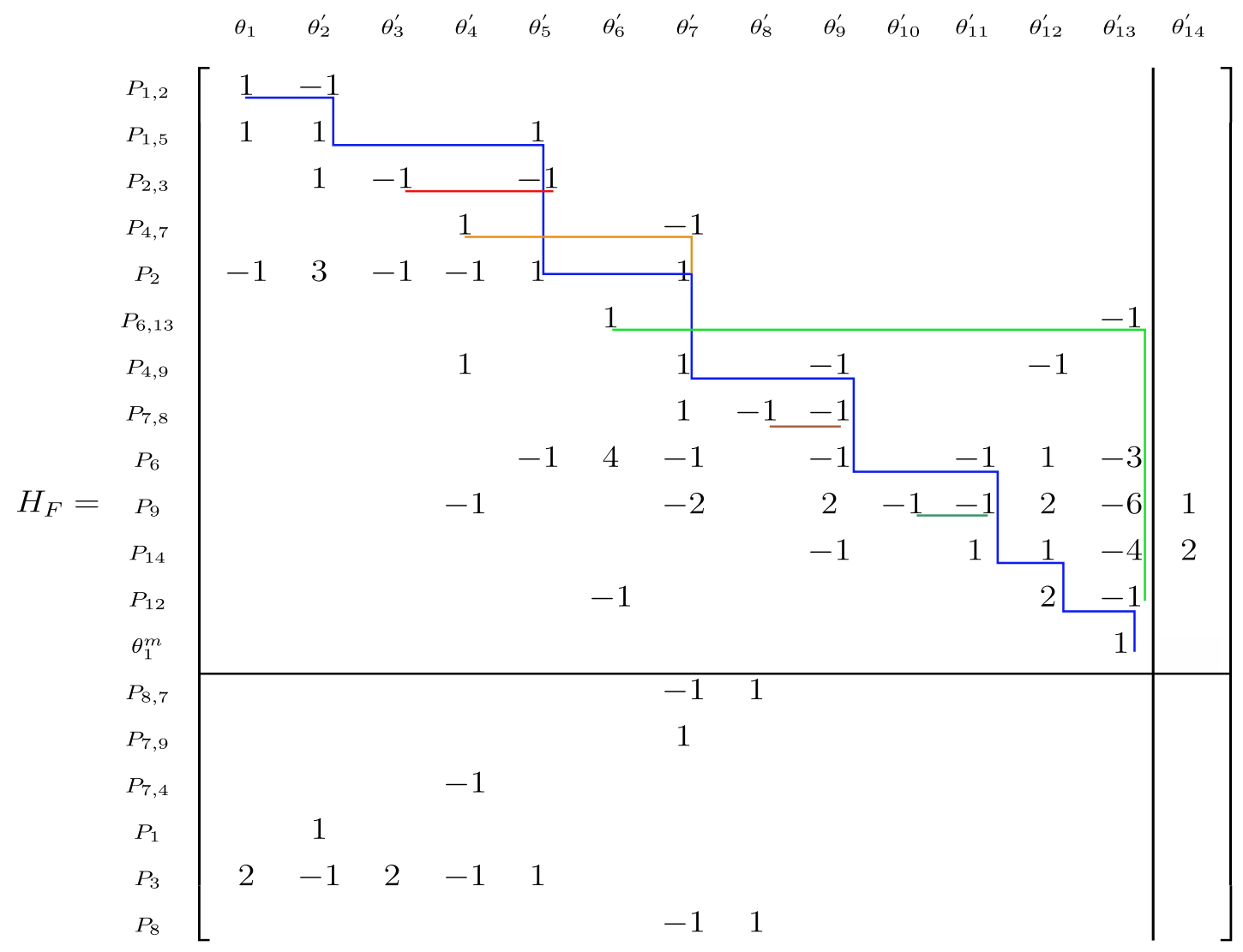

Figura 3.8: Matriz $H_{\theta}$ fatorada (Passo 2) - Sistema de 14 barras do IEEE 
pseudo-medida de ângulo, devido a um pivô nulo (linha 13), o sistema não é observável. Segue-se ao passo 3 .

Passo 3: Por meio dos fatores triangulares obtidos no passo anterior, temos os caminhos de fatoração apresentados na Figura (3.9)

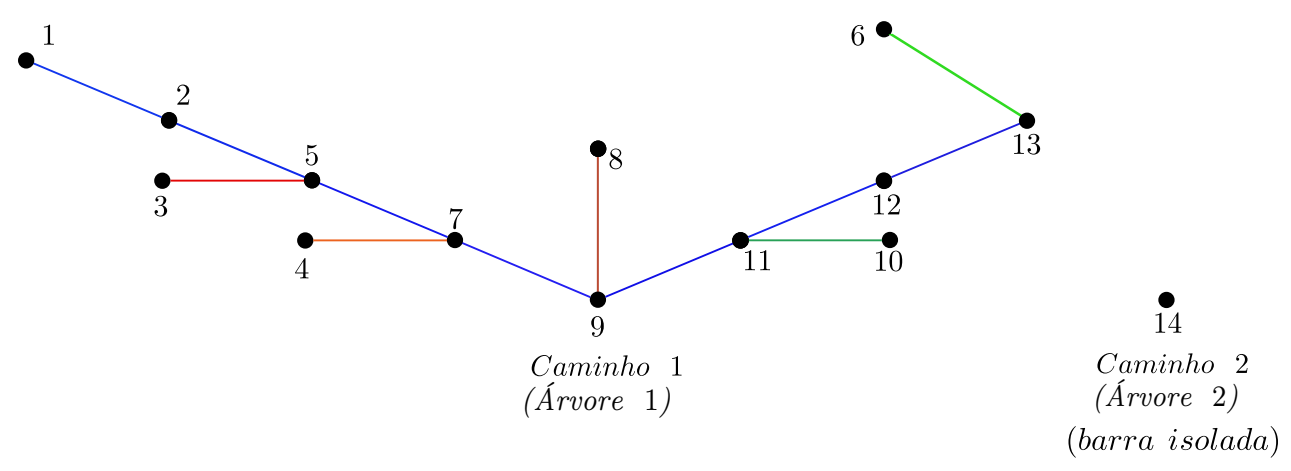

Figura 3.9: Caminhos de fatoração (Passo 3) - Sistema de 14 barras do IEEE

Nota 3: O nó " $i$ " do caminho de fatoração corresponde à barra " $i$ " do sistema.

Nota 4: $\theta_{i}^{\prime}$ simboliza variável de estado equivalente.

Passo 4: Como as medidas $P_{9}$ e $P_{14}$ relacionam variáveis contidas nos caminhos 1 e 2, as mesmas são descartadas. Em seguida, a matriz $H_{\theta}$ é atualizada.

Passo 2': Por meio da decomposição $L U$ da matriz $H_{\theta}$ atualizada (com possíveis permutações e/ou inserção de pseudo-medidas de ângulo), obtém-se a nova matriz fatorada, mostrada na Figura (3.10):

Passo 3': Com essa nova fatoração, obtêm-se os caminhos de fatoração apresentados na Figura (3.11).

Passo 4': Como a medida $P_{6}$ relaciona variáveis contidas nos caminhos 1 e 2 , a mesma é descartada. Em seguida, a matriz $H_{\theta}$ é atualizada.

Passo 2": Por meio da decomposição $L U$ da matriz $H_{\theta}$ atualizada, obtém-se a nova matriz fatorada (Figura (3.12)).

Passo 3": Os caminhos associados a esta nova fatoração são apresentados na Figura (3.13).

Não existe medida de injeção relacionando variáveis de caminhos distintos, logo as ilhas observáveis serão os próprios caminhos de fatoração.

Ilha 1: $\{1,2,3,4,5,7,8,9\}$;

Ilha 2: $\{6,12,13\}$;

Ilha 3: $\{10\}$;

Ilha 4: $\{11\}$;

Ilha 5: $\{14\}$. 


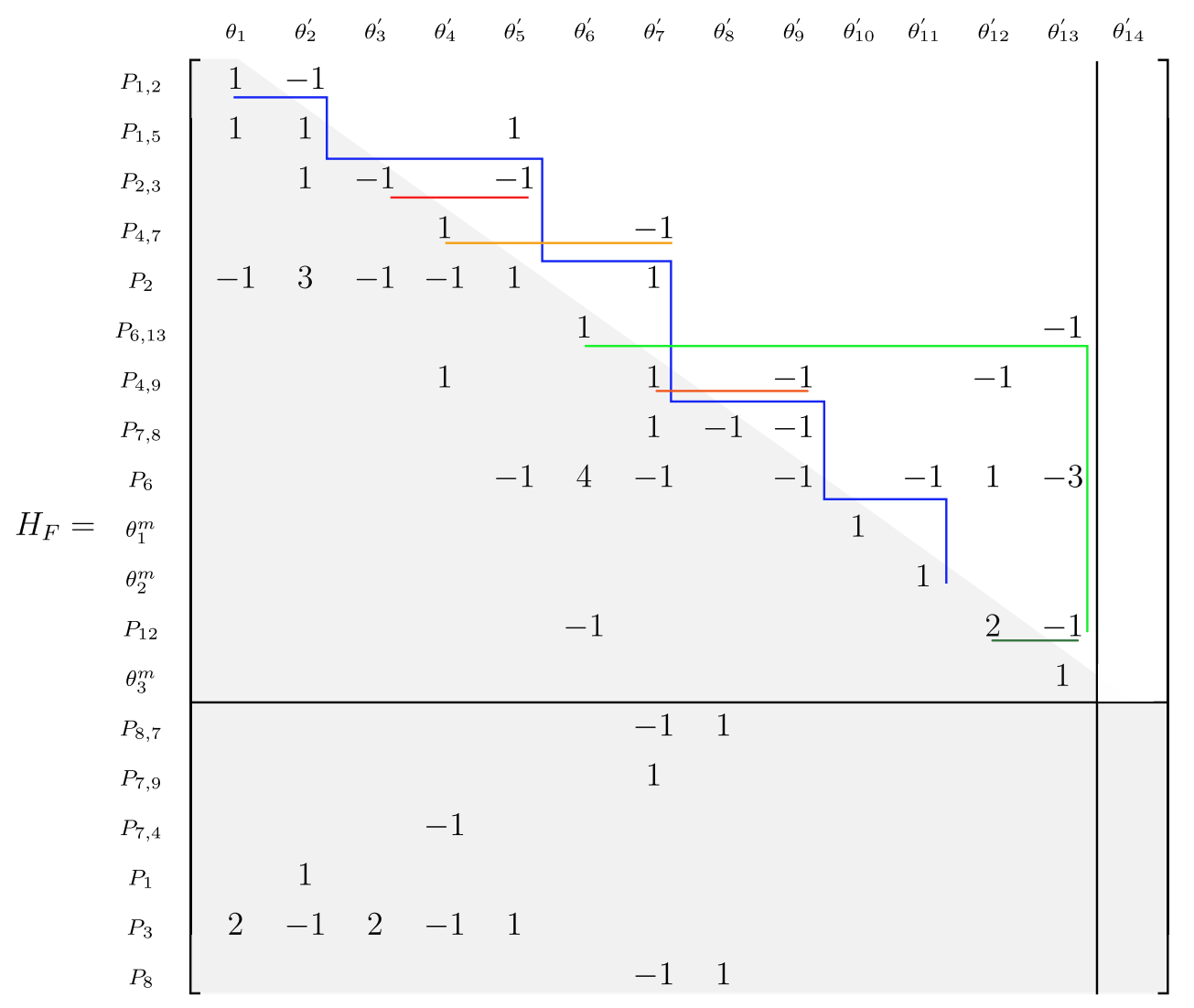

Figura 3.10: Matriz $H_{\theta}$ fatorada (Passo 2') - Sistema de 14 barras do IEEE
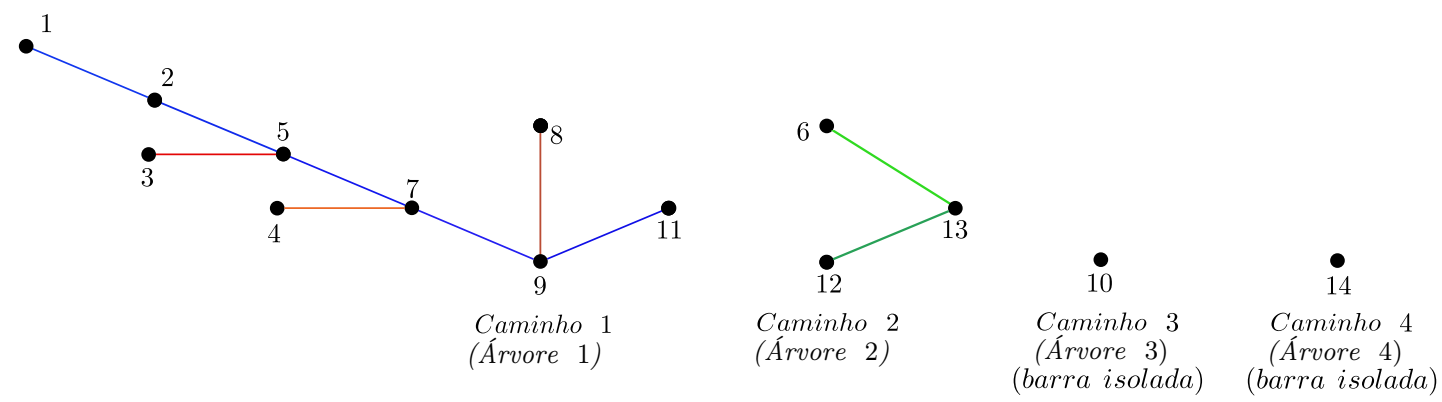

Figura 3.11: Caminhos de fatoração (Passo 3') - Sistema de 14 barras do IEEE 


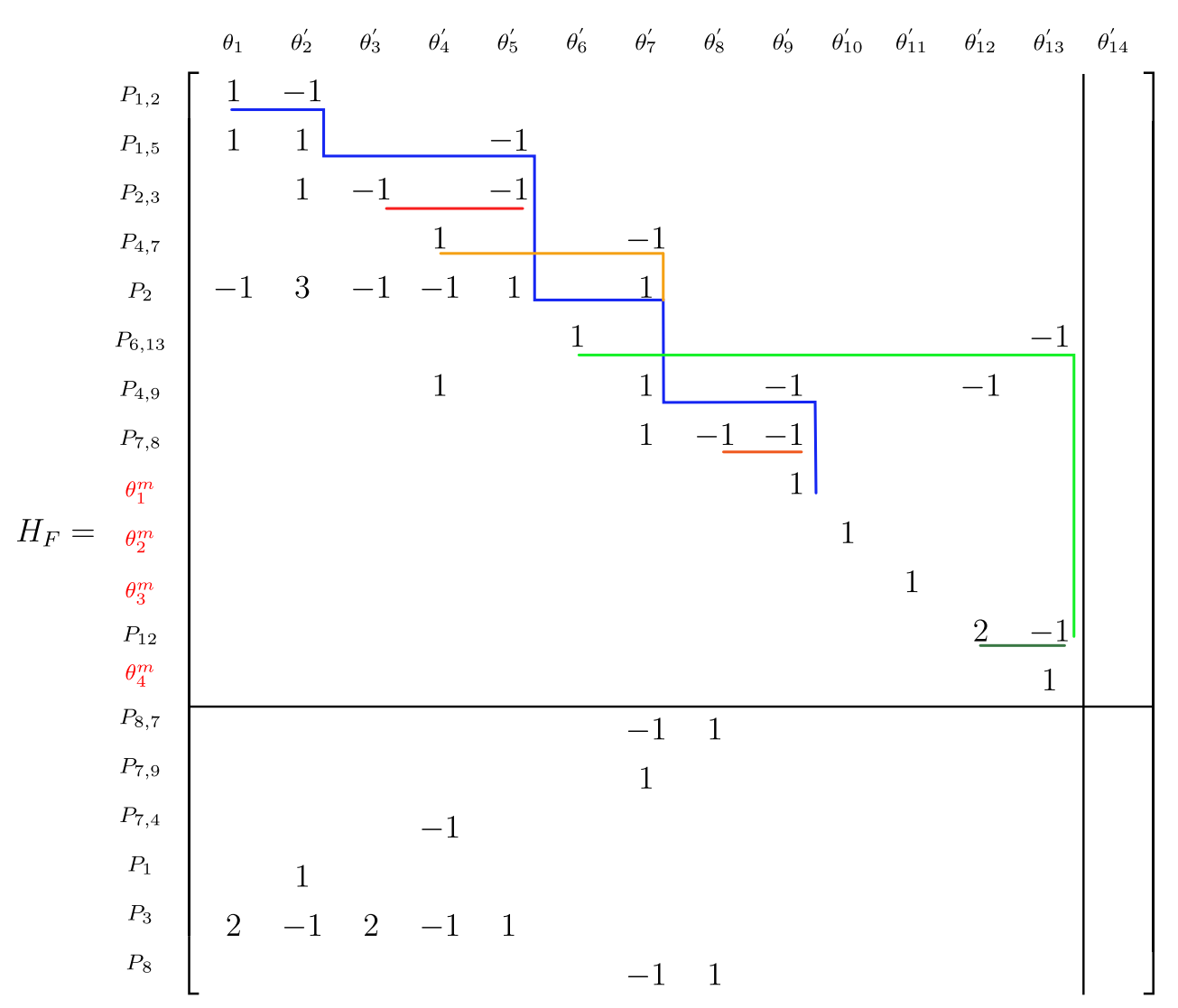

Figura 3.12: Matriz $H_{\theta}$ fatorada (Passo 2") - Sistema de 14 barras do IEEE

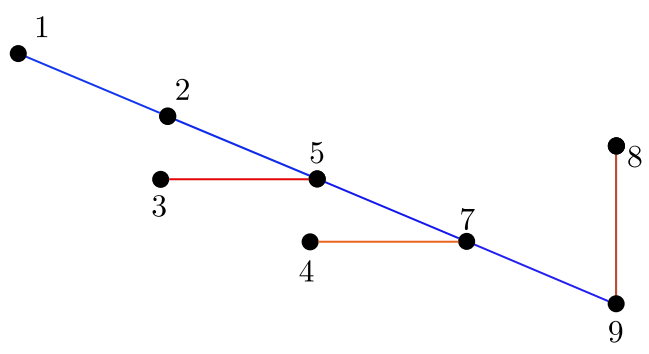

Caminho 1 (Árvore 1)

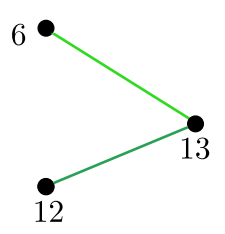

Caminho 2 (Árvore 2)

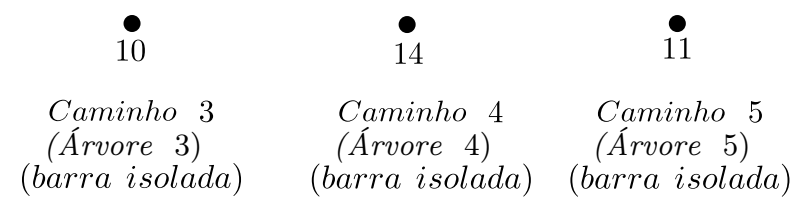

Figura 3.13: Caminhos de fatoração (Passo 3") - Sistema de 14 barras do IEEE 



\section{Capítulo 4}

\section{Estimador de Estado Utilizando Medidas Convencionais e Medidas Fasoriais Sincronizadas}

\section{Introdução}

Na bibliografia especializada, já foram propostos diversos estimadores híbridos, isto é, estimadores que processam medidas convencionais e fasoriais sincronizadas. Dentre esses se destaca o proposto por ZHU; ABUR (2007b), isto em razão das suas seguintes características: não exige muitas mudanças na formulação do processo de estimação de estado convencional, por mínimos quadrados ponderados; não requer a escolha de uma barra como referência angular, nem mesmo a criação de uma barra de referência virtual; e, possibilita o processamento de EGs em medidas fasoriais sincronizadas, desde que a redundância seja adequada. Eis a razão de a formulação desse estimador ter sido escolhida como base para o desenvolvimento do método proposto neste trabalho.

Informações relativas à análise de observabilidade e processamento de EGs serão também apresentadas, bem como exemplos da aplicação desse estimador.

\subsection{Formulação do Problema}

No processo de estimação de estado convencional, isto é, sem considerar PMUs, uma das barras do sistema é escolhida como referência angular. Assim, atribui-se o valor zero para o ângulo de fase de tensão dessa barra e os ângulos estimados, para as demais barras, são referentes ao daquela barra. Tendo em vista que não é usual a monitoração direta dos ângulos de tensão via sistema SCADA convencional, essa prática é apropriada, uma vez que é irrelevante, para o processo de estimação de estado, o valor absoluto do ângulo 
de tensão da barra de referência. Porém, como mencionado no Capítulo 2, quando estão presentes medidas convencionais e PMUs, aquela prática não é adequada. Isto porque as medidas de ângulo de fase da tensão, fornecidas pelas PMUs, são obtidas a partir de outro referencial, que é determinado pelo instante de tempo fornecido pela recepção do sinal emitido pelo sistema GPS.

Na formulação apresentada por ZHU; ABUR (2007b), as medidas fasoriais sincronizadas obtidas pelas PMUs são tratadas como se fossem medidas convencionais, e, na existência de pelo menos uma medida de ângulo de fase de tensão, a referência de ângulo é determinada pelo sinal emitido pelo sistema GPS. Porém, na ausência de tais medidas, utilizar-se-á a prática convencional, ou seja, uma das barras do sistema é escolhida como referência angular.

O modelo de medição e o algoritmo de solução do estimador de estado WLS híbrido, proposto por ZHU; ABUR (2007b), são praticamente os mesmos do estimador convencional WLS, apresentado no Capítulo 2. A diferença é a inclusão das medidas fasorias de tensão e corrente. Dessa forma, a principal diferença entre as formulações desses estimadores está na matriz jacobiana, que passa a ter novas linhas relacionadas às medidas fasoriais de tensão e corrente, conforme apresentado na equação a seguir:

$$
H_{P M U}=P_{l} \quad\left[\begin{array}{cc}
\theta & V \\
Q_{l} \\
P_{i} \\
Q_{i} \\
V^{p m u} \\
\theta^{p m u} \\
I^{p m u} \\
\delta^{p m u}
\end{array}\left[\begin{array}{cc}
\frac{\partial P_{l}}{\partial \theta} & \frac{\partial P_{l}}{\partial V} \\
\frac{\partial P_{i}}{\partial \theta} & \frac{\partial P_{i}}{\partial V} \\
\frac{\partial Q_{i}}{\partial \theta} & \frac{\partial Q_{i}}{\partial V} \\
& 1 \\
\frac{\partial I_{l}^{p m u}}{\partial \theta} & \frac{\partial I_{l}^{p m u}}{\partial V} \\
\frac{\partial \delta^{p m u}}{\partial \theta} & \frac{\partial \delta^{p m u}}{\partial V}
\end{array}\right]\right.
$$

onde:

$P_{l}$ e $P_{i}$ — medidas de fluxo e injeção de potência ativa respectivamente;

$Q_{l}$ e $Q_{i}$ - medidas de fluxo e injeção de potência reativa respectivamente;

$V^{m}$ — medida convencional de magnitude de tensão nodal;

$V^{p m u}$ — medida de PMU de magnitude de tensão nodal;

$\theta^{p m u}$ — medida de PMU de ângulo de fase de tensão nodal;

$I^{p m u}$ — medida de PMU de fluxo de corrente; 
$\delta^{p m u}$ — medida de PMU de ângulo de fase de fluxo de corrente;

$\theta$ — ângulo de fase de tensão nodal;

$V$ — magnitude de tensão nodal.

As expressões para as derivadas parciais, relativas às medidas convencionais e às medidas fasoriais de magnitude de tensão, obtidas pelas PMUs, são as mesmas do estimador de estado convencional, lembrando apenas de que agora existirão derivadas parciais relativas a todos os ângulos de fase de tensão, pois nenhuma das barras será escolhida como referência angular. As medidas fasoriais de ângulo de fase de tensão, obtidas pelas PMUs, são tratadas da mesma forma que as medidas de magnitude de tensão, pois essas quantidades referem-se às variáveis de estado a serem estimadas. As expressões das derivadas das medidas fasoriais de corrente são apresentadas a seguir.

\subsubsection{Medidas de magnitude de corrente}

Para serem mínimas as modificações necessárias no estimador de estado convencional WLS, as expressões para os fasores de corrente, do estimador de estado WLS híbrido, são apresentadas em função das expressões de potência complexa. Considere o modelo apresentado na Figura (4.1).

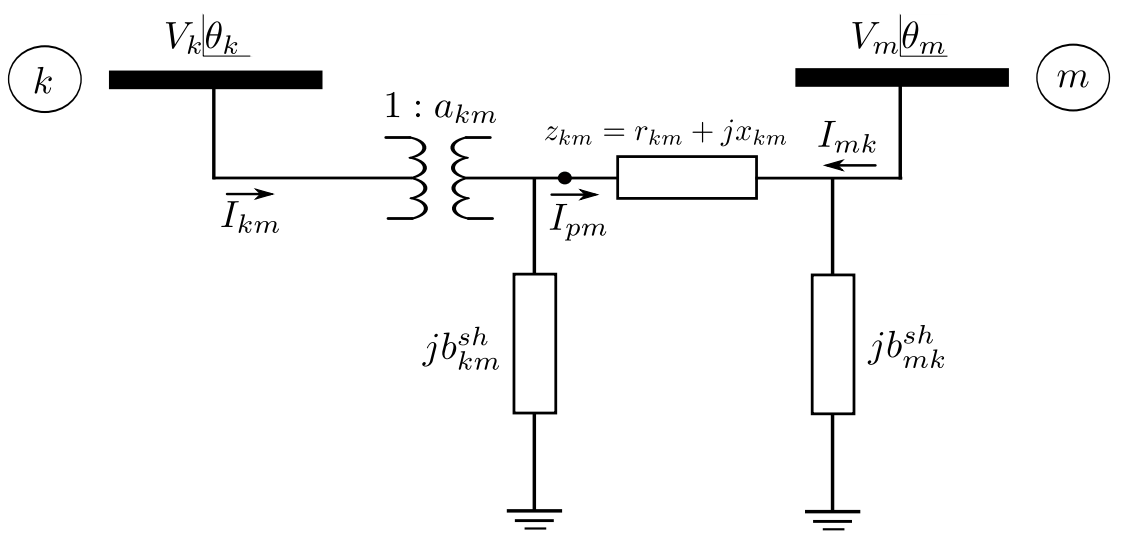

Figura 4.1: Modelo $\pi$ generalizado para equacionamento de fluxo de potência

O módulo da corrente, fluindo da barra $k$ para a barra $m$, pode ser expresso por:

$$
\left|I_{k m}\right|=\frac{S_{k m}}{V_{k}}
$$

sendo, $S_{k m}=\sqrt{\left(P_{k m}^{2}+Q_{k m}^{2}\right)}$ a magnitude do fluxo de potência complexa, da barra $k$ para barra $m$.

Como:

$$
P_{k m}=a_{k m}^{2} \cdot V_{k m}^{2} \cdot g_{k m}-a_{k m} \cdot V_{k} \cdot V_{m} \cdot g_{k m} \cdot \cos \theta_{k m}-a_{k m} \cdot V_{k} \cdot V_{m} \cdot b_{k m} \cdot \operatorname{sen} \theta_{k m}
$$


e

$$
Q_{k m}=-a_{k m}^{2} \cdot V_{k m}^{2} \cdot\left(b_{k m}+b_{k m}^{s h}\right)+a_{k m} \cdot V_{k} \cdot V_{m} \cdot b_{k m} \cdot \cos \theta_{k m}-a_{k m} \cdot V_{k} \cdot V_{m} \cdot g_{k m} \cdot \operatorname{sen} \theta_{k m}
$$

teremos:

$$
\left|S_{k m}\right|=\sqrt{\left(g_{k m}^{2}+b_{k m}^{2}\right) \cdot V_{k}^{2} \cdot\left(V_{k}^{2}+V_{m}^{2}-2 \cdot V_{k} \cdot V_{m} \cdot \cos \theta_{k m}\right)}
$$

A equação do fluxo de corrente, da barra $k$ para a barra $m$, será expressa por:

$$
\left|I_{k m}\right|=\sqrt{\left(g_{k m}^{2}+b_{k m}^{2}\right) \cdot\left(V_{k}^{2}+V_{m}^{2}-2 \cdot V_{k} \cdot V_{m} \cdot \cos \theta_{k m}\right)}
$$

As mesmas considerações valem para o sentido contrário.

Como:

$$
P_{m k}=V_{k}^{2} \cdot g_{k m}-a_{k m} \cdot V_{k} \cdot V_{m} \cdot g_{k m} \cdot \cos \theta_{m k}-a_{k m} \cdot V_{k} \cdot V_{m} \cdot b_{k m} \cdot \operatorname{sen} \theta_{m k},
$$

e

$$
Q_{m k}=-V_{m}^{2} \cdot\left(b_{k m}+b_{k m}^{s h}\right)+a_{k m} \cdot V_{k} \cdot V_{m} \cdot b_{k m} \cdot \cos \theta_{m k}-a_{k m} \cdot V_{k} \cdot V_{m} \cdot g_{k m} \cdot \operatorname{sen} \theta_{m k}
$$

A equação do fluxo de corrente, da barra $m$ para $k$, será então expressa por:

$$
\left|I_{m k}\right|=\sqrt{\left(g_{k m}^{2}+b_{k m}^{2}\right) \cdot\left(V_{k}^{2}+V_{m}^{2}-2 \cdot V_{k} \cdot V_{m} \cdot \cos \theta_{m k}\right)}
$$

\subsubsection{Derivadas parciais}

De forma genérica, dada uma magnitude de corrente, da barra $k$ para a barra $m$, definida como:

$$
|I|=\frac{S}{V_{k}}
$$

onde $S$ é a magnitude de fluxo de potência complexa da barra $k$ para a barra $m$, definida por:

$$
S_{k m}=\sqrt{\left(P^{2}+Q^{2}\right)}
$$

Considerando $x$ qualquer variável de interesse temos:

$$
\frac{\partial\left(S^{2}\right)}{\partial x}=\frac{\partial\left(P^{2}+Q^{2}\right)}{\partial x} \Rightarrow 2 \cdot S \frac{\partial S}{\partial x}=2 \cdot P \frac{\partial P}{\partial x}+2 \cdot Q \frac{\partial Q}{\partial x} \Rightarrow \frac{\partial S}{\partial x}=\frac{P}{S} \cdot \frac{\partial P}{\partial x}+\frac{Q}{S} \cdot \frac{\partial Q}{\partial x}
$$


Desta forma podemos escrever:

$$
\begin{aligned}
\frac{\partial I_{k m}}{\partial \theta_{k}} & =\frac{1}{V_{k}}\left(\frac{P_{k m}}{S_{k m}} \cdot \frac{\partial P_{k m}}{\partial \theta_{k}}+\frac{Q_{k m}}{S_{k m}} \cdot \frac{\partial Q_{k m}}{\partial \theta_{k}}\right) \\
\frac{\partial I_{k m}}{\partial \theta_{m}} & =\frac{1}{V_{k}}\left(\frac{P_{k m}}{S_{k m}} \cdot \frac{\partial P_{k m}}{\partial \theta_{m}}+\frac{Q_{k m}}{S_{k m}} \cdot \frac{\partial Q_{k m}}{\partial \theta_{m}}\right) \\
\frac{\partial I_{k m}}{\partial V_{k}} & =\frac{1}{V_{k}}\left(\frac{P_{k m}}{S_{k m}} \cdot \frac{\partial P_{k m}}{\partial V_{k}}+\frac{Q_{k m}}{S_{k m}} \cdot \frac{\partial Q_{k m}}{\partial V_{k}}\right)-\frac{S_{k m}}{V_{k}^{2}} \\
\frac{\partial I_{k m}}{\partial V_{m}} & =\frac{1}{V_{k}}\left(\frac{P_{k m}}{S_{k m}} \cdot \frac{\partial P_{k m}}{\partial V_{m}}+\frac{Q_{k m}}{S_{k m}} \cdot \frac{\partial Q_{k m}}{\partial V_{k}}\right)
\end{aligned}
$$

Da barra $m$ para a barra $k$ temos:

$$
\begin{aligned}
\frac{\partial I_{m k}}{\partial \theta_{k}} & =\frac{1}{V_{m}}\left(\frac{P_{m k}}{S_{m k}} \cdot \frac{\partial P_{m k}}{\partial \theta_{k}}+\frac{Q_{m k}}{S_{m k}} \cdot \frac{\partial Q_{m k}}{\partial \theta_{k}}\right) \\
\frac{\partial I_{m k}}{\partial \theta_{m}} & =\frac{1}{V_{m}}\left(\frac{P_{m k}}{S_{m k}} \cdot \frac{\partial P_{m k}}{\partial \theta_{m}}+\frac{Q_{m k}}{S_{m k}} \cdot \frac{\partial Q_{m k}}{\partial \theta_{m}}\right) \\
\frac{\partial I_{m k}}{\partial V_{k}} & =\frac{1}{V_{m}}\left(\frac{P_{m k}}{S_{m k}} \cdot \frac{\partial P_{m k}}{\partial V_{k}}+\frac{Q_{m k}}{S_{m k}} \cdot \frac{\partial Q_{m k}}{\partial V_{k}}\right) \\
\frac{\partial I_{m k}}{\partial V_{m}} & =\frac{1}{V_{m}}\left(\frac{P_{m k}}{S_{m k}} \cdot \frac{\partial P_{m k}}{\partial V_{m}}+\frac{Q_{m k}}{S_{m k}} \cdot \frac{\partial Q_{m k}}{\partial V_{m}}\right)-\frac{S_{m k}}{V_{m}^{2}}
\end{aligned}
$$

\subsubsection{Medidas de ângulo de corrente}

O ângulo da corrente $(\delta)$, fornecido por PMUs instaladas no sistema, será definido conforme Figura (4.2):

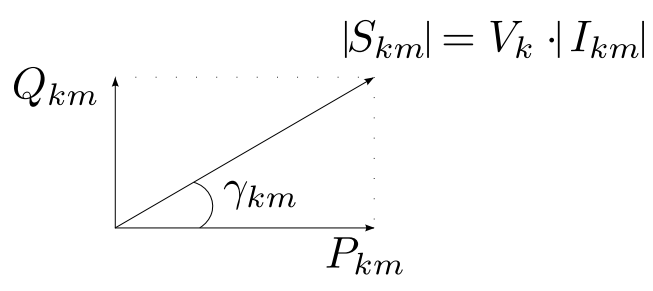

Figura 4.2: Definição do ângulo da corrente

$$
\delta=\theta_{k m}-\gamma_{k m}
$$

Como a medida de magnitude de corrente não revela informação referente ao ângulo de fator de potência, temos que:

$$
\delta=\theta_{k}-\tan ^{-1}\left(\frac{Q}{P}\right)
$$

sendo:

$\cos \gamma_{k m}$ o ângulo do fator de potência 
$\delta$ o ângulo de fase da corrente

$\theta_{k}$ o ângulo de fase da tensão na barra $k$

Considerando as equações de fluxo de corrente, da barra $k$ para a barra $m$, e as variáveis de estado $\left(\theta_{k}, \theta_{m}, V_{k}, V_{m}\right)$, temos as derivadas das equações de ângulo dos fluxos de corrente:

$$
\begin{aligned}
\frac{\partial \delta_{k m}}{\partial \theta_{k}} & =1-\frac{1}{S_{k m}^{2}}\left(P_{k m} \frac{\partial Q_{k m}}{\partial \theta_{k}}-Q_{k m} \frac{\partial P_{k m}}{\partial \theta_{k}}\right) \\
\frac{\partial \delta_{k m}}{\partial \theta_{m}} & =-\frac{1}{S_{k m}^{2}}\left(P_{k m} \frac{\partial Q_{k m}}{\partial \theta_{m}}-Q_{k m} \frac{\partial P_{k m}}{\partial \theta_{m}}\right) \\
\frac{\partial \delta_{k m}}{\partial V_{k}} & =-\frac{1}{S_{k m}^{2}}\left(P_{k m} \frac{\partial Q_{k m}}{\partial V_{k}}-Q_{k m} \frac{\partial P_{k m}}{\partial V_{k}}\right) \\
\frac{\partial \delta_{k m}}{\partial V_{m}} & =-\frac{1}{S_{k m}^{2}}\left(P_{k m} \frac{\partial Q_{k m}}{\partial V_{m}}-Q_{k m} \frac{\partial P_{k m}}{\partial V_{m}}\right)
\end{aligned}
$$

No sentido da barra $m$ para a barra $k$, temos:

$$
\begin{aligned}
\frac{\partial \delta_{m k}}{\partial \theta_{k}} & =-\frac{1}{S_{m k}^{2}}\left(P_{m k} \frac{\partial Q_{m k}}{\partial \theta_{k}}-Q_{m k} \frac{\partial P_{m k}}{\partial \theta_{k}}\right) \\
\frac{\partial \delta_{m k}}{\partial \theta_{m}} & =1-\frac{1}{S_{m k}^{2}}\left(P_{m k} \frac{\partial Q_{m k}}{\partial \theta_{m}}-Q_{m k} \frac{\partial P_{m k}}{\partial \theta_{m}}\right) \\
\frac{\partial \delta_{m k}}{\partial V_{k}} & =-\frac{1}{S_{m k}^{2}}\left(P_{m k} \frac{\partial Q_{m k}}{\partial V_{k}}-Q_{m k} \frac{\partial P_{m k}}{\partial V_{k}}\right) \\
\frac{\partial \delta_{m k}}{\partial V_{m}} & =-\frac{1}{S_{m k}^{2}}\left(P_{m k} \frac{\partial Q_{m k}}{\partial V_{m}}-Q_{m k} \frac{\partial P_{m k}}{\partial V_{m}}\right)
\end{aligned}
$$

\subsection{Algoritmo}

Basicamente, o algoritmo do estimador WLS Híbrido, proposto por ZHU; ABUR (2007b), apresentado a seguir, coincide com o algoritmo de estimação de estado WLS convencional, mas alguns detalhes devem ser levados em consideração. As PMUs, além de fornecerem os fasores de tensão, também fornecem fasores de corrente. Apesar de os fasores de corrente melhorarem a redundância de medidas, os mesmos geram certos problemas numéricos.

Em particular, para o estimador em pauta, o processo de inicialização do algoritmo torna-se difícil, quando medidas fasoriais sincronizadas de corrente estão presentes. Algumas derivadas na matriz jacobiana, correspondentes aos fasores de corrente, serão indefinidas na primeira iteração, pois, partindo do flat start (magnitudes das tensões iguais a 1 e ângulos de fase iguais a zero), a potência aparente $S$, que aparece nas equações das derivadas, será igual a zero. 
Contudo, existem algumas alternativas para este problema. Uma alternativa simples, que foi adotada em nossos testes, é a não inclusão dessas medidas na primeira iteração, e incorporá-las ao processo de estimação somente a partir da segunda iteração. Esta abordagem falha, quando pelo menos uma das medidas fasoriais de corrente for crítica.

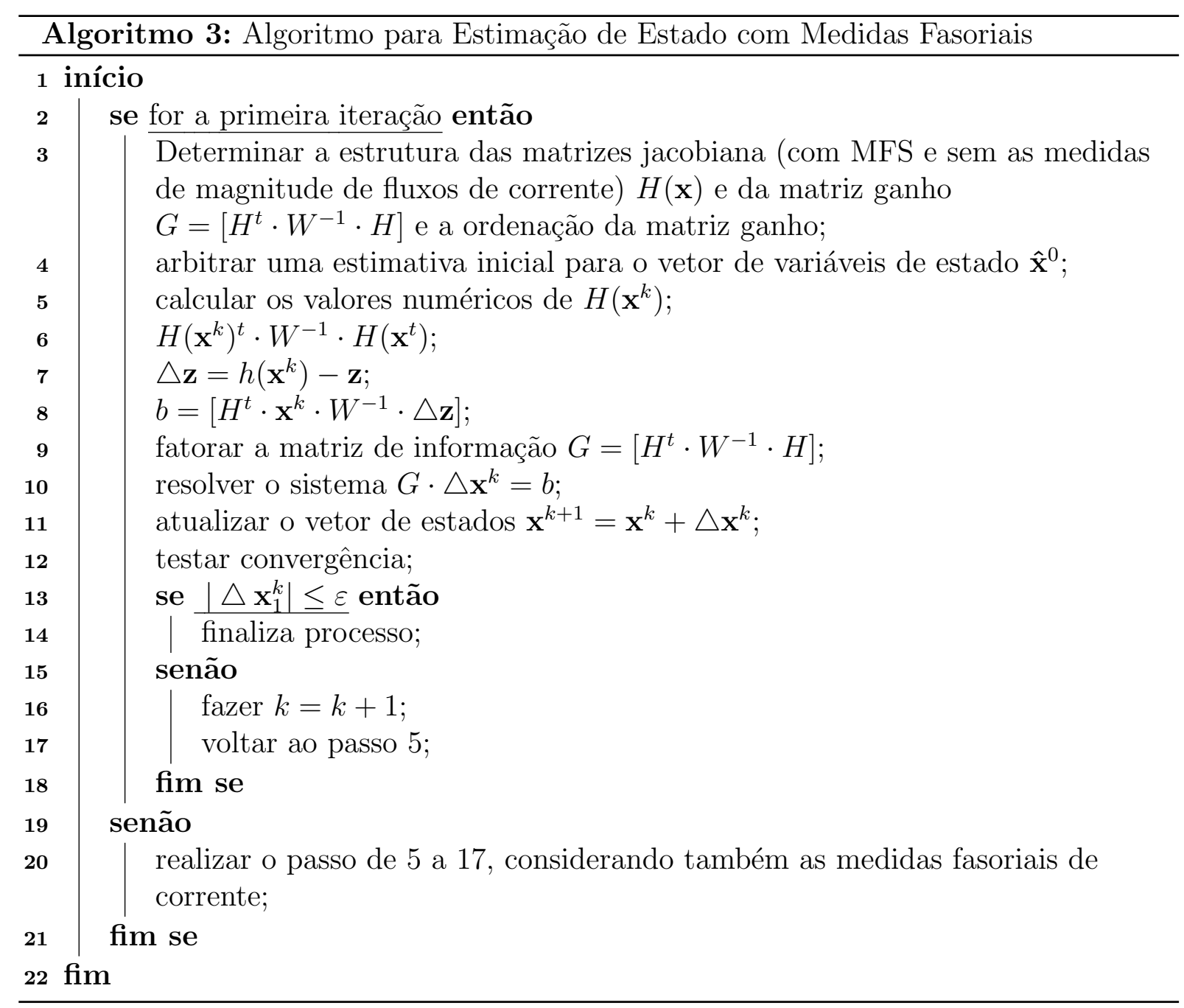

\subsection{Observabilidade e Processamento de Erros Gros- seiros}

Geralmente, para analisar observabilidade de sistemas formados apenas por medidas de potência e de magnitude de tensão, utiliza-se apenas a matriz Ganho do modelo ativo (MONTICELLI; WU, 1985; BRETAS, 1996), tomando por base o chamado desacoplamento do modelo, conforme apresentado no capítulo anterior. Entretanto, tendo em vista que as medidas de corrente não podem ser desacopladas como as medidas de potência 
ativa e reativa, para analisar a observabilidade diante de sistemas de medição formados por medidas convencionais e fasoriais é necessário considerar a matriz Ganho completa (veja Equação (2.9)).

Como apresentado anteriormente, devido à presença de medições fasoriais, o sistema será declarado observável se durante a fatoração da matriz ganho nenhum pivô nulo for encontrado. Quando forem encontradas ilhas observáveis no sistema, excluindo as medidas fasoriais, então será necessário incluir uma medida fasorial em cada ilha, de modo a tornar o sistema observável como um todo.

Detectar e identificar EGs nas medidas fasoriais é de extrema importância, pois MFS com erros geram grande impacto no processo de estimação de estado.

Considerando apenas uma medida de ângulo de fase de tensão, o processo será como no estimador de estado convencional. Erro nesta medida não afetará os resultados obtidos. Já na existência de ao menos duas medidas fasoriais de ângulo de fase de tensão, o processo de detecção de erros requer maior redundância.

Não considerando as MFSs, a análise de observabilidade nos dará, no caso de o SEP não ser observável como um todo, o número de ilhas observáveis no sistema. Uma medição fasorial de ângulo de fase de tensão em cada ilha garante a observabilidade como um todo, pois, topologicamente, através da referência do GPS, seria possível obter uma árvore geradora de posto completo (Figura (4.3)) . Para ser possível detectar e identificar erros nas medições fasoriais, a sua redundância deve ser incrementada em cada ilha observável. Sendo assim, duas medidas garantem detecção, enquanto serão necessárias três medidas para identificar erros associados a qualquer medição fasorial em uma dada ilha observável.

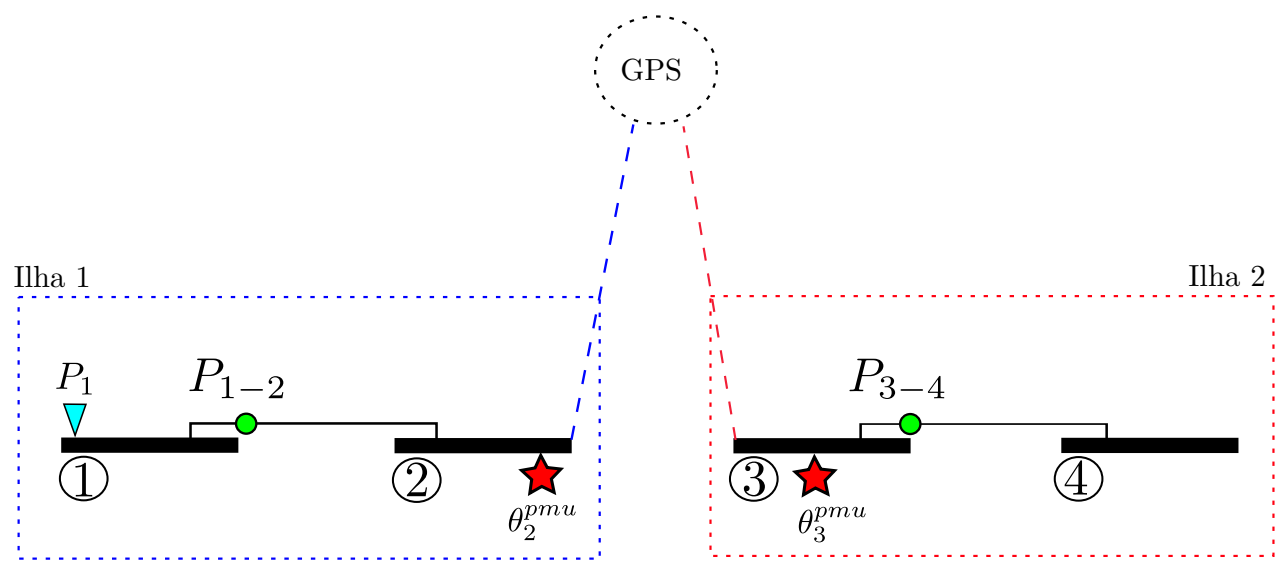

$\nabla$ Medidas de Injeção de Potência

- Medidas de Fluxo de Potência

Thedidas de Ângulo de Fase de Tensão

Figura 4.3: Representação topológica de um sistema observável por meio do GPS. 


\subsection{Exemplos}

Nesta seção mostram-se os testes realizados para comprovar a eficiência do estimador de estado proposto por ZHU; ABUR (2007b). Foi utilizado um sistema teste de 3 barras em anel, apresentado na Figura (4.4).

Em todos os testes, os valores das medidas de cada amostra foram gerados a partir do programa computacional de fluxo de carga ANAREDE ${ }^{\circledR}$. Considera-se o sistema sem a presença de erros nas medidas.

A Tabela (4.1) ilustra os fundos de escala utilizado para medidores de potência (fluxo e injeções) (ALBERTINI, 2010).

O desvio-padrão $(\sigma)$ das medidas é obtido em função do fundo de escala $(f e)$ do medidor, de acordo com as Equações (4.30) a (4.35) (MORAES, 2009).

\begin{tabular}{|c||c|}
\hline \multicolumn{2}{|c|}{ Fundos de escala } \\
\hline \hline Intervalo & $f e$ \\
\hline \hline $2.0 \leq|Z| \leq 2.8$ & 2.80 \\
\hline $1.8 \leq|Z| \leq 2.0$ & 2.00 \\
\hline $1.0 \leq|Z| \leq 1.8$ & 1.80 \\
\hline $0.50 \leq|Z| \leq 1.00$ & 1.00 \\
\hline $0.20 \leq|Z| \leq 0.50$ & 0.50 \\
\hline $0.10 \leq|Z| \leq 0.20$ & 0.20 \\
\hline $0.00 \leq|Z| \leq 0.10$ & 0.10 \\
\hline
\end{tabular}

Tabela 4.1: Fundo de escala para medidores

$$
\begin{aligned}
\sigma_{V} & =\left(0.015 *\left|Z_{f c}\right|\right) / 3 ; \\
\sigma_{P_{l}, Q_{l}, P_{i}, Q_{i}} & =\left(0.02 *\left|Z_{f c}\right|+0.0052 * f e\right) / 3 ; \\
\sigma_{V^{p m u}} & =\left(0.003 *\left|Z_{f c}\right|\right) / 3 ; \\
\sigma_{\theta} & =0.01 / 3 ; \\
\sigma_{I^{p m u}} & =\left(0.003 *\left|Z_{f c}\right|\right) / 3 \\
\sigma_{\delta_{I}} & =\left(0.009-0.005 *\left|Z_{f c}\right|\right) / 3 ;
\end{aligned}
$$

onde:

$\sigma_{Z}$ — é o desvio padrão associado à medida $Z_{i}$;

$\left|Z_{f c}\right|$ — é o módulo do valor "verdadeiro" da medida $Z$, em determinado instante de tempo (obtido pelo cálculo do fluxo de carga);

$f e$ - é o fundo de escala 
Como existem medidas fasoriais no plano de medição, aplicamos o Algoritmo 3, apresentado na subseção (4.2), do Capítulo 4. O critério de convergência foi definido como $10^{-3}$, para as atualizações das variáveis. Utiliza-se nos testes a condição do flat start para inicialização do algoritmo.

\section{Exemplo 1:}

Dado o seguinte sistema teste 3 barras, considere o plano de medição apresentado na Tabela (4.2):

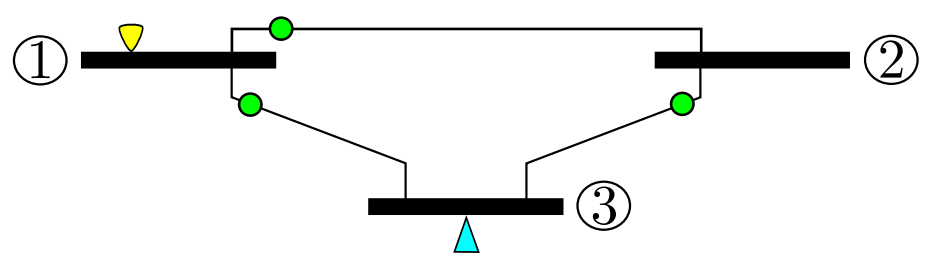

$\nabla$ Medidas de Injeção de Potência

- Medidas de Fluxo de Potência

$\nabla$ Medidas de Magnitude de Tensão

Figura 4.4: Sistema teste de 3 barras em anel.

O sistema apresentado na Figura (4.4), é monitorado por 8 medidas, ou seja, o nível de redundância é elevado. Os valores das medidas são apresentados na Tabela (4.2).

\begin{tabular}{|c||c|}
\hline \multicolumn{2}{|c|}{ Sistema teste de 3 barras } \\
\hline \hline Medida & Valor \\
\hline \hline$P_{1,2}$ & 0.288 \\
$P_{1,3}$ & 0.495 \\
$P_{2,3}$ & 0.469 \\
$Q_{1,2}$ & 0.176 \\
$Q_{1,3}$ & 0.14 \\
$Q_{2,3}$ & 0.092 \\
$P_{3}$ & -0.942 \\
$V_{1}$ & 1.06 \\
\hline
\end{tabular}

Tabela 4.2: Medidas disponíveis para o sistema teste de 3 barras - Exemplo 1

Os valores dos parâmetros das medidas são apresentados na Tabela (4.3).

Na Tabela (4.4) apresenta-se o relatório de saída para o teste do Exemplo 1.

Os valores das tensões e ângulos fornecidos pelo fluxo de carga convergido são apresentados na Tabela (4.5) 


\begin{tabular}{|c|c||c|c|}
\hline \multicolumn{4}{|c|}{ Parâmetros de linha do sistema teste de 3 barras } \\
\hline \hline Parâmetros & Valor [\%] & Parâmetros & Valor [\%] \\
\hline \hline$R_{1,2}$ & 1,94 & $X_{1,2}$ & 5,91 \\
$R_{1,3}$ & 5,40 & $X_{1,3}$ & 22,3 \\
$R_{2,3}$ & 4,69 & $X_{2,3}$ & 19,79 \\
\hline
\end{tabular}

Tabela 4.3: Parâmetros de linha para o sistema teste de 3 barras - Exemplo 1

\begin{tabular}{|c|c|c|}
\hline \multicolumn{3}{|c|}{ Sistema teste de 3 barras } \\
\hline \hline Barra & Magnitude (Volts) & Ângulo (Graus) \\
\hline \hline 1 & 1.059950 & 0.0 \\
2 & 1.044938 & -0.703934 \\
3 & 1.010002 & -5.514334 \\
\hline
\end{tabular}

Tabela 4.4: Relatório de saída do sistema teste de 3 barras - Exemplo 1

\begin{tabular}{|c|c|c|}
\hline \multicolumn{3}{|c|}{ Sistema teste de 3 barras } \\
\hline \hline Barra & Magnitude (Volts) & Angulo (Graus) \\
\hline \hline 1 & 1.060 & 0.0 \\
2 & 1.045 & -0.7 \\
3 & 1.016 & -5.5 \\
\hline
\end{tabular}

Tabela 4.5: Relatório de saída do fluxo de carga - sistema 3 barras em anel

\section{Exemplo 2:}

De modo a realizar uma comparação com o Exemplo 1, a Tabela (4.6) apresenta as novas medidas que juntamente com as medidas do Exemplo 1 irão compôr o novo plano de medição.

Devido ao problema do flat-start neste exemplo não será utilizado o flat start na primeira iteração, mas sim as variáveis de estado estimadas no instante anterior.

\begin{tabular}{|c|c||c|c|}
\hline \multicolumn{4}{|c|}{ Sistema teste de 3 barras } \\
\hline \hline Medida & Valor & Medida & Valor \\
\hline \hline$I_{1,2}$ & 0.318384 & $\delta_{1,2}$ & -0.700574 \\
$I_{2,1}$ & 0.318384 & $\delta_{2,1}$ & -0.675955 \\
$I_{1,3}$ & 0.485488 & $\delta_{1,3}$ & -0.302836 \\
$I_{3,1}$ & 0.485488 & $\delta_{3,1}$ & -0.194315 \\
\hline
\end{tabular}

Tabela 4.6: Medidas disponíveis para o sistema teste de 3 barras - Exemplo 2

Na Tabela (4.7) apresenta-se o relatório de saída para o teste do Exemplo 2. 


\begin{tabular}{|c|c|c|}
\hline \multicolumn{3}{|c|}{ Sistema teste de 3 barras } \\
\hline \hline Barra & Magnitude (Volts) & Angulo (Graus) \\
\hline \hline 1 & 1.059948 & 0.0 \\
2 & 1.044942 & -0.703605 \\
3 & 1.009994 & -5.515540 \\
\hline
\end{tabular}

Tabela 4.7: Relatório de saída do sistema teste de 3 barras - Exemplo 2

\subsection{Conclusões}

Foi apresentado, neste capítulo, o estimador de estado WLS híbrido proposto por ZHU; ABUR (2007b), tecendo informações relativas à observabilidade e processamento de EGs, a partir da formulação do estimador.

O estimador WLS híbrido em pauta foi implementado em computador, em que se realizaram diversas simulações para estudar o seu comportamento, principalmente em termos de observabilidade de redes.

Embora sejam diversas as vantagens do estimador WLS híbrido, proposto por ZHU; ABUR (2007b), o mesmo pode apresentar problemas no flat start, pois as derivadas das medidas fasoriais de corrente tornarem-se indefinidas. Para contornar esse problema, em ZHU; ABUR (2007a) a formulação do estimador WLS híbrido foi desenvolvida em termos de coordenadas retangulares, ao invés de coordenadas polares. Outra saída, para solução desse problema, é a inclusão das medidas fasoriais de corrente, apenas a partir da segunda iteração do processo iterativo de solução do estimador. Essa solução não foi adotada na implementação do estimador realizada neste trabalho, pois, tal solução pode acarretar problemas de observabilidade na primeira iteração, se tais medidas forem críticas.

Tendo em vista que a metodologia proposta para análise de observabilidade de sistemas de medição, formados por medidas convencionais e fasoriais sincronizadas, baseia-se na formulação do estimador de estado apresentado neste capítulo, o qual apresenta problemas no flat start, pode tornar-se impossível a estimação de estado para um SEP identificado como observável, pela metodologia proposta. Assim, a melhor saída para fazer uso da metodologia proposta, juntamente com o estimador WLS híbrido em pauta, é não utilizar o flat start na primeira iteração, mas sim as variáveis de estado estimadas no instante anterior. 


\section{Capítulo 5}

\section{Metodologia Proposta para Análise de Observabilidade e Identificação de Medidas Críticas para Sistemas de Medição Formados por Medidas Convencionais e Fasoriais}

\section{Introdução}

Conforme mencionado anteriormente, a metodologia proposta destinada à análise de observabilidade e identificação de medidas críticas, para sistemas de medição formados por medidas convencionais e MFSs, baseia-se nos métodos desenvolvidos por LONDON; ALBERTO; BRETAS (2007) e (BENEDITO et al., 2008). Esses métodos fundamentamse na fatoração triangular da matriz jacobiana, associada ao modelo $P \theta$. Vale lembrar que o desacoplamento $P \theta-Q V$ foi bem estabelecido para sistemas de medidas convencionais, formados por medidas de potência (ativa e reativa) e de magnitude de tensão.

Como a metodologia proposta destina-se à análise de observabilidade e identificação de medidas críticas, para sistemas de medição formados por medidas convencionais e fasoriais sincronizadas, a mesma requer a fatoração da matriz jacobiana, associada a um estimador de estado híbrido, que permite o processamento de medidas convencionais e fasoriais sincronizadas.

Dentre os estimadores híbridos propostos na literatura, destaca-se, conforme apresentado no Capítulo 4, o estimador proposto por ZHU; ABUR (2007b), tendo em vista que o mesmo não exige muitas mudanças na formulação do processo de estimação de estado convencional, por meio do método dos mínimos quadrados ponderados.

A metodologia proposta poderia ser aplicada diretamente à matriz jacobiana do esti- 
mador híbrido proposto por ZHU; ABUR (2007b), apresentada no Capítulo 4, Equação (4.1). Entretanto, para obtenção de um procedimento mais simples, de mais rápida execução, menos susceptível a problemas numéricos, a metodologia proposta restringirá sua análise ao modelo $P \theta$. Para isto exigir-se-à a introdução de algumas considerações e/ou aproximações no problema, conforme se há de apresentar na subseção 5.1.1.

Para ilustrar como a metodologia proposta funciona, considerando apenas o modelo $P \theta$ e as considerações propostas a seguir, apresentar-se-ão diversos exemplos da sua aplicação em um sistema teste de 4 barras. Para validar os resultados obtidos para o modelo $P \theta$, a metodologia será aplicada na matriz jacobiana completa do estimador de estado Híbrido proposto em ZHU; ABUR (2007b). Para possibilitar tais análises, a metodologia proposta foi implementada em $\mathrm{C}++$.

\subsection{Metodologia Proposta}

Fundamentando-se nos trabalhos de BENEDITO et al. (2008) e LONDON; ALBERTO; BRETAS (2007), a metodologia permite a análise de observabilidade e identificação de medidas críticas, por meio da fatoração triangular da matriz jacobiana $H$, formada por medidas convencionais e fasoriais sincronizadas.

\subsubsection{Matriz Jacobiana com MFS}

A metodologia proposta faz uso do desacoplamento $P \theta-Q V$, restringindo sua análise ao modelo $P \theta$.

Analisando a estrutura da matriz jacobiana, do estimador de estado híbrido proposto por ZHU; ABUR (2007b), apresentada no Capítulo 4, verifica-se que o tratamento dado à medida de ângulo de fase de tensão é análogo ao da medida de magnitude de tensão, pois essas quantidades referem-se às variáveis de estado a serem estimadas. Na presença de medidas fasoriais de corrente, o desacoplamento do problema de observabilidade $P \theta$ $Q V$ não é imediato. Para verificar isto, basta analisar as derivadas do fasor de corrente, na matriz jacobiana do estimador híbrido proposto por ZHU; ABUR (2007b) (Equação (4.13) até a Equação (4.20) — Seção (4.1.2)).

Face ao exposto, conclui-se que são necessárias considerações e/ou aproximações adicionais, para viabilizar a utilização do desacoplamento $P \theta-Q V$, visando à análise de observabilidade na presença de medidas convencionais e fasoriais sincronizadas. Consideremos que uma dada PMU possua um número de canais para medição, tal que a mesma possibilite a medição do fasor de tensão, na barra onde está instalada, bem como dos fasores de corrente nos ramos incidentes àquela barra (CHEN; ABUR, 2006; LONDON et al., 2009). Considerando que a impedância de todos os ramos seja igual a 1, a parte real de um fasor 
de corrente pode ser representada da seguinte forma (CHEN; ABUR, 2006):

$$
\operatorname{real}\left(I_{i j}\right) \cong \theta_{i}-\theta_{j}
$$

Sendo $\theta_{i}$ e $\theta_{j}$ os ângulos de tensão das barras $i$ e $j$, respectivamente. Dessa forma, as linhas da matriz $H$, correspondentes às medidas de uma PMU instalada na barra $i$, podem ser representadas da seguinte forma:

$$
H_{\theta P M U}={ }_{\theta_{i}} \begin{array}{ccccc} 
& \theta_{i} & & \theta_{j} & \\
I_{i j} \\
\vdots
\end{array}\left[\begin{array}{ccccc}
\cdots & \vdots & \cdots & \vdots & \cdots \\
& 1 & & \vdots & \\
\cdots & 1 & \cdots & -1 & \cdots \\
& \vdots & & \vdots &
\end{array}\right]
$$

Em (LONDON et al., 2009) demonstrou-se que a partir da fatoração triangular da matriz $H_{\theta P M U}$, supracitada, é possível realizar análise de observabilidade e de redundância de medidas. Porém, não foram tratados os problemas de restauração de observabilidade e identificação de ilhas observáveis. A metodologia proposta neste trabalho possibilitará também a realização dessas análises e, para isso, baseia-se nas metodologias propostas em LONDON; ALBERTO; BRETAS (2007) e BENEDITO et al. (2008).

Conforme apresentado no Capítulo 3, a metodologia proposta em BENEDITO et al. (2008) possibilita a identificação de ilhas observáveis através da análise dos caminhos de fatoração associados a matriz jacobiana do modelo $P \theta,\left(H_{P \theta}\right)$, lembrando que essa metodologia não considera a existência de medidas fasoriais sincronizadas. Dessa forma, a identificação das ilhas observáveis ocorre através da análise dos caminhos de fatoração.

Vale destacar que para utilizar os caminhos de fatoração, para efeito de identificação de ilhas observáveis, as equações de medida devem relacionar pelo menos duas barras do sistema (ou duas variáveis de estado), indicando assim a existência de um caminho medido (ou ramo com medida) entre essas barras.

Para montar os caminhos de fatoração, a metodologia desenvolvida em BENEDITO et al. (2008) considera apenas medidas de potência ativa, pois a análise restringe-se ao modelo $P \theta$ e não foram consideradas medidas fasoriais sincronizadas. Uma medida de potência ativa relaciona duas (medida de fluxo) ou mais (medida de injeção) barras do sistema, ou, mais especificamente, relaciona ângulos de fase de tensão de pelo menos duas barras do sistema. Assim, a análise foi realizada diretamente na matriz $\left(H_{P \theta}\right)$, sem nenhuma consideração adicional. Entretanto, a metodologia proposta considerará, também, a existência de medidas fasoriais de ângulo de fase de tensão, que, conforme apresentado no Capítulo 4, contém informação apenas sobre a barra onde a medição é realizada, ou seja, relaciona apenas uma barra do sistema.

Face ao exposto, para possibilitar a identificação de ilhas observáveis, através da aná- 
lise de caminhos de fatoração na presença de medidas de ângulo de fase de tensão, torna-se necessário uma modelagem particular para essas medidas. Tendo em vista que as mesmas são obtidas utilizando como referência o sinal de GPS, elas podem ser modeladas como se fossem medidas de fluxo de potência em ramos fictícios, com impedância unitária, que conectam as barras onde as medidas foram realizadas com uma barra extra, representando a referência de GPS. Dessa forma, as linhas da matriz jacobiana, correspondente às medidas de uma PMU instalada na barra $i$, podem ser representadas da seguinte forma:

$$
H_{\theta P M U}^{\prime}={ }_{I_{i j}}^{\theta_{i}}\left[\begin{array}{cccccc} 
& \theta_{i} & & \theta_{j} & & \theta_{G P S} \\
\vdots & \vdots & \cdots & \vdots & \cdots & \vdots \\
& 1 & & \vdots & & -1 \\
\cdots & 1 & \cdots & -1 & \cdots & \vdots \\
& \vdots & & \vdots & & \vdots
\end{array}\right]
$$

Observe que $\theta_{G P S}$ indica a referência de GPS para obtenção das medidas de ângulo de fase de tensão.

\subsection{Análise de Observabilidade com Medidas Con- vencionais e Fasoriais}

Para verificar se o sistema em análise é observável, realiza-se a fatoração triangular da correspondente matriz $H_{\theta P M U}$, que deve ser feita através de combinações lineares das colunas dessa matriz, assim como apresentado por LONDON; ALBERTO; BRETAS (2007).

Como as colunas da matriz $H_{\theta P M U}$ correspondem às variáveis de estado do sistema, as colunas da matriz fatorada correspondem às variáveis de estado equivalentes, que são combinações lineares das variáveis de estado do sistema.

Conforme apresentado na Seção 3.1, quando não existem MFSs, a condição para observabilidade $P \theta$ é expressa pela Equação (3.3), pois uma das barras é escolhida como referência angular.

Contudo, quando o sistema de medição possui medidas convencionais e MFSs, temos duas situações para analisar. A condição de observabilidade $P \theta$, expressa pela Equação (3.3), manter-se-á quando não existirem medidas de ângulo de fase de tensão. Porém, se existir pelo menos uma medida de ângulo de fase de tensão, o sistema elétrico será $P \theta$ algebricamente observável se (LONDON et al., 2009):

$$
\operatorname{posto}\left(H_{\theta P M U}\right)=n
$$

pois a referência de ângulo será determinada pelo sinal emitido pelo sistema GPS, sendo 
$n$ o número de barras do sistema.

Assim, caso o sistema seja $P \theta$ observável, a fatoração triangular da matriz $H_{\theta P M U}$ resultará em apenas um pivô nulo na diagonal $(n, n)$, se não existirem medidas de ângulo de fase tensão. Nessa situação a última coluna da matriz fatorada será composta somente por zeros. Por outro lado, na existência de pelo menos uma medida de ângulo de fase de tensão, se a mesma for tratada da forma indicada em ZHU; ABUR (2007b)(conforme apresentado na matriz $H_{\theta P M U}$ ilustrada na seção anterior), a fatoração triangular da correspondente matriz $H_{P \theta}$, associada a um sistema observável, não resultará em pivô nulo algum e nenhuma das colunas da matriz fatorada será composta apenas por zeros. Porém, considerando a modelagem de medidas de ângulo de fase de tensão proposta neste trabalho, conforme ilustrado na matriz $H_{\theta P M U}^{\prime}$ apresentada na seção anterior, a fatoração triangular resultará em apenas um pivô nulo na diagonal $(n+1, n+1)$. Lembrando que a coluna $n+1$ da matriz $H_{\theta P M U}^{\prime}$ corresponde à variável de estado $\theta_{G P S}$, que simboliza a referência de GPS para obtenção das medidas de ângulo de fase de tensão.

Observe que em ambos os casos, com ou sem medidas de ângulo de fase de tensão, permutações de linhas poderão ser necessárias para evitar possíveis pivôs nulos durante o processo de fatoração.

Entretanto, caso o sistema não seja observável como um todo, aparecerá um pivô nulo no elemento diagonal $(i, i)$, durante a fatoração triangular, sendo $(i \leq n-1)$, no caso de não existirem medidas de ângulo de fase de tensão, ou, $(i \leq n)$, se existir pelo menos uma medida de ângulo. Em tais situações, não haverá elementos não-nulos nas demais linhas de $H_{\theta P M U}^{\prime}$, na coluna do pivô nulo, indicando a falta de medida fornecendo informação da variável de estado equivalente, correspondente àquela coluna.

Quando o sistema não é observável, a metodologia proposta permite: a) Restauração da observabilidade, caso estejam disponíveis as pseudo-medidas necessárias; caso contrário b) Identificação das ilhas observáveis.

Com o intuito de restaurar a observabilidade, efetua-se uma busca por pseudo-medida, que forneça informação da variável de estado equivalente, correspondente à coluna do pivô nulo. Isto é feito através dos fatores triangulares, obtidos durante o processo de fatoração de $H_{\theta P M U}^{\prime}$, exatamente como apresentado por LONDON; ALBERTO; BRETAS (2007) e pode ser resumida pelo Algoritmo (4).

Se não for possível restaurar a observabilidade, fazendo uso das pseudo-medidas disponíveis, a metodologia proposta permite a identificação das ilhas observáveis.

Realiza-se a identificação das ilhas observáveis pelo conceito de caminhos de fatoração, assim como apresentado por BENEDITO et al. (2008). Para isto é necessário substituir a linha do pivô nulo por uma nova linha, com elemento não nulo igual a 1, na coluna do pivô nulo, e continuar a fatoração até a diagonal $(n, n)$ no caso de não existirem medidas de ângulo de tensão, ou $(n-1, n-1)$, se existir ao menos uma medida desse tipo. Observe que esse procedimento é equivalente à inserção de uma pseudo-medida crítica de ângulo 


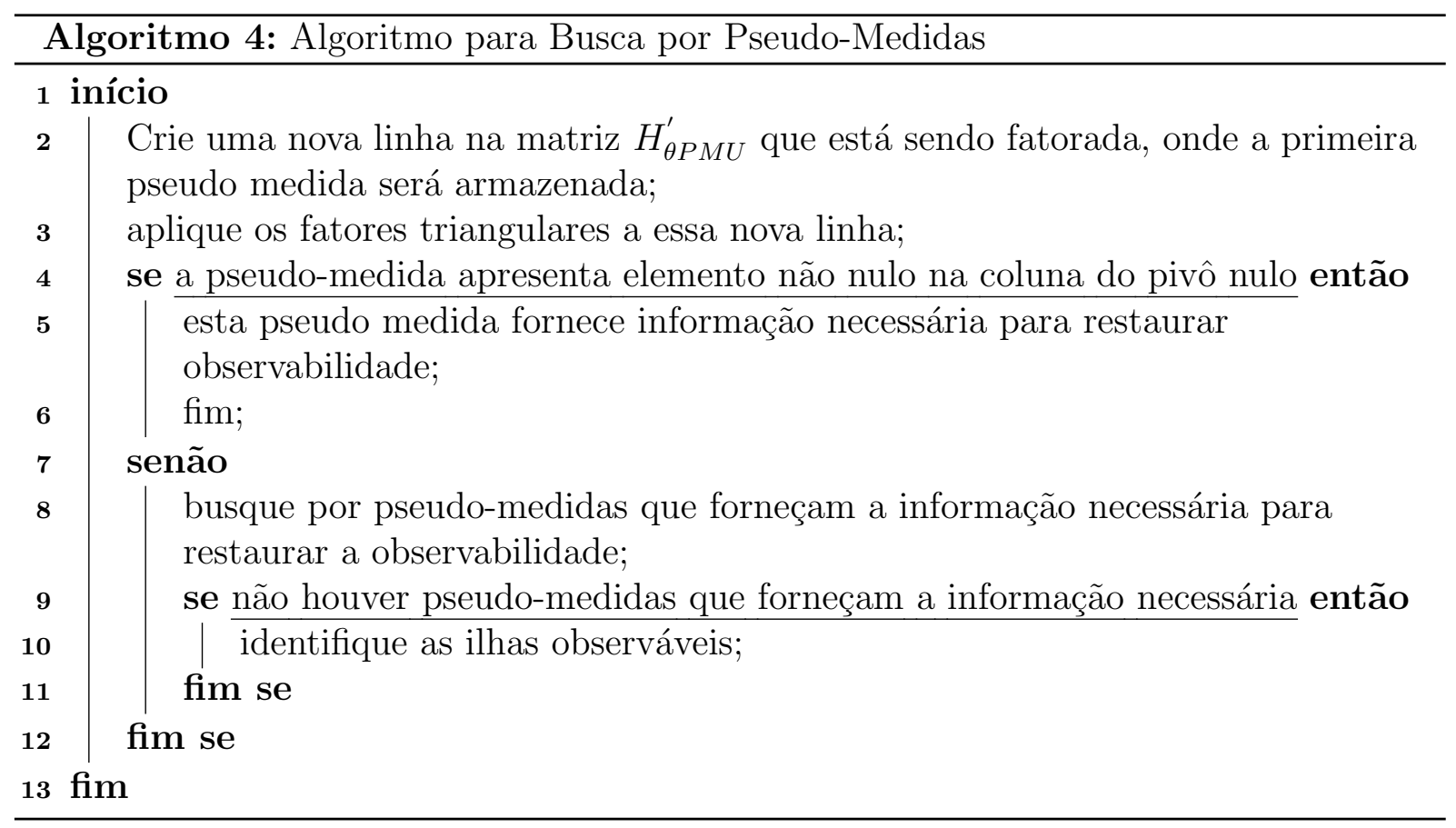

(MONTICELLI; WU, 1985; BENEDITO et al., 2008), cujo objetivo é tornar o sistema "artificialmente observável"1. Observe que essa pseudo-medida de ângulo serve apenas para possibilitar a identificação de ilhas observáveis através de caminhos de fatoração. Dessa forma a mesma não deve relacionar barras distintas.

A Figura (5.1) mostra as matrizes $L$ e $U$ da fatoração $L U$ (fatoração triangular) da matriz $H_{\theta P M U}^{\prime}$, associada a um sistema não observável, sem medida de ângulo de fase de tensão, contendo $m$ medidas; sistema esse que se tornou observável após a inclusão de uma pseudo-medida de ângulo $\left(\theta_{1}^{p}\right)$. As áreas em branco dessas figuras correspondem a elementos nulos e as áreas sombreadas a possíveis elementos não nulos.

As matrizes $L$ e $U$, obtidas para um sistema não observável, o qual possui pelo menos uma medida de ângulo de fase de tensão tornando-se observável após a inclusão de uma pseudo-medida de ângulo $\left(\theta_{1}^{p}\right)$, têm basicamente as mesmas estruturas das matrizes ilustradas na Figura (5.1), porém, ao invés de apresentarem coluna e linha $n$ formadas apenas por zeros, apresentarão coluna e linha $n+1$ formadas apenas por zeros.

A partir dos caminhos de fatoração associados à matriz de fatores $U$, a metodologia proposta permite a identificação das ilhas observáveis, por intermédio dos seguintes passos (BENEDITO et al., 2008):

Passo 1: Se não existirem medidas de injeção relacionando variáveis de estado equivalentes (ou nós de grafo) de caminhos de fatoração distintos (ou de distintas árvores de caminhos de fatoração), então cada sub-rede associada a cada caminho de fatoração (ou árvore) isolado constitui uma ilha observável do sistema.

\footnotetext{
${ }^{1}$ Artificialmente observável significa que o sistema não é observável como um todo, mas sim formado por ilhas observáveis, cuja identificação exigiu a inclusão de pseudo-medidas de ângulos.
} 


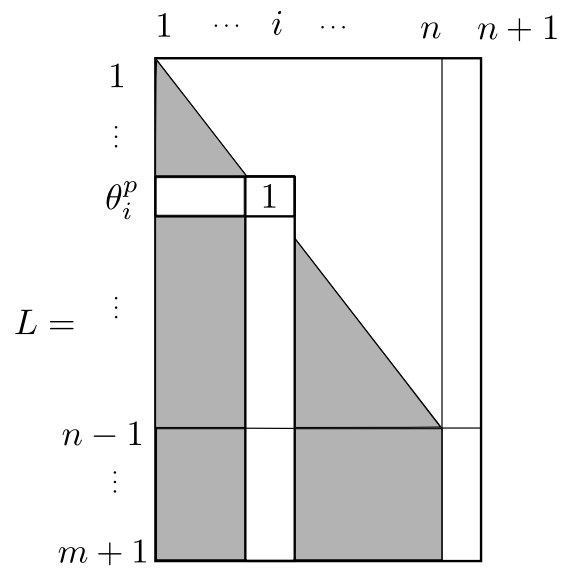

(a) Matriz trapezoidal inferior associada a um sistema não observável com MFS de ângulo de fase de tensão

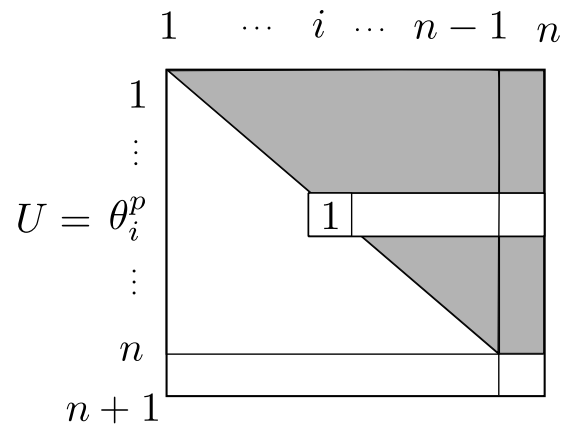

(b) Matriz trapezoidal superior associada a um sistema não observável com MFS de ângulo de fase de tensão

Figura 5.1: Matrizes associadas a um sistema não observável com MFS de ângulo de fase de tensão

Passo 2: Se existirem medidas de injeção, relacionando variáveis de estado equivalentes de diferentes caminhos de fatoração (ou árvores de caminhos de fatoração), então nada se pode afirmar sobre a observabilidade das sub-redes, associadas aos caminhos de fatoração (ou árvores) obtidos. Assim, para identificar as ilhas observáveis, importa identificar e descartar tais medidas de injeção (essas medidas são irrelevantes ao processo de estimação de estado das ilhas observáveis) e, depois, fatorar a nova matriz jacobiana.

Repete-se esse procedimento até não existirem mais medidas de injeção relacionando variáveis de estado equivalentes, de distintos caminhos de fatoração (ou distintas árvores) resultantes. Com isso, os caminhos de fatoração resultantes (ou árvores de caminhos de fatoração) resultantes serão as ilhas observáveis do sistema.

\subsection{Identificação de Medidas Críticas}

Para identificação de medidas críticas (MCs) a metodologia proposta faz uso da chamada matriz $H_{\triangle}$, como apresentado por LONDON; ALBERTO; BRETAS (2007).

Essa matriz $H_{\triangle}$ é obtida através da fatoração triangular de uma matriz jacobiana, associada a um sistema de medição formado apenas por medidas convencionais. Neste trabalho, entretanto, essa matriz será obtida a partir também da fatoração triangular de uma matriz jacobiana, mas associada a um sistema de medição formado por medidas convencionais e fasoriais.

Face ao exposto, para obter a matriz $H_{\triangle}$, formada apenas por medidas convencionais, a matriz $L$ resultante da decomposição $L U$ da correspondente matriz $H$ é fatorada novamente $(L D U)$, conforme ilustrada na Figura (5.2) onde: $I$ é a matriz identidade de dimensão $[(n-1) \times(n-1)] ; R$ é uma submatriz de dimensão $\left[m_{t}-(n-1) \times(n-1)\right]$; 
$m_{t}$ é o número de medidas disponíveis, incluindo pseudo-medidas de ângulo.

$$
H_{\triangle}=\left[\begin{array}{c|c}
I_{(n-1)} & 0 \\
& \vdots \\
\hline R & \vdots \\
& 0
\end{array}\right]
$$

Figura 5.2: Matriz $H_{\triangle}$ para um sistema observável

Nota 1: A última coluna da matriz $H_{\triangle}$ é composta somente por zeros e corresponde à barra adotada como referência do ângulo da tensão.

As medidas correspondentes as linhas da submatriz $I$ são chamadas de básicas, no sentido de assegurar observabilidade. As medidas correspondentes às linhas da matriz $R$ são chamadas de suplementares.

Analisando a estrutura da matriz $H_{\triangle}$ é possível identificar os conjuntos $p$-crítico de medidas (LONDON; ALBERTO; BRETAS, 2007).

Definição 1: Um conjunto $p$-crítico de medidas, para $p \geq 1$, de um sistema observável, é o conjunto de $p$ medidas, as quais quando removidas do conjunto de medidas, torna o sistema não-observável; entretanto, a remoção de qualquer conjunto de $k$ medidas deste conjunto, com $k<p$, não torna o sistema não-observável.

Observe que uma medida crítica é um conjunto $p$-crítico com $p=1$ e um par-crítico é um conjunto $p$-crítico com $p=2$.

As $p$ medidas, correspondentes aos $p$ elementos não-nulos da coluna da matriz, formam um conjunto $p$-crítico, contendo apenas uma medida básica. Consequentemente, através dos elementos não-nulos que aparecem na matriz, é possível identificar todos os conjuntos p-críticos formados por uma medida básica somente.

Face ao exposto, as MCs são identificadas pelas colunas da matriz, possuindo apenas um elemento não nulo.

\subsection{Matriz $H_{\triangle}$ Formada por Medidas Convencionais e Fasoriais}

A estrutura da matriz $H_{\triangle}$ obtida para um sistema observável com medidas convencionais e fasoriais sincronizadas é praticamente a mesma quando estão presentes apenas medidas convencionais (está última apresentada na Figura (5.2)). A diferença é que ao invés de apresentar a coluna $\mathrm{n}$ formada apenas por zero, apresentará a coluna $n+1$ formada apenas por zeros. Isto em razão da modelagem de medidas de ângulo de fase de tensão proposta neste trabalho, apresentada na seção 5.1.1. 


\subsection{Exemplos: Análise de Observabilidade}

Nota 2: Na sequência deste capítulo utilizar-se-á a seguinte nomenclatura: $P_{k}$ medida de injeção de potência ativa na barra " $k$ "; $P_{k, m}$ - medida de fluxo de potência ativa, da barra " $k$ " para barra " $m$ "; $\theta_{k}$ - medida fasorial de ângulo de fase de tensão na barra " $k$ "; $I_{k, m}$ - medida fasorial de magnitude da corrente, da barra " $k$ " para barra " $m$ ".

Nota 3: Para facilitar a apresentação dos exemplos, ao invés de apresentar as matrizes dos fatores triangulares (matriz $U$ da decomposição $L U$ da matriz jacobiana), os fatores triangulares serão apresentados diretamente nas matrizes jacobianas transpostas parcialmente fatoradas $\left(H_{f}^{t}\right)$. São os elementos em vermelho abaixo da diagonal principal dessas matrizes.

\section{Exemplo 1:}

Neste exemplo, a metodologia será aplicada ao sistema teste de 4 barras radial representado na Figura (5.3), considerando o sistema de medição ilustrado nessa figura. Para aplicar a metodologia considerar-se-á que a reatância de todos as linhas seja igual a $1[p . u]$.

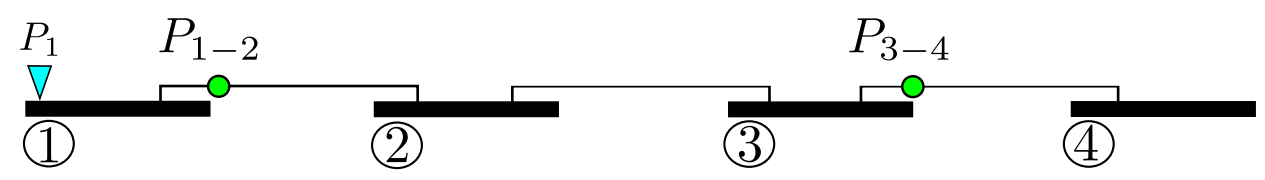

$\nabla$ Medidas de Injeção de Potência

O Medidas de Fluxo de Potência

Figura 5.3: Sistema teste de 4 barras radial - Exemplo 1

O primeiro passo para análise de observabilidade é a obtenção da matriz $H$.

$$
H=\underset{P_{3,4}}{P_{1}}\left[\begin{array}{cccc}
\theta_{1} & \theta_{2} & \theta_{3} & \theta_{4} \\
1 & -1 & & \\
& & 1 & -1 \\
1 & -1 & &
\end{array}\right]
$$

Por uma questão de praticidade, iremos trabalhar com a matriz jacobiana transposta:

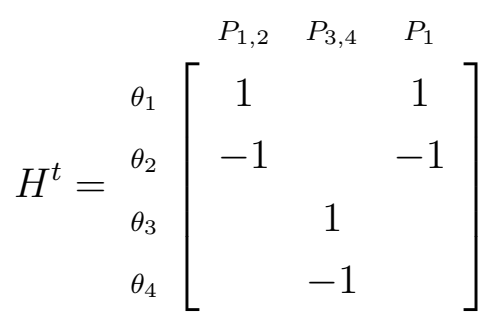


Análise de Observabilidade: Pela decomposição $L U$, da matriz $H^{t}$, (com as permutações de linhas necessárias) verificou-se o aparecimento de um pivô nulo no elemento diagonal $(2,2)$. Dessa forma, o sistema não é observável. A matriz $H^{t}$ parcialmente fatorada está representada a seguir:

$$
H^{t}=\begin{gathered}
P_{1,2} \\
\theta_{1}^{\prime} \\
\theta_{3} \\
\theta_{4}
\end{gathered}\left[\begin{array}{ccc}
1 & & 1 \\
& 0 & \\
& 1 & \\
& -1 &
\end{array}\right]
$$

Nota 4: $\theta_{i}^{\prime}$ simboliza variável de estado equivalente.

Identificação de Ilhas Observáveis: devido ao aparecimento de um pivô nulo, a pseudo-medida de ângulo $\left(\theta_{1}^{p}\right)$ é introduzida na coluna (2) da matriz $H^{t}$ que está sendo fatorada.

Prosseguindo o processo de fatoração, obtém-se a seguinte matriz $H_{f}^{t}$, representada na Figura (5.4).

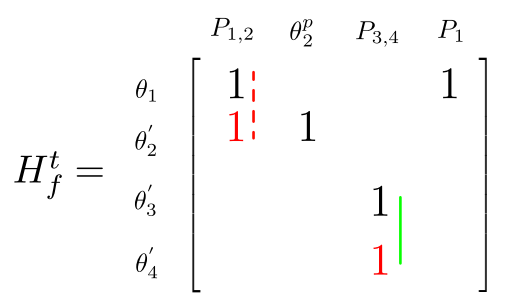

Figura 5.4: Matriz jacobiana transposta fatorada - Sistema teste 4 barras - Exemplo 1

Por meio dos fatores triangulares (elementos em vermelho), têm-se os caminhos de fatoração (ou árvores de caminhos de fatoração) representados na Figura (5.5).

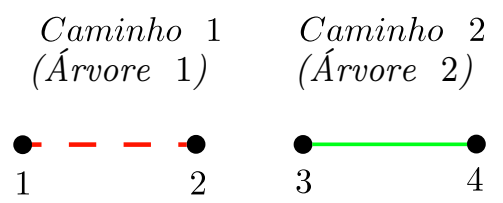

Figura 5.5: Caminhos de Fatoração - Sistema teste 4 barras radial - Exemplo 1

Como não existem medidas de injeção relacionando variáveis de estado equivalentes (ou nós) de diferentes caminhos de fatoração, os caminhos de fatoração encontrados formam duas ilhas observáveis: Ilha 1: $\{1,2\}$; e Ilha 2: $\{3,4\}$.

Vale lembrar que a análise realizada garante que as ilhas são observáveis para o modelo $P \theta$. Para serem observáveis para o modelo $Q V$, é necessária a existência de paridade das medidas de potência ativa e reativa e a existência de pelo menos uma medida de magnitude de tensão em cada uma das ilhas. 
Destaca-se que a observabilidade desse sistema pode ser restaurada, fazendo uso de uma pseudo-medida, relacionando variáveis de estado dos dois caminhos de grafo. Neste caso, seria possível restaurar a observabilidade, através das pseudo-medidas convencionais de injeção de potência, nas barras 2 e 3; e de fluxo de potência, no ramo 2-3.

Seria possível restaurar a observabilidade, também a partir da inclusão de pelo menos uma medida de ângulo de fase de tensão em cada uma das ilhas observáveis, como será demonstrado no Exemplo 3. Entretanto, a inclusão de duas medidas de ângulo de fase de tensão, na mesma ilha observável, não possibilitaria a restauração da observabilidade do sistema, conforme será apresentado no Exemplo 2.

Identificação de MCs: Continuando o processo de fatoração da matriz $H_{f}^{t}$, obtêm-se a seguinte matriz $H_{\triangle}^{t}$ :

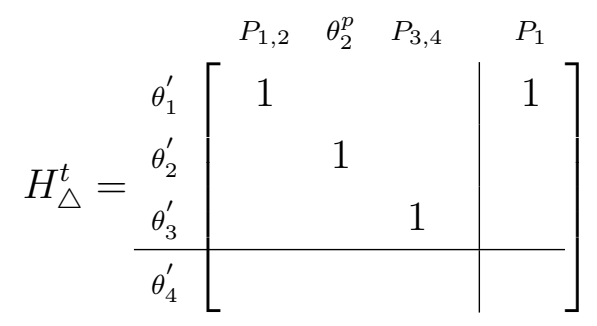

Analisando-se a estrutura da matriz $H_{\triangle}$ identificam-se as seguintes medidas críticas:

$2^{\text {a }}$ linha: Possui apenas um elemento não nulo na linha da variável de estado equivalente $\theta_{2}^{\prime}$. Logo a medida $\theta_{2}^{p}$ é crítica.

$3^{\text {a }}$ linha: medida crítica: $P_{3,4}$.

Restauração da Observabilidade: Para ilustrar como a metodologia proposta possibilita a restauração da observabilidade, consideremos que a pseudo-medida de fluxo de potência ativa, da barra 2 para barra $3\left(P_{2,3}^{p}\right)$ esteja disponível. Assim, após a ocorrência do pivô nulo no elemento diagonal $(2,2)$, como ilustrado na matriz $H^{t}$ parcialmente fatorada apresentada anteriormente, cria-se a coluna 4 para armazenar a pseudo-medida $P_{2,3}^{p}$. Aplicando os fatores triangulares a essa coluna, um elemento não-nulo aparece na linha do pivô-nulo (coluna 2). Consequentemente, a pseudo-medida $P_{2,3}^{p}$ dará a informação necessária para restauração da observabilidade do sistema. Após permutações de linhas, obtém-se a seguinte matriz $H_{f}^{t}$

$$
H_{f}^{t}=\begin{gathered}
\theta_{1} \\
\theta_{2}^{\prime} \\
\theta_{3}^{\prime} \\
\theta_{4}^{\prime}
\end{gathered}\left[\begin{array}{cccc}
P_{1,2} & P_{2,3}^{p} & P_{3,4} & P_{1} \\
1 & & & 1 \\
& 1 & & \\
& & 1 & \\
& & &
\end{array}\right]
$$

\section{Exemplo 2:}

Neste exemplo, considerar-se-á o sistema de medição ilustrado na Figura (5.3), acres- 
cido de PMUs nas barras 1 e 2, que estão disponibilizando as seguintes MFSs: $\theta_{1}^{m}, I_{1,2}$ e $\theta_{2}^{m}$.

A matriz jacobiana transposta inicial está apresentada na Figura (5.6).

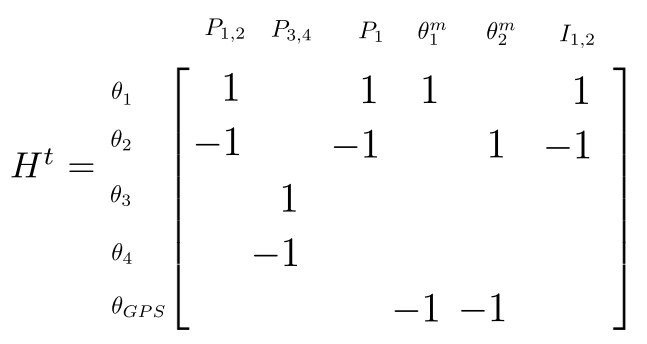

Figura 5.6: Matriz $H^{t}$ inicial - Sistema teste 4 barras radial - Exemplo 2

Análise de Observabilidade: a partir da decomposição $L U$ da correspondente matriz $H^{t}$, verificou-se o aparecimento de um pivô nulo no elemento diagonal $(4,4)$. Logo se conclui que o sistema não é observável, mesmo com a inclusão de duas medidas de ângulo de fase de tensão.

Identificação de Ilhas Observáveis: devido ao aparecimento de um pivô nulo, a pseudo-medida de ângulo $\theta_{4}^{p}$ é introduzida na coluna 4 da matriz $H^{t}$ que está sendo fatorada. Prosseguindo o processo de fatoração, obtém-se a matriz $H_{f}^{t}$ apresentada na Figura (5.7):

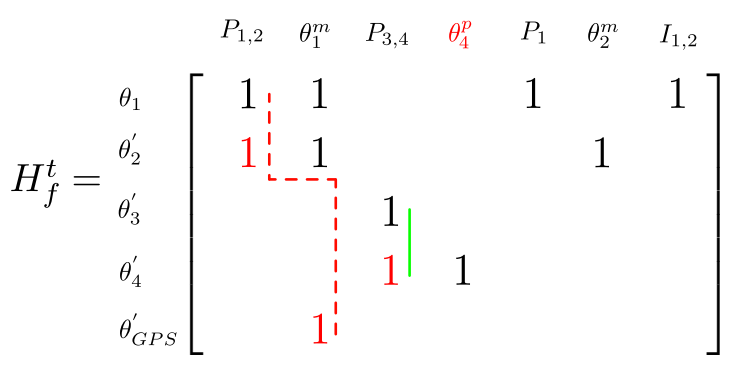

Figura 5.7: Matriz $H^{t}$ fatorada - Sistema teste 4 barras radial - Exemplo 2

A partir dos fatores triangulares, têm-se os caminhos de fatoração apresentados na Figura (5.8)

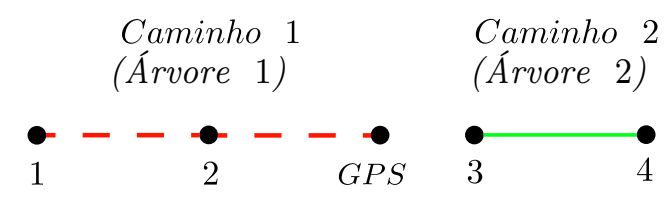

Figura 5.8: Caminhos de Fatoração - Sistema teste 4 barras radial - Exemplo 2

Como não existem medidas de injeção relacionando variáveis de estado equivalentes de diferentes caminhos de fatoração, os dois caminhos de fatoração mostrados na Figura (5.8) formam duas ilhas observáveis: Ilha 1:\{1,2,GPS\}; e Ilha 2:\{3, 4\};

Destaca-se o fato que, tendo em vista a existência de medidas fasoriais de ângulo de fase de tensão na ilha 1, a estimação de estado para essa ilha utilizará como referência 
o sinal de GPS. Por outro lado, a estimação de estado para a ilha 2 será processada escolhendo uma das barras como referência angular.

Identificação de MCs: Continuando o processo de fatoração da matriz $H_{f}^{t}$, obtêm-se a seguinte matriz:

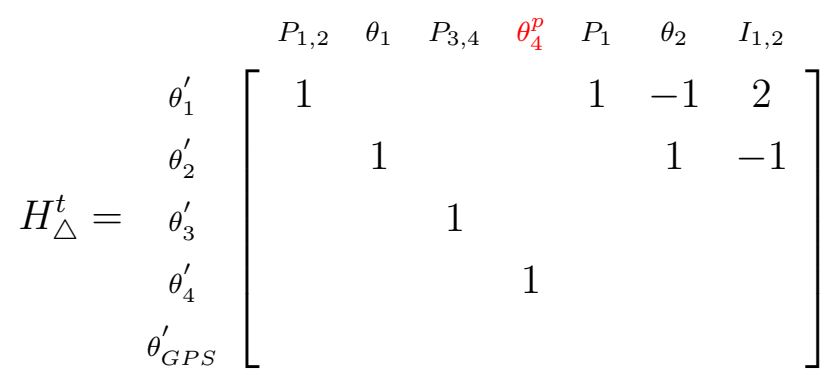

Analisando-se a estrutura da matriz $H_{\triangle}^{t}$ identificam-se as seguintes medidas críticas:

$3^{\text {a }}$ linha: medida crítica: $P_{3,4}$;

$4^{\mathrm{a}}$ linha: medida crítica: $\theta_{4}^{p}$

\section{Exemplo 3:}

Considerar-se-á novamente o sistema de medição apresentado na Figura (5.3), mas agora com a adição das PMUs nas barras 1 e 4 disponibilizando as seguintes MFSs: $\theta_{1}^{m}$, $I_{1,2}, \theta_{4}^{m}$ e $I_{4,3}$.

Análise de Observabilidade: a partir da decomposição $L U$, da correspondente matriz $H^{t}$, verificar-se-á que o sistema é observável como um todo, já que não houve ocorrência de pivô nulo. O ramo $2-3$ torna-se observável pois uma árvore geradora é formada por meio da barra extra. Veja a matriz $H^{t}$ fatorada na Figura (5.9):

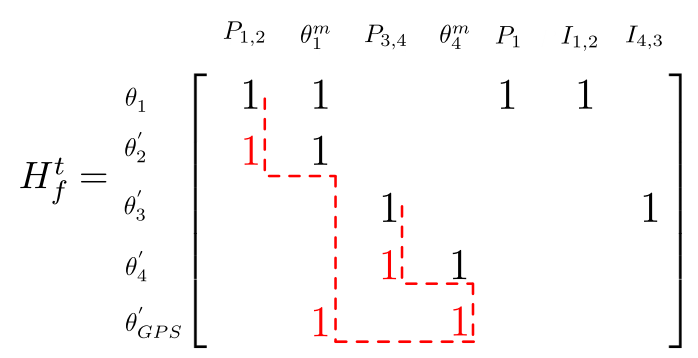

Figura 5.9: Matriz $H^{t}$ fatorada - Sistema teste 4 barras radial - Exemplo 3

Identificação de MCs: Continuando o processo de fatoração da matriz $H_{f}^{t}$, obtêm-se a seguinte matriz: 


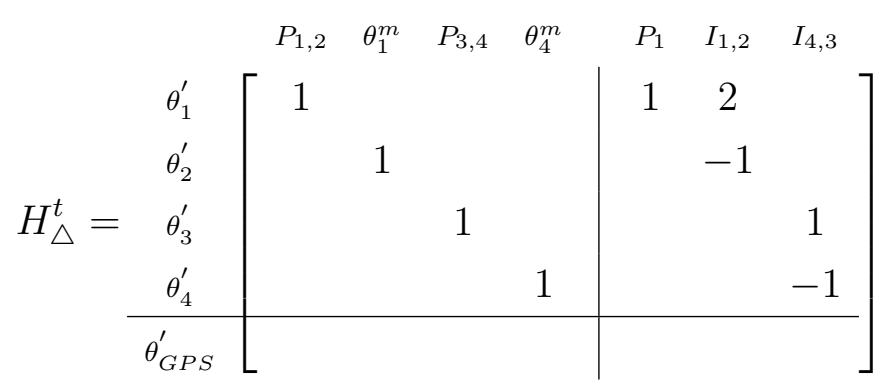

Analisando-se a estrutura da matriz $H_{\triangle}^{t}$ verifica-se que não existem mais MCs. Além de tornar o sistema observável como um todo, a inclusão das medidas fasoriais aumentou a redundância local das medidas.

\section{Exemplo 4:}

Considerar-se-á, mais uma vez, o sistema de medição apresentado na Figura (5.3), mas agora com a disponibilidade da medida $P_{2,3}$ e a adição de uma PMU na barra 1 , disponibilizando as medidas : $\theta_{1}^{m}, I_{1,2}$.

Análise de Observabilidade: com a decomposição $L U$, verifica-se que o sistema é observável como um todo. A matriz $H^{t}$ fatorada esta representada na Figura (5.10).

$$
\begin{aligned}
& \begin{array}{llllll}
P_{1,2} & P_{2,3} & P_{3,4} & \theta_{1}^{m} & P_{1} & I_{1,2}
\end{array}
\end{aligned}
$$

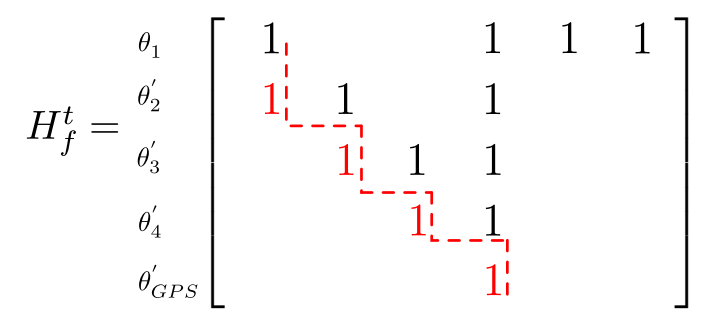

Figura 5.10: Matriz $H^{t}$ fatorada - Sistema teste 4 barras radial- Exemplo 4

Identificação de MCs: Continuando o processo de fatoração da matriz $H_{f}^{t}$, obtêm-se a seguinte matriz:

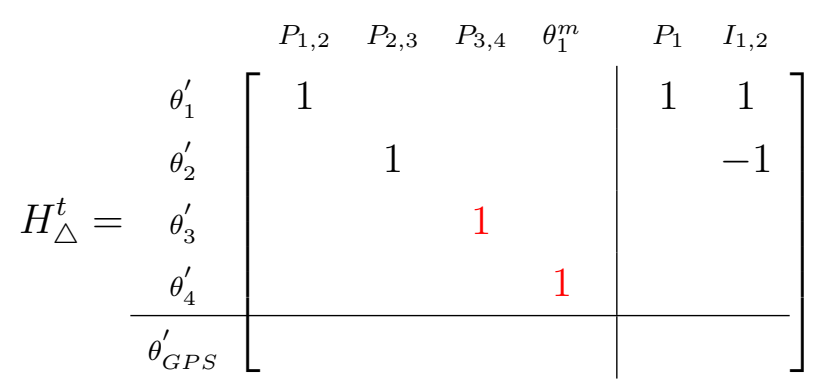

Analisando-se a estrutura da matriz $H_{\triangle}^{t}$ encontram-se as seguinte MCs:

$3^{\text {a }}$ linha: medida crítica: $P_{3,4}$;

$4^{\text {a }}$ linha: medida crítica: $\theta_{1}^{m}$;

Observe que a medida de ângulo de fase de tensão na barra 1 foi identificada como 
crítica, pois é a única que dá informação da variável de estado equivalente $\theta_{4}^{\prime}$, em relação a referência do GPS $\left(\theta_{G P S}\right)$, conforme indicado no fator $H_{f}^{t}(5,4)$ da matriz apresentada na Figura (5.10) e conforme ilustrado na Figura (5.11(a)). Porém, a retirada dessa medida vai tornar o sistema não observável para referência de GPS, mas o sistema será observável tomando uma das barras do sistema como referência, conforme ilustrado na Figura (5.11(b)). Assim, a medida de ângulo de fase de tensão na barra 1 não é critica de uma forma geral, mas apenas para referência de GPS, sendo possível, através de um estimador de estado convencional, estimar todas as variáveis do sistema quando tal medida não estiver disponível.

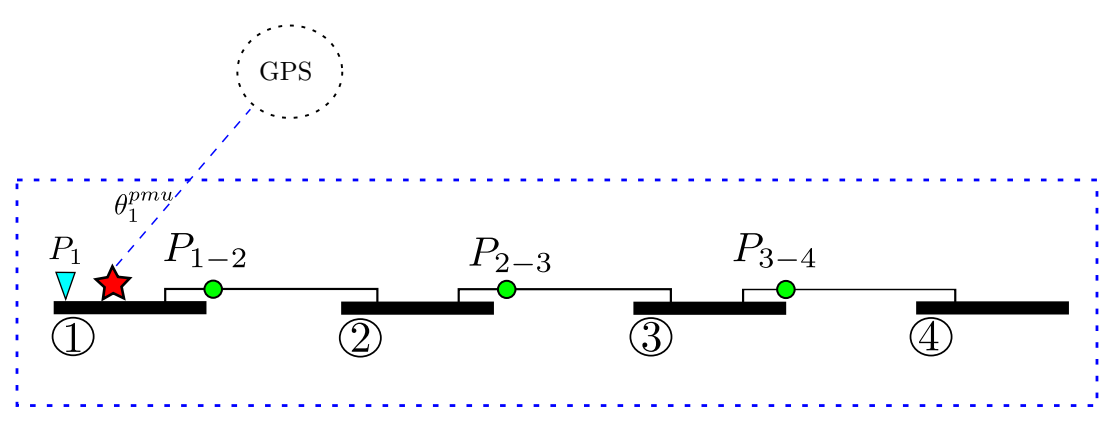

(a) Sistema observável com referência ao GPS

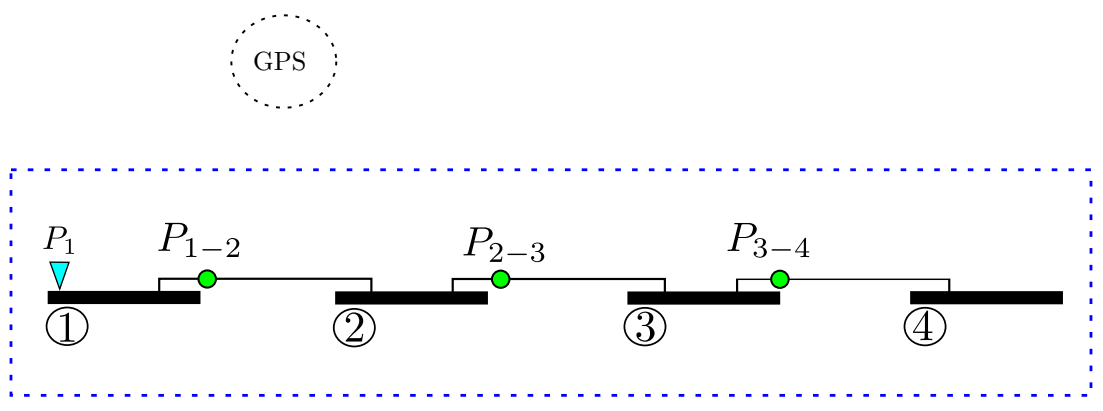

(b) Sistema observável sem referência ao GPS

Figura 5.11: Observabilidade sob o ponto de vista topológico

\subsection{Aplicando a metodologia proposta na matriz Ja- cobiana Completa}

Para validar os resultados obtidos na seção anterior, resultantes da aplicação da metodologia proposta considerando apenas o modelo $P \theta$ e as aproximações apresentadas na seção (5.1.1), realizar-se-ão novamente os mesmos testes apresentados na seção anterior, porém, nesta seção, a metodologia proposta será aplicada na matriz jacobiana completa, do estimador de estado híbrido proposto em ZHU; ABUR (2007b).

Quando se realiza análise de observabilidade através de matrizes completas, associadas 
a estimadores WLS, utilizam-se normalmente as matrizes obtidas na primeira iteração do estimador, calculadas a partir do flat start. Porém, conforme discutido na conclusão do Capítulo 4, esse procedimento não deve ser aplicado à matriz jacobiana completa do estimador de estado WLS híbrido proposto em ZHU; ABUR (2007b). Isto em razão de as derivadas das medidas fasoriais de corrente se tornam indefinidas, se calculadas no flat start. Para contornar esse problema, a metodologia proposta deve ser aplicada na matriz jacobiana da primeira iteração daquele estimador de estado híbrido, porém calculada a partir das variáveis de estado estimadas no instante anterior, e não do flat start.

Para aplicar a metodologia proposta na matriz jacobiana completa, as medidas de ângulo de fase de tensão serão tratadas da forma proposta na seção (5.1.1), ou seja, elas serão modeladas como se fossem medidas de fluxo de potência em ramos fictícios, com impedância unitária, que conectam as barras onde as medidas foram realizadas com uma barra extra, representando a referência de GPS.

Conforme apresentado na seção (3.1), para o modelo completo e quando não existem MFSs, a condição para observabilidade é expressa pela Equação (5.3), ou seja, se o sistema é observável o posto da correspondente matriz jacobiana deve ser igual a " $2 n-1$ ", sendo " $n$ " o número de barras do sistema. Observe que " $2 n-1$ " é o número de variáveis de estado a serem estimadas, pois o ângulo de fase de tensão de uma das barras é escolhido como referência angular.

Quando o sistema de medição possui MFSs, temos que considerar duas situações. A condição de observabilidade supracitada manter-se-á quando não existir medida de ângulo de fase de tensão. Entretanto, se existir pelo menos uma medida desse tipo, o sistema elétrico será observável se:

$$
\operatorname{Posto}(H)=2 n
$$

Isto em razão de a referência de ângulo ser agora determinada pelo sinal emitido pelo sistema GPS.

Face ao exposto, se o sistema for observável, a fatoração triangular da matriz jacobiana completa, do estimador de estado híbrido proposto em ZHU; ABUR (2007b), resultará em apenas um pivô nulo na diagonal $(2 n, 2 n)$, apenas se não existirem medidas de ângulo de fase de tensão. Por outro lado, na existência de pelo menos uma medida de ângulo de fase de tensão, se a mesma for tratada da forma indicada anteriormente, conforme ilustrado na matriz $H_{P M U}^{\prime}$ apresentada na seção (5.1.1), a fatoração triangular resultará em apenas um pivô nulo, na diagonal corresponde à variável de estado $\theta_{G P S}$. Vale lembrar que essa variável simboliza a referência de GPS para obtenção das medidas de ângulo de fase de tensão.

Quando o sistema não é observável como um todo, o procedimento para restauração da observabilidade e identificação de ilhas observáveis ocorre exatamente como apresentado na seção (5.2), para o modelo $P \theta$. Assim, a restauração realizar-se-á através dos fato- 
res triangulares obtidos durante o processo de fatoração da matriz jacobiana completa, conforme ilustrado no Algoritmo (4) apresentado na seção (4.2).

Para identificar as ilhas observáveis, serão utilizados os caminhos de fatoração associados à fatoração da matriz jacobiana completa. Porém, para agilizar o processo de construção dos caminhos de fatoração, serão analisados apenas os caminhos relacionados com as variáveis de estado do tipo ângulo de fase de tensão. A observabilidade completa, das ilhas identificadas através desses caminhos de fatoração, vai depender da existência, nas mesmas, de pelo menos uma medida de magnitude de tensão.

Mais detalhes do processo de análise de observabilidade e redundância de medidas através da matriz jacobiana completa serão apresentados nas análises dos exemplos apresentados a seguir.

\section{Exemplo 5:}

Neste exemplo, considerar-se-á o sistema de 4 barras radial, com o sistema de medição ilustrado na Figura (5.12). A diferença do sistema de medição mostrado aqui, em relação ao apresentado na Figura (5.3), foi a inclusão das medidas reativas e da medida de magnitude de tensão na barra 1 .

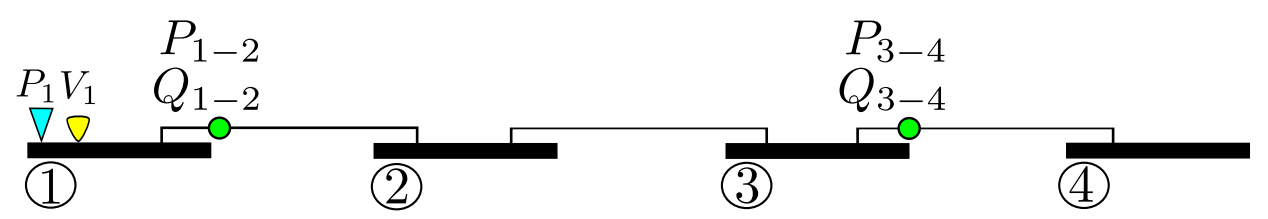

$\nabla$ Medidas de Injeção de Potência

- Medidas de Fluxo de Potência

$\nabla$ Medidas de Magnitude de Tensão

Figura 5.12: Sistema teste de 4 barras radial - Exemplo 5

Os dados das medidas do sistema teste de 4 barras radial são apresentados na Tabela (5.1). Os parâmetros de linha deste sistema são apresentados na Tabela (5.2), sendo $R$ e $X$ a resistência e a reatância da linha respectivamente. 


\begin{tabular}{|c||c|}
\hline \multicolumn{2}{|c|}{ Sistema Teste 4 barras } \\
\hline \hline Medidas & Valor $[p . u]$ \\
\hline \hline$P_{1}$ & 209,0 \\
\hline$V_{1}$ & 1 \\
\hline$P_{1,2}$ & 209,0 \\
\hline$Q_{1,2}$ & $-53,4$ \\
\hline$P_{3,4}$ & 98,9 \\
\hline$Q_{3,4}$ & $-13,0$ \\
\hline$P_{2,3}$ & 218,3 \\
\hline$Q_{2,3}$ & $-3,4$ \\
\hline
\end{tabular}

Tabela 5.1: Medidas disponíveis para o sistema teste de 4 barras

\begin{tabular}{|c|c||c|c|}
\hline \multicolumn{4}{|c|}{ Sistema Teste 4 barras } \\
\hline \hline Parâmetros de linha & Valor [\%] & Parâmetros de linha & Valor [\%] \\
\hline \hline$R_{1,2}$ & 1,94 & $X_{1,2}$ & 5,91 \\
\hline$R_{2,3}$ & 5,4 & $X_{2,3}$ & 22,3 \\
\hline$R_{3,4}$ & 4,69 & $X_{3,4}$ & 19,79 \\
\hline
\end{tabular}

Tabela 5.2: Parâmetros de linha do sistema teste 4 barras

A matriz jacobiana transposta está representada a seguir:

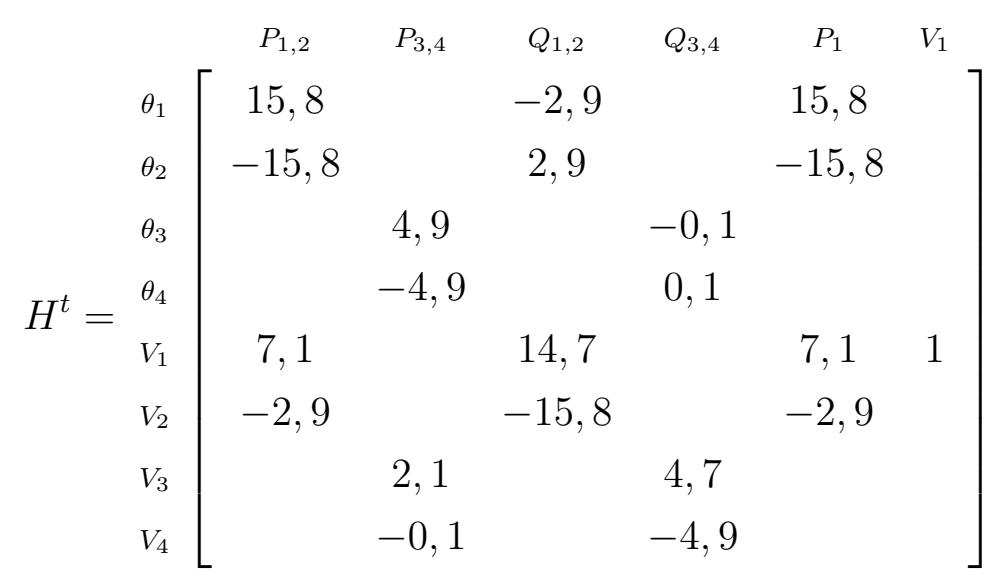

Pela decomposição $L U$, da matriz $H^{t}$, (com as permutações de linhas necessárias) 
verifica-se o aparecimento de um pivô nulo no elemento da diagonal $(2,2)$.

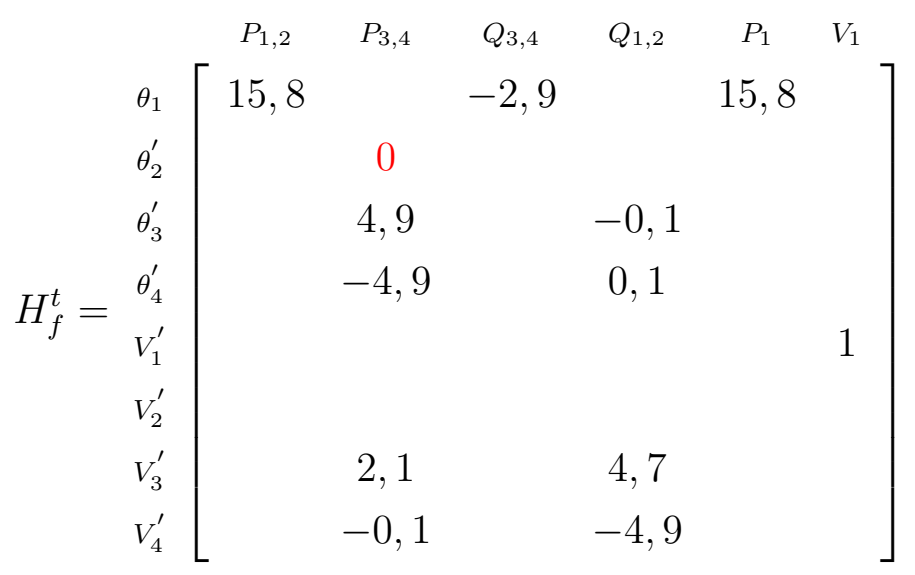

Insere-se uma primeira pseudo-medida de ângulo $\theta_{2}^{p}$ que fornece informação da diagonal $(2,2)$, e o sistema tornou-se "artificialmente observável". Dessa forma, o sistema não é observável como um todo. A seguir temos a matriz parcialmente fatorada.

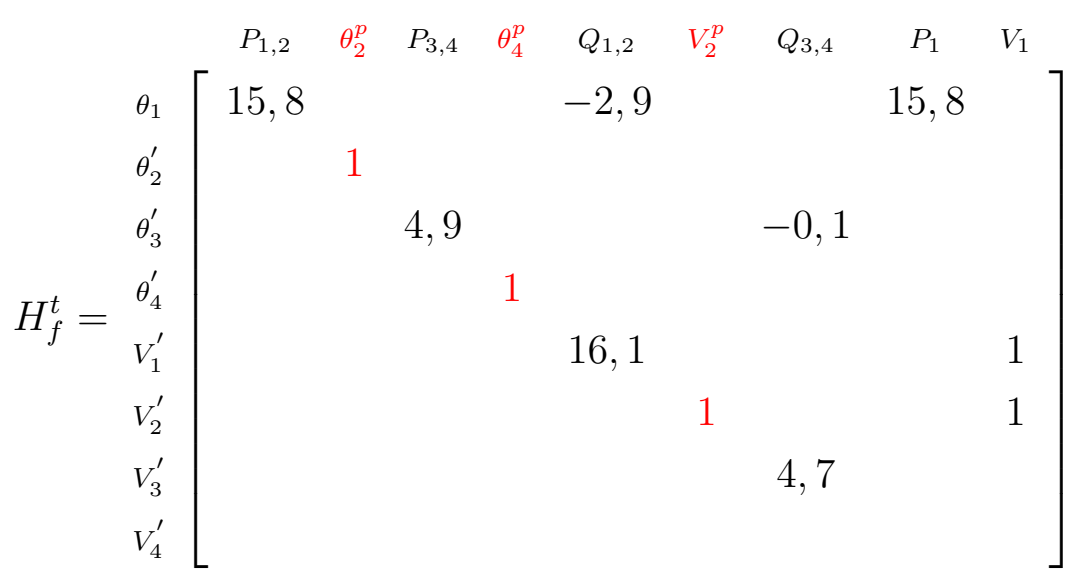

Observe que para tornar o sistema artificialmente observável foram necessários outras duas pseudo-medidas, $\theta_{4}^{p}$ e $V_{2}^{p}$. Observe que essa última pseudo-medida é de magnitude de tensão, indicando a falta de medidas de magnitude de tensão no sistema.

A matriz fatorada com os fatores triangulares é a seguinte:

Por meio da análise dos fatores triangulares, associados às variáveis de estado $\theta$, têm-se os seguintes caminhos de fatoração:

Como não existem medidas de injeção relacionando variáveis de estado equivalentes de ângulos de fase de tensão de diferentes caminhos de fatoração, os caminhos de fatoração encontrados formam duas ilhas: Ilha 1: $\{1,2\}$ e Ilha 2: $\{3,4\}$;

Entretanto, para essas ilhas serem observáveis no modelo completo, é necessário uma medida de magnitude de tensão em cada ilha. Porém, na ilha 2, formada pelas barras 3 e 4, não existe tal medida, o que torna a ilha não observável.

A observabilidade desse sistema poderia ser restaurada como um todo, fazendo uso de pseudo-medidas convencionais relacionando variáveis de estado dos dois caminhos de 


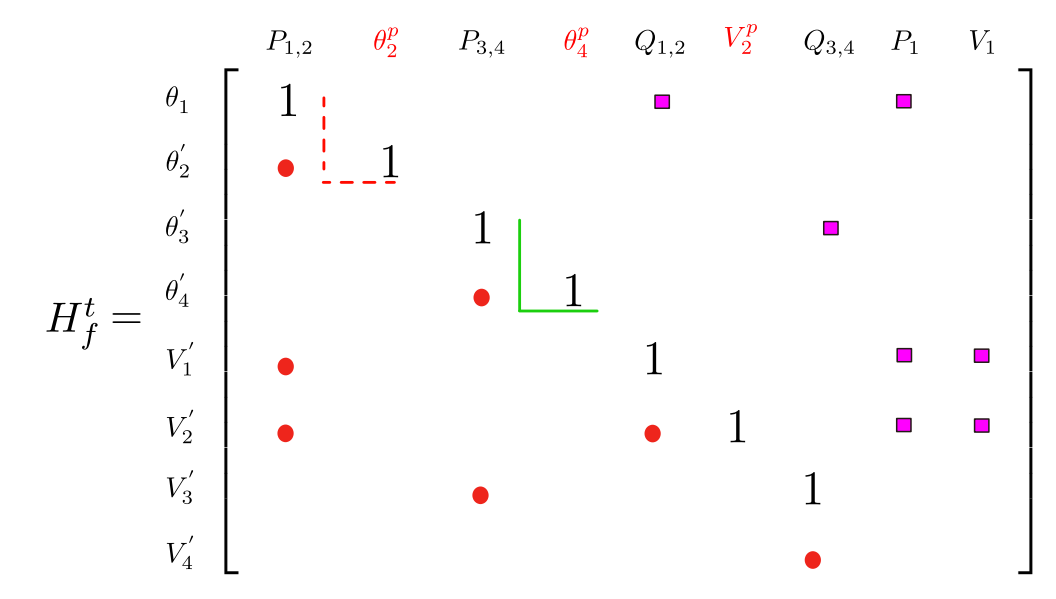

- Fatores Triangulares $\square$ Elementos não-nulos

Figura 5.13: Matriz $H^{t}$ fatorada - Sistema teste 4 barras radial - Exemplo 5

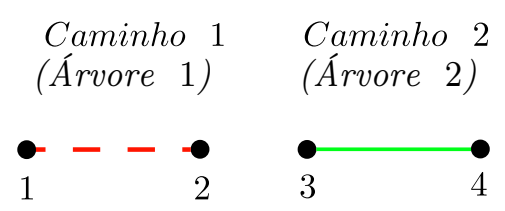

Figura 5.14: Caminhos de Fatoração - Sistema teste 4 barras radial - Exemplo 5

grafo, como, por exemplo, uma medida de fluxo de potência no ramo $2-3$ bem como uma medida de injeção de potência na barra 2 (ou 3).

Continuando o processo de fatoração da matriz $H_{f}^{t}$, obtêm-se a matriz $H_{\triangle}^{t}$ apresentada na Figura (5.15) e analisando a estrutura desta matriz, identifica-se as medidas, $\theta_{2}^{p}, P_{3,4}$, $\theta_{4}^{p}$ e $Q_{3,4}$ como críticas.

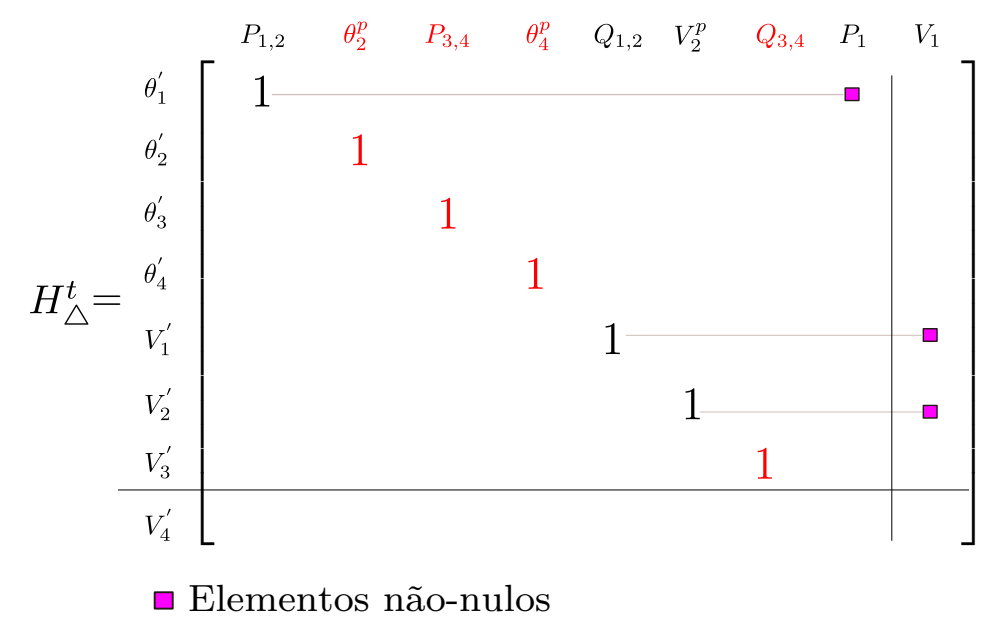

Figura 5.15: Matriz $H_{\triangle}^{t}$ fatorada - Sistema teste 4 barras radial - Exemplo 5

Observe que a criticalidade das medidas $P_{3,4}$ e $Q_{3,4}$ não faz sentido, uma vez que a ilha 2 não é observável para o modelo completo. Observe também, que a medida $P_{3,4}$ é crítica para modelo $P \theta$. Assim, para identificar as medidas críticas do modelo completo, no final da análise das linhas da matriz $H_{\triangle}^{t}$, recorre-se ao resultado da análise de observabilidade 
completa das ilhas. Destaca-se que a existência de uma medida de magnitude de tensão em uma das barras da ilha 2 a tornaria observável para o modelo completo e as medidas $P_{3,4}, Q_{3,4}$ e de magnitude de tensão na ilha 2 seriam críticas para observabilidade completa dessa ilha.

\section{Exemplo 6:}

Neste exemplo, considerar-se-á o sistema de medição analisado no exemplo (5), acrescido de uma PMU na barra 1, que está disponibilizando as seguintes MFSs: $\theta_{1}^{m}, I_{1,2}$.

Análise de Observabilidade: a partir da decomposição $L U$ da correspondente matriz $H^{t}$ verificou-se o aparecimento de um pivô nulo no elemento diagonal $(4,4)$. Logo, conclui-se que o sistema não é observável mesmo com a inclusão das MFSs.

Identificação de Ilhas Observáveis: devido ao aparecimento de um pivô nulo, a pseudo-medida de ângulo $\theta_{4}^{p}$ é introduzida na coluna 4 da matriz $H^{t}$ que está sendo fatorada. Prosseguindo com o processo de fatoração, obtém-se a matriz $H_{f}^{t}$ apresentada na Figura (5.16).

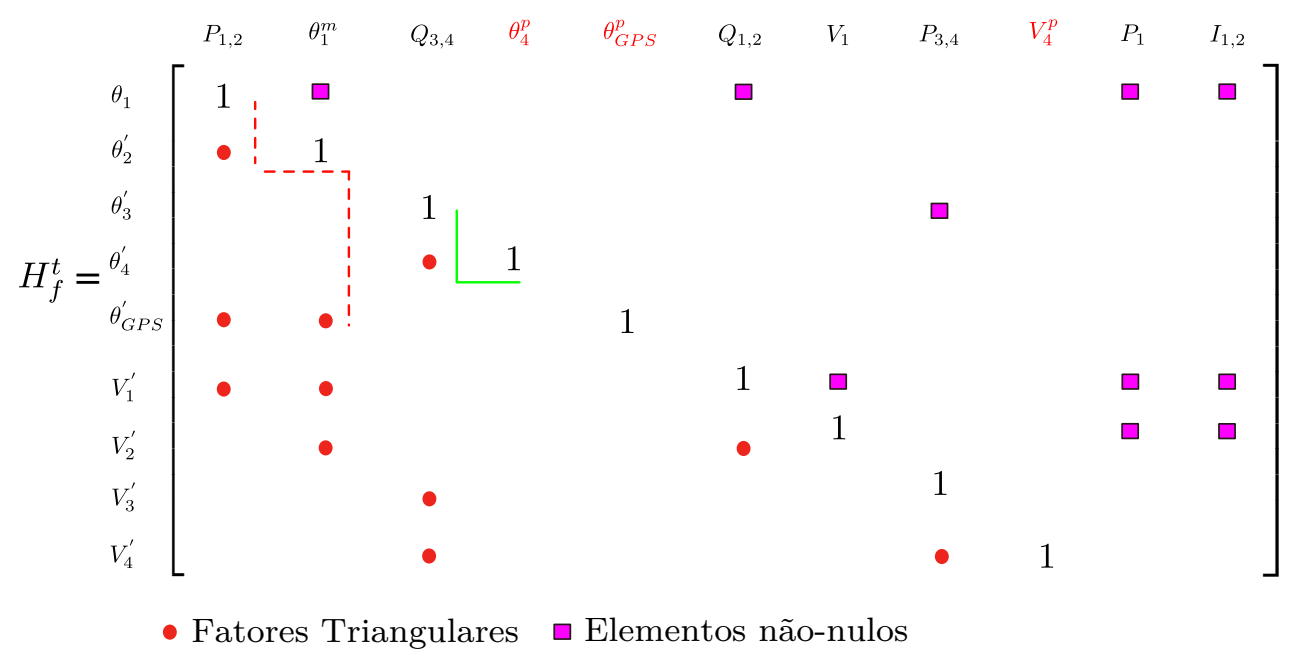

Figura 5.16: Matriz $H_{f}^{t}$ fatorada - Sistema teste 4 barras radial - Exemplo 6

A partir dos fatores triangulares, têm-se os caminhos de fatoração apresentados na Figura (5.17). Como não existem medidas de injeção relacionando variáveis de estado

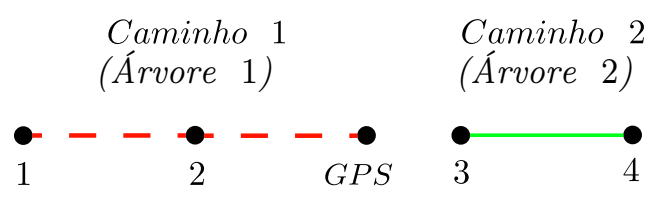

Figura 5.17: Caminhos de Fatoração - Sistema teste 4 barras radial - Exemplo 6 equivalentes de diferentes caminhos de fatoração, os caminhos de fatoração encontrados formam as duas ilhas: Ilha 1: $\{1,2, G P S\}$; Ilha 2: $\{3,4\}$. 
Da mesma forma como no exemplo anterior, a ilha 2 não será observável para o modelo completo, pois não apresenta medida alguma de magnitude tensão.

Como pode ser visto na matriz $H_{f}^{t}$ do Exemplo 6, destaca-se que a referência da ilha 1 será o GPS, enquanto a ilha 2 apresenta uma barra como referência angular.

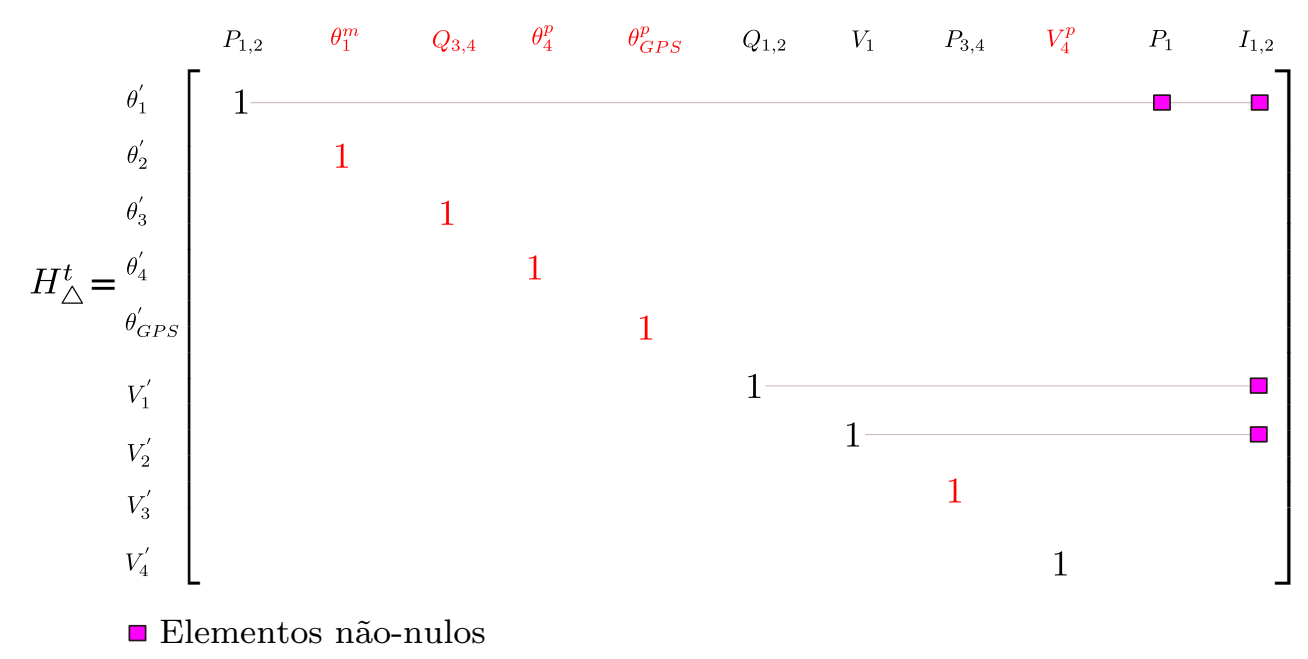

Figura 5.18: Matriz $H_{\triangle}^{t}$ fatorada - Sistema teste 4 barras radial - Exemplo 6

Identificação de MCs: Continuando o processo de fatoração da matriz $H_{f}^{t}$, obtêm-se a matriz $H_{\triangle}^{t}$, e, analisando a estrutura dessa matriz, lembrando o fato de a ilha 2 não ser observável para o modelo completo, identificam-se as seguintes MCs: $\theta_{1}^{m}, \theta_{4}^{p}, \theta_{G P S}^{p}, V_{4}^{p}$

Observe que assim como no exemplo 4, a medida de ângulo de fase de tensão na barra $1, \theta_{1}^{m}$, foi identificada como crítica. Porém, a retirada dessa medida tornará a ilha 1 não observável para referência de GPS, mas a mesma continuará observável tomando uma das barras do sistema como referência. Assim, a medida de ângulo de fase de tensão na barra 1 não é critica de uma forma geral, mas apenas para referência de GPS, sendo possível, através de um estimador de estado convencional, estimar todas as variáveis daquela ilha.

\section{Exemplo 7:}

Considere novamente o sistema de medição analisado no exemplo (5), mas agora com adição das PMUs nas barras 1 e 4 , disponibilizando as seguintes MFSs: $\theta_{1}^{m}, \theta_{4}^{m}, I_{1,2}$ e $I_{4,3}$.

Análise de Observabilidade: a partir da decomposição $L U$ da correspondente matriz $H^{t}$ verificou-se o aparecimento de apenas um pivô nulo nos elementos das diagonal $(n+1, n+1)$ correspondente à variáveis de estado de ângulo $\left(\theta_{G P S}\right)$. Logo, conclui-se que o sistema é observável para o modelo completo. Veja a matriz $H_{f}^{t}$ na Figura (5.19):

Identificação de MCs: Continuando o processo de fatoração da matriz $H_{f}^{t}$, obtêmse a matriz $H_{\triangle}^{t}$, apresentada na Figura (5.20) e por meio da análise da estrutura dessa matriz, pode-se identificar as seguintes MCs:

$2^{\mathbf{a}}$ linha: medida crítica: $\theta_{1}^{m}$;

$4^{\text {a }}$ linha: medida crítica: $\theta_{4}^{m}$; 


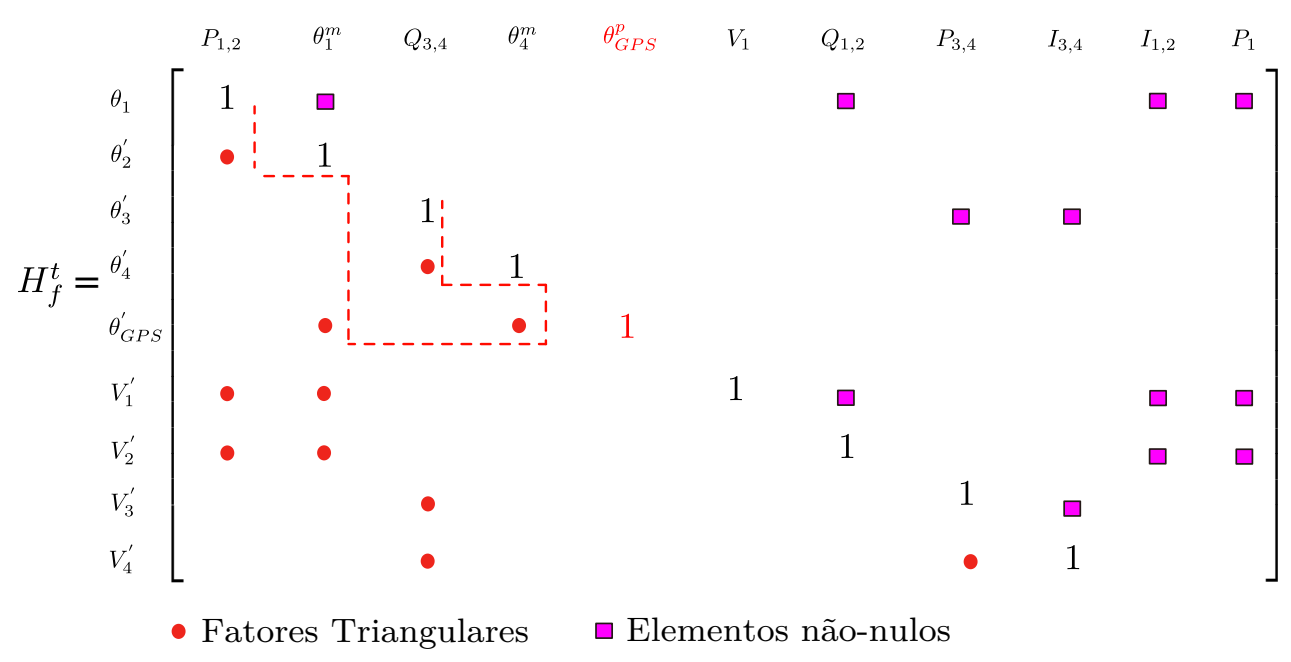

Figura 5.19: Matriz $H^{t}$ fatorada - Sistema teste 4 barras radial - Exemplo 7

$5^{\mathbf{a}}$ linha: medida crítica: $\theta_{G P S}^{p}$;

9a linha: medida crítica: $I_{3,4}$;

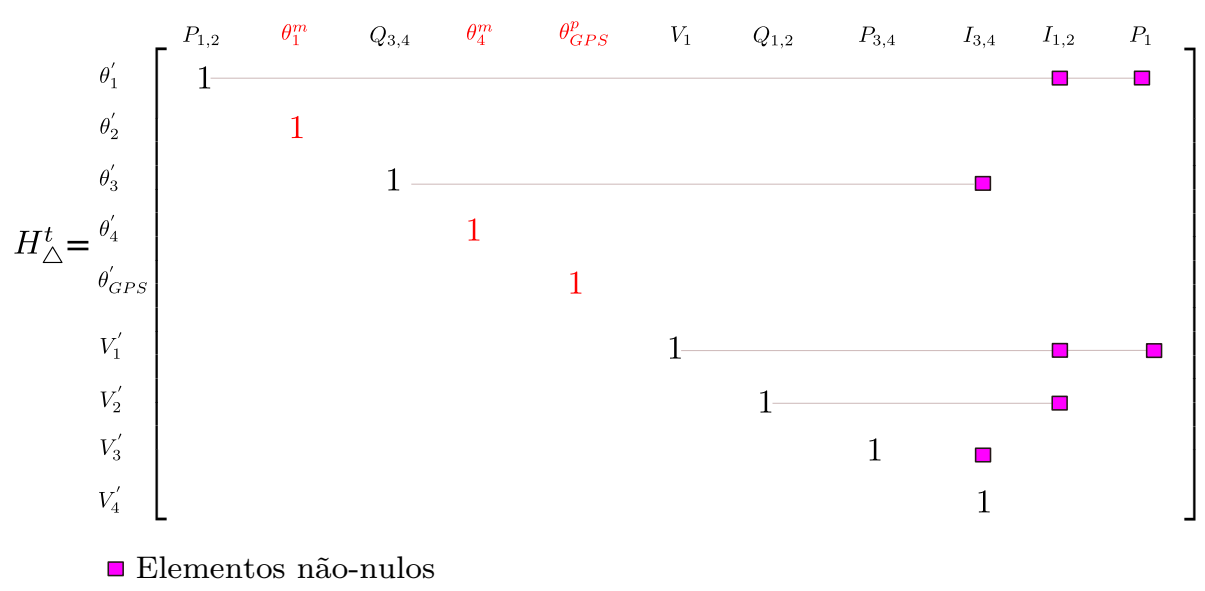

Figura 5.20: Matriz $H_{\triangle}^{t}$ fatorada - Sistema teste 4 barras radial - Exemplo 7

\section{Exemplo 8:}

Neste exemplo, considerar-se-á a adição de uma PMU na barra 1, disponibilizando as MFSs, $\theta_{1}^{m}$ e $I_{1,2}$, bem como a inclusão do par medida de fluxo de potência $P_{2,3}$ e $Q_{2,3}$.

Análise de Observabilidade: a partir da decomposição $L U$ da correspondente matriz $H^{t}$ verificou-se o aparecimento de apenas um pivô nulo nos elementos das diagonal $(n+1, n+1)$ correspondente à variáveis de estado de ângulo $\left(\theta_{G P S}\right)$. Logo, conclui-se que o sistema é observável para o modelo completo como um todo. Veja a matriz $H_{f}^{t}$ na Figura (5.21).

Identificação de MCs: Continuando o processo de fatoração da matriz $H_{f}^{t}$, obtêmse a matriz $H_{\triangle}^{t}$ e por meio da análise da estrutura dessa matriz (Figura (5.22)), pode-se identificar as seguintes MCs:

$4^{\text {a }}$ linha: medida crítica: $\theta_{1}^{m}$; 


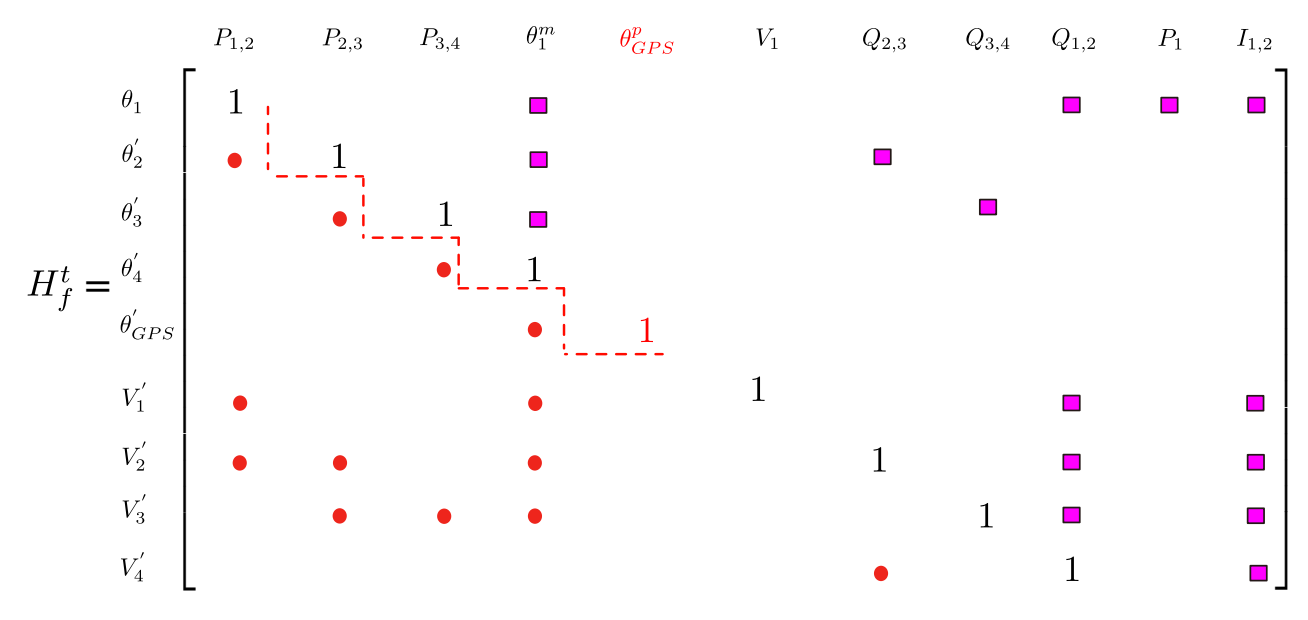

- Fatores Triangulares घElementos não-nulos

Figura 5.21: Matriz $H^{t}$ fatorada - Sistema teste 4 barras radial - Exemplo 8

$5^{\mathbf{a}}$ linha: medida crítica: $\theta_{G P S}^{p}$;

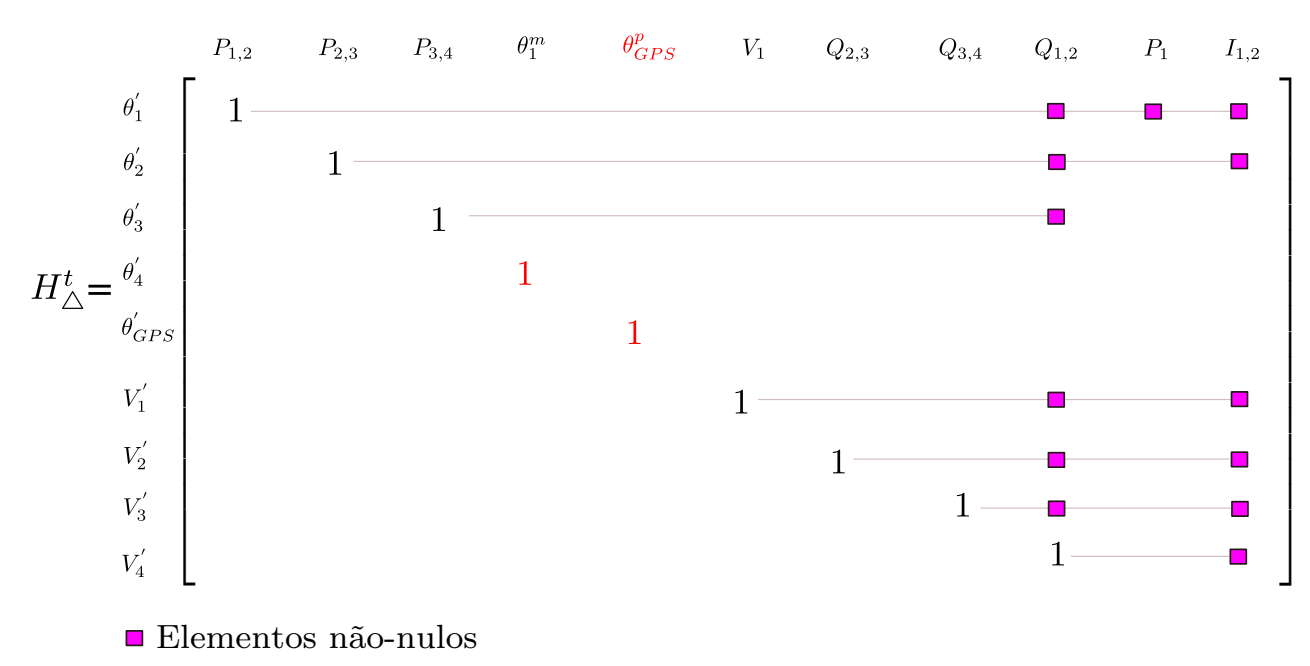

Figura 5.22: Matriz $H_{\triangle}^{t}$ fatorada - Sistema teste 4 barras radial - Exemplo 8

Observe que a medida de ângulo de fase de tensão na barra 1 foi identificada como crítica, pois é a única que dá informação da variável de estado equivalente $\theta_{4}^{\prime}$. Porém, a retirada dessa medida vai tornar o sistema não observável apenas para referência de GPS, mas o sistema será observável tomando uma das barras do sistema como referência. Assim, a medida de ângulo de fase de tensão na barra 1 não é critica de uma forma geral, mas apenas para referência de GPS, sendo possível, através de um estimador de estado convencional, estimar todas as variáveis de sistema, mesmo com a remoção dessa medida. 


\subsection{Simulações Computacionais com os Sistemas de 14, 30 e 57 barras do IEEE}

As simulações computacionais que serão analisadas nesta seção referem-se à aplicação da metodologia proposta nos sistemas de 14, 30 e 57 barras do IEEE.

Para cada simulação a metodologia foi aplicada tanto na matriz jacobiana do modelo $P \theta$, considerando as aproximações apresentadas na seção (5.1.1), quanto na matriz jacobiana completa do estimador de estado híbrido proposto em ZHU; ABUR (2007a). Os resultados obtidos através da aplicação da metodologia nas duas matrizes foram exatamente os mesmos, quando consideradas as hipóteses de paridade de medidas de potência e existência de pelo menos uma medida de magnitude de tensão nas ilhas observáveis identificadas através da análise da matriz jacobiana do modelo $P \theta$. Vale lembrar que, conforme apresentado no Capítulo 3, essas hipóteses são necessárias para estender o resultado da análise de observabilidade do modelo $P \theta$ para o modelo $Q V$.

Face ao exposto, apresentar-se-ão apenas os resultados obtidos considerando a matriz jacobiana do modelo $P \theta$.

\subsubsection{Sistema de 14 barras do IEEE}

Nesta seção a metodologia proposta será aplicada ao sistema de 14 barras do IEEE, cuja topologia está ilustrada na Figura (5.23), associado a dois cenários de medidas. Em ambos os cenários considerar-se-á a indisponibilidade de pseudo-medidas. Assim, para sistemas não observáveis, a metodologia será empregada para identificação de ilhas observáveis.

Cenário A: Para este cenário, serão consideradas apenas as medidas convencionais apresentadas na Tabela (5.3).

\begin{tabular}{|c||c|}
\hline \multicolumn{2}{|c|}{ Sistema Teste 14 barras do IEEE } \\
\hline \hline Tipo de Medidas & Medidas \\
\hline \hline \multirow{3}{*}{ Convencionais } & $P_{1} ; P_{2} ; P_{3} ; P_{8} ; P_{11} ; P_{1,2} ; P_{1,5} ; P_{2,3} ; P_{2,5} ; P_{3,4} ;$ \\
& $P_{6,11} ; P_{6,12} ; P_{6,13} ; P_{7,8} ; P_{7,9} ; P_{9,14} ; P_{10,11} ;$ \\
& $P_{12,13} ; P_{4,2}$ \\
\hline Fasoriais & $\theta_{2}^{m} ; \theta_{8}^{m} ; \theta_{12}^{m}$ \\
\hline
\end{tabular}

Tabela 5.3: Sistema de Medição (IEEE - 14 barras)

Neste caso, o sistema não é observável como um todo e apresenta as seguintes ilhas observáveis:

Ilha 1: $\{1,2,5,3,4\}$;

Ilha 2: $\{6,11,13,10,12\}$; 


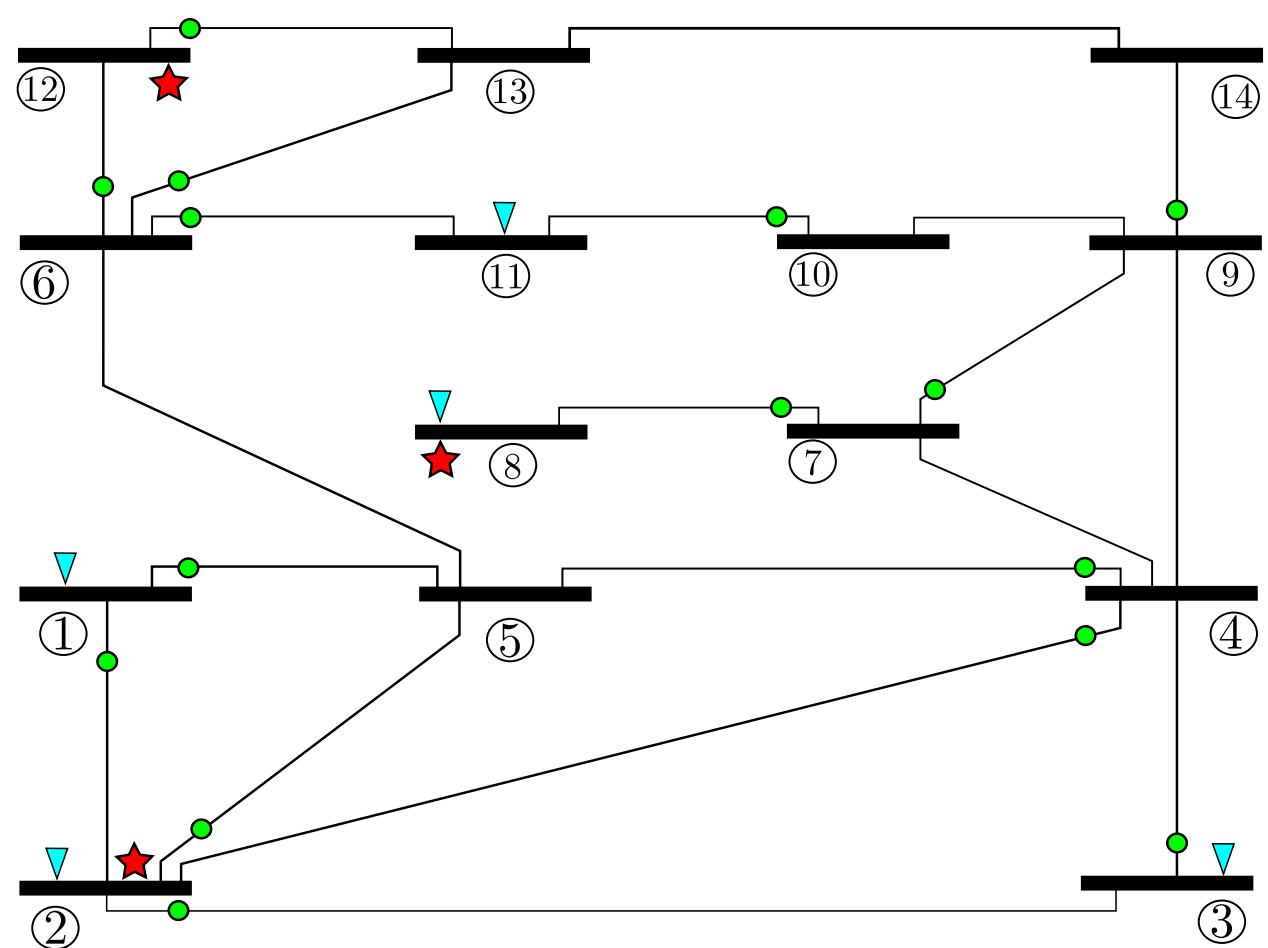

$\nabla$ Medidas de Injeção de Potência

- Medidas de Fluxo de Potência

Medidas de Ângulo de Fase de Tensão

Figura 5.23: Sistema teste de 14 barras do IEEE

Ilha 3: $\{7,8,9,14\}$.

Para identificar as ilhas, torna-se o sistema artificialmente observável através do uso das pseudo-medidas $\theta_{13}^{p}$ e $\theta_{5}^{p}$.

Analisando-se a estrutura da matriz $H_{\triangle}^{t}$ verificam-se as seguinte MCs: $P_{7,9}, P_{9,14}, \theta_{13}^{p}$ e $\theta_{5}^{p}$.

Cenário B: Neste cenário estão sendo consideradas todas as medidas (convencionais e fasoriais) apresentadas na Tabela (5.3).

Para este cenário, o sistema é observável e analisando-se a estrutura da matriz $H_{\triangle}^{t}$ verifica-se as seguinte MCs: $P_{7,9}, P_{9,14}, \theta_{12}^{m}, \theta_{8}^{m}$ e $\theta_{2}^{m}$.

Neste caso, cada medida de " $\theta$ " fornece informação de uma ilha observável distinta, tornando o sistema observável. Porém, a perda de qualquer uma dessas medidas fasoriais, fará com que o sistema deixe de ser observável, pois as medidas fasoriais são críticas para observabilidade do sistema.

\subsubsection{Sistema de 30 barras do IEEE}

Nesta seção, a metodologia será aplicada ao sistema teste de 30 barras do IEEE apresentado na Figura (5.24). 


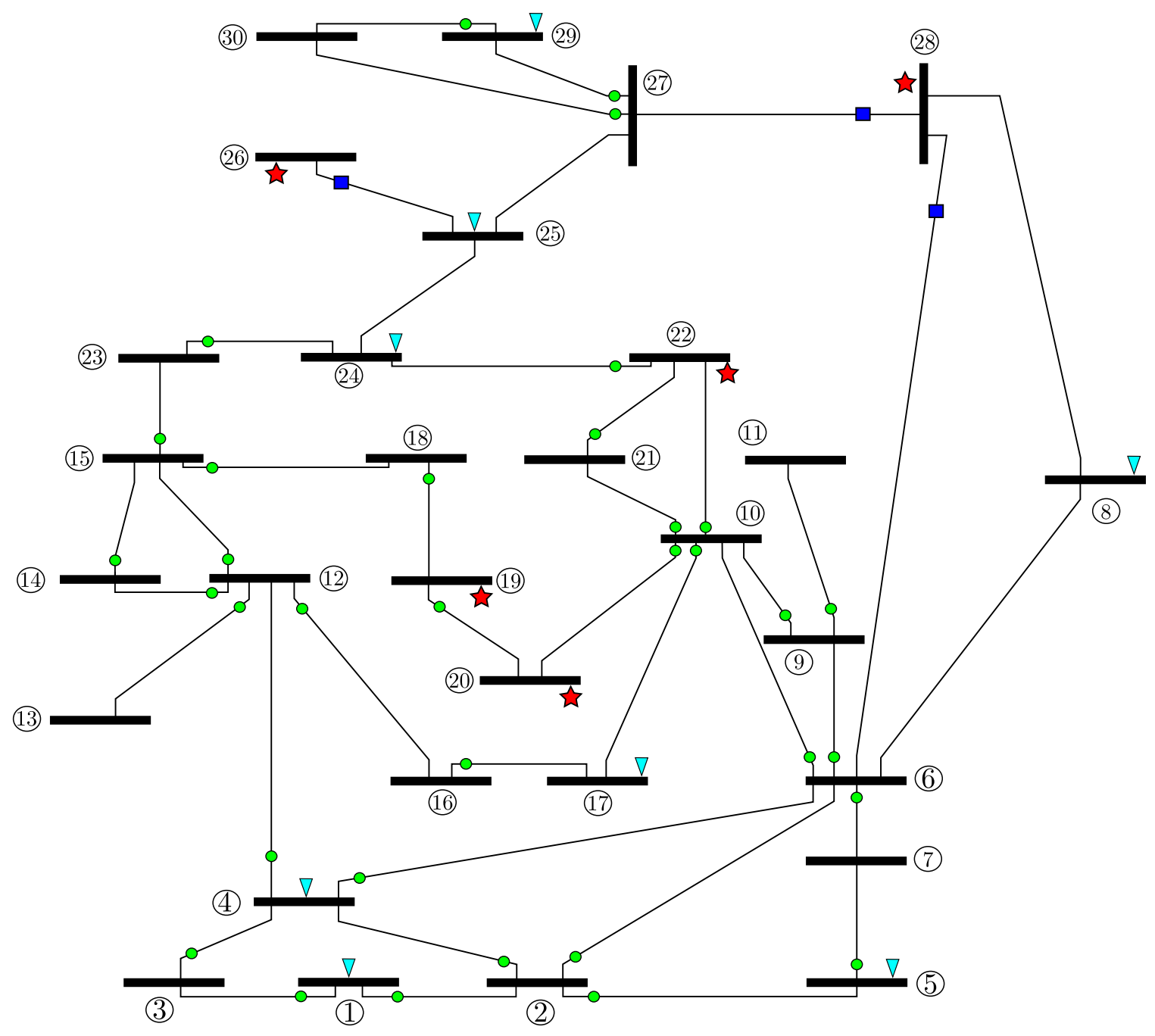

$\nabla$ Medidas de Injeção de Potência

- Medidas de Fluxo de Potência

Medidas de Ângulo de Fase de Tensão

- Medidas de Fluxo de Corrente

Figura 5.24: Sistema teste de 30 barras do IEEE

Cenário A: Considere apenas as medidas convencionais apresentada na Tabela (5.4) e a indisponibilidade de pseudo-medidas:

\begin{tabular}{|c||c|}
\hline \multicolumn{2}{|c|}{ Sistema Teste 30 barras do IEEE } \\
\hline \hline Tipo de Medidas & Medidas \\
\hline \hline \multirow{5}{*}{ Convencionais } & $P_{1} ; P_{4} ; P_{5} ; P_{8} ; P_{17} ; P_{24} ; P_{25} ; P_{29} ; P_{1,2} ; P_{1,3} ; P_{2,4} ;$ \\
& $P_{2,5} ; P_{2,6} ; P_{3,4} ; P_{4,6} ; P_{4,12} ; P_{5,7} ; P_{6,2} ; P_{6,4} ; P_{6,7} ; P_{6,9} ;$ \\
& $P_{6,10} ; P_{9,10} ; P_{9,11} ; P_{10,17} ; P_{10,20} ; P_{10,21} ; P_{10,22} ; P_{12,4} ;$ \\
& $P_{12,13} ; P_{12,14} ; P_{12,15} ; P_{12,16} ; P_{14,15} ; P_{15,18} ; P_{15,23} ; P_{16,17} ;$ \\
& $P_{18,19} ; P_{19,20} ; P_{21,22} ; P_{22,24} ; P_{23,24} ; P_{27,29} ; P_{27,30} ; P_{29,30}$ \\
\hline Fasoriais & $\theta_{26}^{m} ; \theta_{28}^{m} ; I_{26,25} ; I_{28,27} ; I_{28,8} ; I_{28,6}$ \\
\hline
\end{tabular}

Tabela 5.4: Sistema de Medição (IEEE - 30 barras) 
Neste caso, o sistema não é observável como um todo e como não existem pseudomedidas disponíveis, não é possível restaurar a observabilidade do sistema. Assim, identificam-se as ilhas observáveis:

Ilha 1: $\{1,2,3,4,5,6,7,9,10,11,12,13,14,15,16,17,18,19,20,21,22,23,24,25\}$;

Ilha 2: $\{8\}$;

Ilha 3: $\{26\}$;

Ilha 4: $\{27,29,30\}$;

Ilha 5: $\{28\}$.

Durante o processo de identificação de ilhas observáveis as medidas $P_{8}$ e $P_{25}$ foram identificadas como irrelevantes e descartadas da análise.

Para identificar as ilhas, torna-se o sistema artificialmente observável através do uso das pseudo-medidas $\theta_{8}^{p}, \theta_{25}^{p}, \theta_{26}^{p}$ e $\theta_{28}^{p}$.

Analisando-se a estrutura da matriz $H_{\triangle}^{t}$ verifica-se as seguinte MCs: $P_{9,11}, P_{12,13}, P_{24}$, $\theta_{25}^{p}, \theta_{26}^{p}$ e $\theta_{28}^{p}$.

Cenário B: Considere agora todas as medidas (convencionais e fasoriais), apresentadas na Tabela (5.4), com indisponibilidade de pseudo-medidas.

Neste caso, o sistema torna-se observável, e identificam-se as medidas $P_{9,11}$ e $P_{12,13}$ como críticas.

\subsubsection{Sistema de 57 barras do IEEE}

Nesta seção, a metodologia será aplicada ao sistema teste de 57 barras do IEEE apresentado na Figura (5.25).

Cenário A: Considere apenas as medidas convencionais apresentada na Tabela (5.5) e a indisponibilidade de pseudo-medidas:

Neste caso, o sistema não é observável e como não existem pseudo-medidas disponíveis, não é possível restaurar a observabilidade do sistema. Assim, identificam-se as ilhas observáveis:

Ilha 1: $\{1,2,3,16,17,51,10,12,50\}$;

Ilha 2: $\{4,6,7,18,19,20,21,29,30,31,32,33,34,35,52,53,54,55,5,8,22,23,24,25$, $26,27,28\}$;

Ilha 3: $\{9\}$;

Ilha 4: $\{11,13,15,41,42,43,45,46,47,48,49,56,57,14,36,37,38,39,40,44\}$.

Durante o processo de identificação de ilhas observáveis a medida $P_{9}$ foi identificada como irrelevante e descartada da análise.

Para identificar as ilhas, torna-se o sistema artificialmente observável através do uso das pseudo-medidas $\theta_{9}^{p}, \theta_{51}^{p}$ e $\theta_{55}^{p}$. 


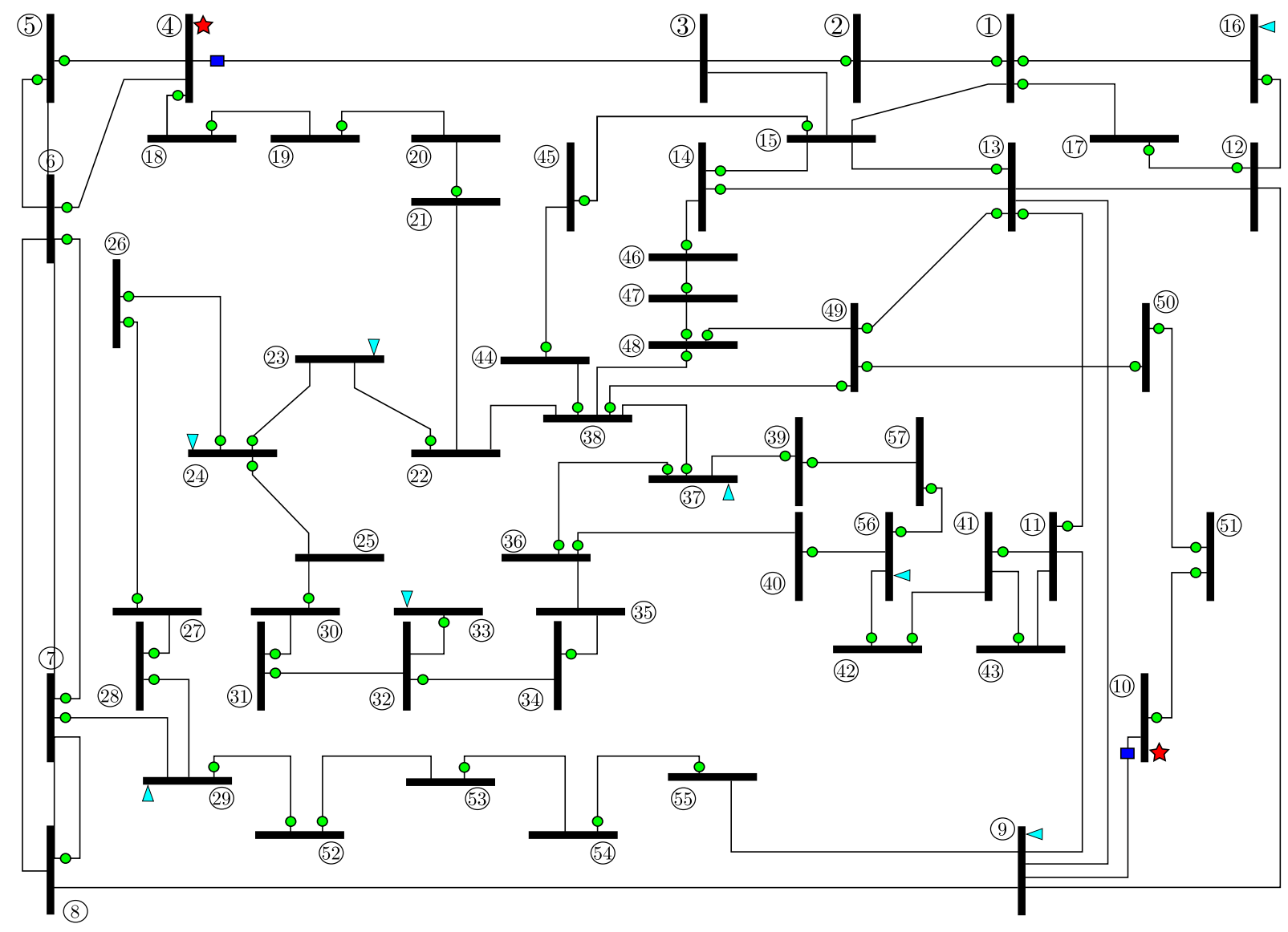

$\nabla$ Medidas de Injeção de Potência

- Medidas de Fluxo de Potência

ڤ Medidas de Ângulo de Fase de Tensão

Medidas de Fluxo de Corrente

Figura 5.25: Sistema teste de 57 barras do IEEE

Analisando-se a estrutura da matriz $H_{\triangle}^{t}$ verifica-se as seguinte MCs: $P_{1,2}, P_{2,3}, P_{8,7}$, $P_{21,20}, P_{30,25}, P_{31,30}, P_{31,32}, P_{32,34}, P_{34,35}, P_{43,41}, P_{52,53}, P_{53,54}, P_{31,32}, \theta_{9}^{p}$ e $\theta_{55}^{p}$.

Cenário B: Considere agora todas as medidas apresentadas na Tabela (5.5), (convencionais e fasoriais) com indisponibilidade de pseudo-medidas.

Neste caso, o sistema torna-se observável, e identificam-se as medidas $P_{21,20}, P_{30,25}$, $P_{31,30}, P_{31,32}, P_{32,34}, P_{34,35}$, e $P_{43,41}$ como críticas.

\subsection{Conclusões}

Neste capítulo foi proposta uma metodologia para análise de observabilidade e identificação de MCs para sistemas de medição formados por medidas convencionais (medidas de magnitude de tensão e de potência obtidas via sistema SCADA) e medidas fasoriais sincronizadas. 


\begin{tabular}{|c||c|}
\hline \multicolumn{1}{|c|}{ Sistema Teste 57 barras do IEEE } \\
\hline \hline Tipo de Medidas & Medidas \\
\hline \hline \multirow{5}{*}{ Convencionais } & $P_{9}, P_{16}, P_{29}, P_{33}, P_{37}, P_{54}, P_{56} ; P_{1,2} ; P_{4,5} ; P_{6,4} ; P_{6,7} ; P_{7,6} ;$ \\
& $P_{14,13} ; P_{13,15} ; P_{1,16} ; P_{1,17} ; P_{4,18} ; P_{18,4} ; P_{5,6} ; P_{8,7} ; P_{10,12} ; P_{12,10} ;$ \\
& $P_{11,13} ; P_{16,12} ; P_{12,17} ; P_{17,12} ; P_{14,15} ; P_{18,19} ; P_{19,20} ; P_{21,20} ; P_{22,23} ;$ \\
& $P_{24,25} ; P_{24,26} ; P_{26,24} ; P_{26,27} ; P_{27,26}, P_{27,28} ; P_{28,27} ; P_{28,29} ; P_{7,29} ;$ \\
& $P_{30,25} ; P_{31,30} ; P_{31,32} ; P_{33,32} ; P_{32,34} ; P_{34,35} ; P_{36,37} ; P_{37,36} ; P_{37,38} ;$ \\
& $P_{39,37} ; P_{40,36} ; P_{41,11} ; P_{42,41} ; P_{43,41} ; P_{38,44} ; P_{15,45} ; P_{45,15} ; P_{46,14} ;$ \\
& $P_{47,46} ; P_{48,47} ; P_{48,49} ; P_{50,51} ; P_{51,50} ; P_{10,51} ; P_{51,10} ; P_{13,49} ; P_{49,13} ;$ \\
& $P_{29,52} ; P_{52,29} ; P_{52,53} ; P_{53,54} ; P_{54,55} ; P_{44,45} ; P_{40,56} ; P_{56,41} ; P_{41,56} ; P_{42,56} ;$ \\
& $P_{39,57} ; P_{57,56} ; P_{56,57} ; P_{38,49} ; P_{49,38} ; P_{48,38}$ \\
\hline Fasoriais & $\theta_{4}^{m} ; \theta_{10}^{m} ; I_{4,3} ; I_{10,9}$ \\
\hline
\end{tabular}

Tabela 5.5: Sistema de Medição (IEEE - 57 barras)

A metodologia permite análise de observabilidade a partir da fatoração triangular da matriz jacobiana. Para possibilitar a identificação de ilhas observáveis, a mesma faz uso do conceito de caminho de fatoração, associado à fatoração da matriz jacobiana formada por medidas convencionais e fasoriais sincronizadas. As MCs são identificadas a partir da análise da estrutura da matriz $H_{\triangle}^{t}$, obtida a partir de medidas convencionais e fasoriais sincronizadas.

Foram apresentados diversas simulações computacionais, cujos resultados comprovaram a eficiência da metodologia proposta.

Conforme demonstrado neste capítulo, através de exemplos numéricos, a metodologia proposta pode ser aplicada tanto na matriz jacobiana do modelo $P \theta$, considerando as aproximações apresentadas na seção (5.1.1), quanto na matriz jacobiana completa do estimador de estado híbrido proposto em ZHU; ABUR (2007a).

Como pode ser observado na seção (5.7), torna-se mais complicada a aplicação da metodologia proposta na matriz completa, tendo em vista o fato de estar sendo analisada, ao mesmo tempo, a observabilidade para ambos os modelos $P \theta$ e $Q V$. Consequentemente, a análise de observabilidade e de redundância de medidas, através da aplicação da metodologia proposta na matriz jacobiana do modelo $P \theta$, é mais simples e mais rápida, sendo indicada para aplicação on-line.

Outro ponto que merece destaque é a definição da criticalidade de medidas de ângulo de fase de tensão para referência de GPS, conforme ilustrado nos exemplos 4 e 6 . Observe que a perda desse tipo de medida não inviabiliza a estimação do estado de todo o sistema, inviabiliza apenas a utilização da referência de GPS. Ou seja, as estimativas são ainda possíveis, mas tomando uma das barras do sistema como referência angular. 


\section{Capítulo 6}

\section{Conclusão}

Apresenta-se-nos, neste trabalho, o processo de estimação de estado, que é importante para operação em tempo real dos sistemas elétricos de potência. Destacou-se que diversas pesquisas vêm sendo desenvolvidas para inclusão de PMUs no processo, juntamente com as justificativas para tanto.

Deve-se salientar, contudo, que devido aos elevados custos envolvidos para instalação de PMUs, principalmente decorrentes das necessidades de telecomunicação num SEP de grande dimensão, os atuais sistemas de medição, destinados ao processo de EESEP, não serão completamente substituídos por PMUs, em um curto período de tempo.

Vislumbra-se, assim, que as PMUs devem ser instaladas por etapas, ao longo dos próximos anos, e que serão utilizadas, no processo de estimação de estado, em conjunto com as medidas convencionais. Ante o exposto, torna-se necessário o desenvolvimento de metodologias para analisar as diversas etapas do processo de EESEP, considerando medidas convencionais e medidas fasoriais sincronizadas.

Após uma análise das publicações tratando da inclusão de MFSs no processo de EESEP, pode-se considerar que:

i) Um dos problemas enfrentados, referente aos estimadores de estado híbridos, que, no contexto deste trabalho, representam estimadores que fazem uso de medidas convencionais e fasoriais sincronizadas, é o tratamento dado à referência angular. Dentre as soluções propostas para contornar esse problema, destaca-se o estimador de estado WLS híbrido apresentado por ZHU; ABUR (2007b), em razão das seguintes características do mesmo: não exige muitas mudanças na formulação do processo de estimação de estado convencional por mínimos quadrados ponderados; não requer a escolha de uma barra como referência angular, nem mesmo a criação de uma barra de referência virtual; e, possibilita o processamento de erros grosseiros em medidas fasoriais sincronizadas, desde que a redundância seja adequada;

ii) Embora sejam diversas as vantagens do estimador híbrido proposto por (ZHU; ABUR, 2007b), o mesmo pode apresentar problemas na primeira iteração do pro- 
cesso de convergência, pois, no "flat start" tornam-se indefinidas as derivadas das medidas fasoriais de corrente. Para contornar esse problema, ao invés de utilizar o flat start na primeira iteração, utilizam-se as variáveis de estado estimadas no instante anterior. Destaca-se que para possibilitar um entendimento maior das particularidades desse estimador, o mesmo foi implementado, em $\mathrm{C}++$, e aplicado em um sistema teste de 4 barras. No Capítulo 4, encontram-se os resultados de algumas das simulações computacionais realizadas;

iii) Poucas são as pesquisas desenvolvidas para desenvolvimento de métodos destinados à análise das características qualitativas de sistemas de medição (análise de observabilidade e redundância de medidas), formados por medidas convencionais e fasoriais sincronizadas. Importa destacar que as metodologias desenvolvidas para sistema de medição, formado apenas por medidas convencionais, não podem ser aplicadas de forma direta quando existem MFSs.

Face ao exposto, desenvolveu-se, nesse trabalho, uma metodologia para análise de observabilidade (restauração e identificação de ilhas) e identificação de MCs, baseada na fatoração triangular da matriz jacobiana, associada ao estimador de estado WLS híbrido, proposto por ZHU; ABUR (2007b). A metodologia proposta baseia-se nos trabalhos apresentados por LONDON; ALBERTO; BRETAS (2007) e BENEDITO et al. (2008).

Para possibilitar a identificação de ilhas observáveis, através de caminhos de fatoração, as medidas de ângulo de fase de tensão foram modeladas como se fossem medidas de fluxo de potência em ramos fictícios, com impedância unitária, que conectam as barras onde as medidas foram realizadas com uma barra extra, representando a referência de GPS.

Demonstrou-se, neste trabalho, que em termos de observabilidade do sistema as medidas de ângulo de fase de tensão têm um comportamento bem particular, pois, as mesmas podem ser essenciais para observabilidade em termos da referência de GPS, mas não para observabilidade do sistema. Sendo assim, em algumas situações, a perda dessas medidas não inviabiliza a estimação do estado de todo o sistema, inviabiliza apenas a utilização da referência de GPS. Isto é, as estimativas são ainda possíveis, mas tomando uma das barras do sistema como referência angular. Para caracterizar esse comportamento das medidas de ângulo de fase de tensão foi cunhado o termo medida crítica para referência de GPS.

Destaca-se que foram desenvolvidas duas versões da metodologia proposta. Uma para aplicação na matriz jacobiana do modelo $P \theta$ e outra para aplicação na matriz jacobiana completa do estimador de estado híbrido proposto em ZHU; ABUR (2007a). Através de simulações computacionais verificou-se que são exatamente os mesmos os resultados obtidos através das duas versões, quando consideradas as hipóteses de paridade de medidas de potência e existência de pelo menos uma medida de magnitude de tensão nas ilhas observáveis identificadas através da análise da matriz jacobiana do modelo $P \theta$. Tendo 
em vista ser mais simples e mais rápida a versão da metodologia que considera apenas a matriz jacobiana do modelo $P \theta$, essa é a indicada para aplicação on-line.

Finalmente vale destacar que os resultados de diversas simulações, apresentadas no Capítulo 5, comprovam a eficiência das duas versões da metodologia proposta.

\subsection{Publicação}

Artigo completo publicado em anal de congresso nacional.

Título: Estimação de Estado em Sistemas Elétricos de Potência: Metodologia para Análise de Observabilidade Considerando Medidas Convenionais e Fasoriais -

Nome e local do Evento: XVIII CBA - Congresso Brasileiro de Automática, 2010, Bonito-MS.

Autores: Guilherme Pereira Borges, Raphael Augusto de Souza Benedito, João Bosco Augusto London Jr. e Newton Geraldo Bretas.

\subsection{Perspectivas Futuras}

Este trabalho propiciou, ao nosso grupo de pesquisa, um primeiro contato com o processo de EESEP através de medidas convencionais e fasoriais sincronizadas. Pretendemos dar continuidade aos estudos realizados, tendo como metas principais:

i - Estender a metodologia desenvolvida para identificação de conjuntos críticos de medidas;

ii - Analisar as interações que ocorrem entre as medidas convencionais e fasoriais sincronizadas, no que tange ao processamento de EGs;

iii - Analisar outros estimadores híbridos apresentados na literatura, para verificar o que apresenta melhor desempenho e robustez. 



\section{Referências Bibliográficas}

ABUR, A.; EXPOSITO, A. G. Power system state estimation theory and implementation. New York, NY, USA: Marcel Dekker Publishers, 2004.

ALBERTINI, M. R. M. C. Metodologia para depuração off-line de parâmetros série e shunt de linhas de transmissão através de diversas amostras de medidas. 2010. Tese (Doutorado em Engenharia Elétrica) — Escola de Engenharia de São Carlos - Universidade de São Paulo.

ALMEIDA, M. C.; ASADA, E. N.; GARCIA, A. V. Power system observability analysis based on gram matrix and minimum norm solution. IEEE Transactions on power systems, [S.1.], v.23, n.4, p.1676-1681, 2008.

BALDWIN, T. L.; MILLI, L.; BOISEN M. B., J.; ADAPA, R. Power System observability with minimal phasor measurement placement. IEEE J PWRS, [S.l.], v.2, n.2, p.707715, 1993.

BENEDITO, R. A. S.; LONDON, J. B. A.; BRETAS, N. G. Análise de observabilidade em sistemas elétricos de potência: identificação de ilhas observáveis através de caminhos de fatoração associados à matriz jacobiana. Belém, 2009.

BEnEDITO, R. A. S.; MOREIRA, E. M.; LONDON, J. B. A.; BRETAS, N. G. Observability analysis based on path graph concepts and triangular factorization of the Jacobian matrix. [S.1.]: IEEE Transmission and Distribution Conference and Exposition, 2008. 1-7p.

BI, T.; QIN, X.; YANG, Q. A novel hybrid state estimator for including synchronized phasor measurements. Electric Power Systems Research, [S.l.], v.78, n.8, p.13431352, Aug. 2008.

BRETAS, N. G. Network observability: theory and algorithms based on triangular factorisation and path graph concepts. IEE Proceedings Generation, Transmission and Distribution, [S.l.], v.143, n.1, p.123-128, 1996.

BRETAS, N. G.; LONDON JR, J. B. A.; ALBERTO, L. F. C.; BRETAS, A. S. A topological approach to the identification of critical measurements in power-system 
state Eetimation. IEEE Transactions on Circuits and Systems., [S.l.], v.52, n.1, p.139-147, 2005.

CEASE, M. R. M.; FELDHAUSS, B. Real-time monitoring of the TVA power system. [S.l.: s.n.], 1999. 47-51p. v.7.

CHEN, J.; ABUR, A. Placement of PMUs to enable bad data detection in state estimation. IEEE Transactions on Power Systems, [S.1.], v.21, n.4, p.1608-1615, 2006.

CLEMENTS, K. A.; KRUMPHOLZ, G. R.; DAVIS, P. W. Power system state estimation residual analysis: an algorithm using network topology. IEEE Power Engineering Review, [S.1.], p.49-50, 1981.

COSTA, A. S.; PIAZZAM, T. S.; MANDEL, A. Qualitative methods to solve qualitative problems in power system state estimation. IEEE Transactions on Power Systems., [S.l.], v.5, n.3, p.941-949, 1990.

DO COUTTO FILHO, M. B.; SOUZA, J. C. S. Forecasting-Aided state estimation part I: panorama. IEEE Transactions on Power Systems, [S.1.], v.24, p.1667-1677, 2009.

DO COUTTO FIlHO, M. B.; SOUZA, J. C. S.; OliveirA, F. M. F.; SCHILlinG, M. T. Identifying critical measurements sets for power system state estimation. IEEE Porto Power Tech., [S.l.], v.3, 2001.

EIPP(2005) Performance Requiriments Task Team. Performance requiriments part II: targeted applications: state estimation, [S.l.], 2006.

EMAMI, R.; ABUR, A.; GALVAN, F. Optimal placement of phasor measurements for enhanced state estimation: a case study. Proceedings of the 16th Power Systems Computation Conference, Glasgow, Scotland, 2008.

FALCÃO, D. M.; ARIAS, M. State estimation and observability analysis based on echelon forms of the linearized measurement models. IEEE Transactions on Power Apparatus and Systems, [S.1.], v.2, n.2, p.979-987, 1994.

HANDSCHIN, E.; SCHWEPPE, F. C.; KOHLAS, J.; FIECHTER, A. Bad data analysis for power systems state estimation. IEEE Transactions on Power Apparatus and Systems, [S.1.], v.94, n.2, p.329-337, 1975.

IEEE-C37.118. IEEE Standard for Synchrophasor for Power Systems. Power System Relaying Committee of the Power Engineering Society, [S.l.], 2005.

KORRES, G. N.; CONTAXIS, G. C. Identification and updating of minimally dependent sets of measurements in state estimation. IEEE Transactions on Power Systems., [S.l.], v.6, n.3, p.999-1005, 1991. 
KRUMPHOLZ, G.; CLEMENTS, K.; DAVIS, P. Power system observability: a practical algorithm using network topology. IEEE Transactions on Power Apparatus and Systems, [S.l.], n.4, p.1534-1542, 1980.

LONDON, J. B. A.; ALBERTO, L. F. C.; BRETAS, N. G. Analysis of measurement-set qualitative characteristics for state-estimation purposes. Generation, Transmission \& Distribution, IET, [S.l.], v.1, n.1, p.39-45, 2007.

LOndon, J. B. A.; PIEREti, S. A. R.; BenEDItO, R. A. S.; BREtAS, N. G. Redundancy and observability analysis of conventional and PMU measurements. IEEE Transactions on Power Systems, [S.1.], v.24, n.3, p.1629-1630, Aug. 2009.

MILLI, L.; VAN CUTSEM, T.; RIBBENS-PAVELLA, M. Hypothesis testing identification: a new method for bad data analysis in power system state estimation. IEEE Power Engineering Reviw., [S.l.], n.11, p.31-32, 1984.

MONTICELLI, A. J. State estimation in eletric power system: a generalized approach. Massachusetts, USA: Kluwer Academic Publishers, 1999.

MONTICELLI, A. J.; WU, F. F. Network observability: identification of observable islands and measurement placement. IEEE Transactions on Power Apparatus and Systems, [S.1.], n.5, p.1035-1041, 1985.

MONTICELLI, A.; WU, F. Observability analysis for orthogonal transformation based state estimation. IEEE Transactions on Power Apparatus and Systems, [S.l.], v.1, n.1, p.201-208, 1986.

MORAES, R. M. Sincrofasores em sistemas de potência: aplicações na estimação de estado. 2009. Tese (Doutorado em Engenharia Elétrica) — Universidade Federal Fluminense - Instituto de Computação.

MORI, H.; TSUZUKI, S. A fast method for topological observability analysis using a minimun spanning tree technique. IEEE Transactions on Power Apparatus and Systems, [S.l.], p.491-499, 1991.

PHADKE, A. G. State Estimation with phasor measurements. IEEE Transactions on Power System, [S.1.], v.1, n.1, p.233-240, 1986.

PHADKE, A. G. Synchronized sampling and phasor measurements for relaying and control. IEEE Transactions on Power Delivery, [S.l.], v.9, n.1, 1994.

PHADKE, A. G. Synchronized phasor measurements- a historical overview. Proc. Transmission and Distribution Conf and Exhibition: Asia Pacific. IEEE/PES, [S.l.], v.1, p.476-479, 2002. 
PHADKE, A. G.; THORP, J. S. Synchronized phasor measurements and their applications. New York, NY, USA: Springer, 2008.

PHADKE, A. G.; THORP, J. S.; ADAMIAK, M. G. A new measurement technique for tracking voltage phasor, local system frequency, and rate of change of frequency. IEEE Transactions on PAS, [S.1.], v.102, n.5, p.1025-1038, 1983.

QUARTERONI, A.; SACCO, R.; SALERI, F. Numerical Mathematics. Verlag New York, NY, USA: Springer, 2000.

QUINTANA, V. H.; COSTA, A. S.; MANDEL, A. Power system topological observability using a direct graph-theoretic approach. IEEE Transactions on Power Apparatus and Systems, [S.1.], p.617-626, 1982.

SCHWEPPE, F. C. Power system static-state estimation, part III: implementation. IEEE Transactions on Power Apparatus and Systems, [S.l.], n.1, p.130-135, 1989.

SCHWEPPE, F. C. State estimation and observability analysis based on echelon forms of the linearized measurement models, part II. IEEE Transactions on Power Apparatus and Systems, [S.l.], v.89, n.1, p.125-130, 1989.

SCHWEPPE, F.; HANDSCHIN, E. Static state estimation in electric power systems. Proceedings of the IEEE, [S.l.], v.62, n.7, p.972-982, 1974.

SCHWEPPE, F.; WILDES, J. Power system static-state estimation, part I: exact model. part i. IEEE Transactions on Power Apparatus and Systems, [S.l.], v.89, n.1, p.120-125, 1989.

THORP, J. S.; PHADKE, A. G.; KARIMI, K. J. Real time voltage-phasor measurement for static state estimation. IEEE Transactions on Power Apparatus and Systems, [S.l.], v.PAS-104, n.11, p.3098-3106, 1985.

TINNEY, W. F.; BRANDWAJN, V.; CHAN, S. M. Sparse vector methods. IEEE Transactions on Power Apparatus and Systems, [S.1.], v.104, n.2, p.295-301, 1985.

WU, F. F. Power system state estimation: a survey. Electrical Power e Energy System, [S.l.], v.12, p.80-87, 1990.

XU, B.; ABUR, A. Observability analysis and measurements placement for systems with PMUs. IEEE PES Power Systems Conf. and Exposition, [S.l.], p.943-946, 2004.

ZHOU, M.; CENTENO, V. A.; THORP, J. S.; PHADKE, A. G. An alternative for including phasor measurements in state estimators. IEEE Transactions on Power Systems, [S.l.], v.21, n.4, p.1930-1937, 2006. 
ZHU, J.; ABUR, A. Bad data identification when using phasor measurements. IEEE Lausanne Power Tech, [S.l.], p.1676-1681, 2007.

ZHU, J.; ABUR, A. Effect of phasor measurements on the choice of reference bus for state estimation. IEEE Power Engineering Society General Meeting, [S.l.], p.15, 2007.

ZIVANOVIC, R.; CAIRNS, C. Implementation of PMU technology in state estimation: an overview. [S.1.]: Proceedings of IEEE. AFRICON, 1996. 1006-1011p. v.2. 